\title{
Global, regional, and national comparative risk assessment of 79 behavioural, environmental and occupational, and metabolic risks or clusters of risks in 188 countries, 1990-2013: a systematic analysis for the Global Burden of Disease Study 2013

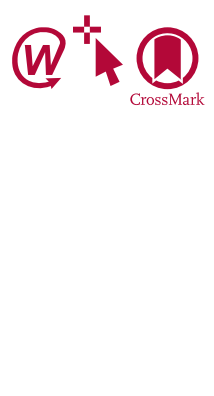

GBD 2013 Risk Factors Collaborators*

\section{Summary}

Background The Global Burden of Disease, Injuries, and Risk Factor study 2013 (GBD 2013) is the first of a series of annual updates of the GBD. Risk factor quantification, particularly of modifiable risk factors, can help to identify emerging threats to population health and opportunities for prevention. The GBD 2013 provides a timely opportunity to update the comparative risk assessment with new data for exposure, relative risks, and evidence on the appropriate counterfactual risk distribution.

Methods Attributable deaths, years of life lost, years lived with disability, and disability-adjusted life-years (DALYs) have been estimated for 79 risks or clusters of risks using the GBD 2010 methods. Risk-outcome pairs meeting explicit evidence criteria were assessed for 188 countries for the period 1990-2013 by age and sex using three inputs: risk exposure, relative risks, and the theoretical minimum risk exposure level (TMREL). Risks are organised into a hierarchy with blocks of behavioural, environmental and occupational, and metabolic risks at the first level of the hierarchy. The next level in the hierarchy includes nine clusters of related risks and two individual risks, with more detail provided at levels 3 and 4 of the hierarchy. Compared with GBD 2010, six new risk factors have been added: handwashing practices, occupational exposure to trichloroethylene, childhood wasting, childhood stunting, unsafe sex, and low glomerular filtration rate. For most risks, data for exposure were synthesised with a Bayesian metaregression method, DisMod-MR 2.0, or spatial-temporal Gaussian process regression. Relative risks were based on meta-regressions of published cohort and intervention studies. Attributable burden for clusters of risks and all risks combined took into account evidence on the mediation of some risks such as high body-mass index (BMI) through other risks such as high systolic blood pressure and high cholesterol.

Findings All risks combined account for $57 \cdot 2 \%$ (95\% uncertainty interval [UI] $55 \cdot 8-58 \cdot 5)$ of deaths and $41 \cdot 6 \%$ $(40 \cdot 1-43 \cdot 0)$ of DALYs. Risks quantified account for $87 \cdot 9 \%(86 \cdot 5-89 \cdot 3)$ of cardiovascular disease DALYs, ranging to a low of $0 \%$ for neonatal disorders and neglected tropical diseases and malaria. In terms of global DALYs in 2013, six risks or clusters of risks each caused more than 5\% of DALYs: dietary risks accounting for 11.3 million deaths and 241.4 million DALYs, high systolic blood pressure for 10.4 million deaths and 208.1 million DALYs, child and maternal malnutrition for 1.7 million deaths and 176.9 million DALYs, tobacco smoke for $6 \cdot 1$ million deaths and 143.5 million DALYs, air pollution for 5.5 million deaths and 141.5 million DALYs, and high BMI for 4. 4 million deaths and 134.0 million DALYs. Risk factor patterns vary across regions and countries and with time. In sub-Saharan Africa, the leading risk factors are child and maternal malnutrition, unsafe sex, and unsafe water, sanitation, and handwashing. In women, in nearly all countries in the Americas, north Africa, and the Middle East, and in many other high-income countries, high BMI is the leading risk factor, with high systolic blood pressure as the leading risk in most of Central and Eastern Europe and south and east Asia. For men, high systolic blood pressure or tobacco use are the leading risks in nearly all high-income countries, in north Africa and the Middle East, Europe, and Asia. For men and women, unsafe sex is the leading risk in a corridor from Kenya to South Africa.

Interpretation Behavioural, environmental and occupational, and metabolic risks can explain half of global mortality and more than one-third of global DALYs providing many opportunities for prevention. Of the larger risks, the attributable burden of high BMI has increased in the past 23 years. In view of the prominence of behavioural risk factors, behavioural and social science research on interventions for these risks should be strengthened. Many prevention and primary care policy options are available now to act on key risks.

Funding Bill \& Melinda Gates Foundation.

Lancet 2015; 386: 2287-323 Published Online September 11, 2015 http://dx.doi.org/10.1016/ s0140-6736(15)00128-2 See Comment page 2235 ${ }^{*}$ Collaborators listed at the end of the Article

Correspondence to: Prof Christopher J L Murray, Institute for Health Metrics and Evaluation, 23015 th Avenue, Suite 600, Seattle, WA 98121 USA cjlm@uw.edu 


\section{Introduction}

The Global Burden of Disease, Injuries, and Risk Factor study 2013 (GBD 2013) is the first of a series of annual updates of the GBD. Quantification of functional health loss and mortality by disease and injury is an important input to more informed health policy, as is the contribution of different risk factors to patterns of disease and injury across countries. Risk factor quantification, particularly for modifiable risk factors, can help to identify emerging threats to population health and opportunities for prevention.

The Global Burden of Disease study 2010 (GBD 2010) provided the most comprehensive comparative assessment of risk factors covering 67 risk factors or clusters of risks for 21 regions from 1990 to $2010 .{ }^{1}$ The GBD comparative risk assessment (CRA) brings together data for excess mortality and disability associated with risk factors, data for exposure to risks, and evidencebased assumptions on the desired counterfactual distribution of risk exposure to estimate how much of the burden observed in a given year can be attributed to risk exposure in that year and in all previous years. GBD 2010 generated broad interest in the scientific community and public health agencies..$^{2-4}$ GBD 2010 also generated several scientific debates on topics such as the magnitude of burden related to diet, the low estimates of burden related to unsafe water and sanitation, and exclusion of some risk-outcome pairs from the analysis. ${ }^{2,5-10}$ Additionally, new studies have been published since the release of GBD 2010 that inform both estimates of relative risks and exposure in different countries. ${ }^{11-15}$

The GBD 2013 provides a timely opportunity to update each aspect of the CRA with new data for exposure, add new risk-outcome pairs meeting study inclusion criteria, and incorporate new data for relative risks and the appropriate counterfactual risk distribution. Important insights from scientific debates on GBD 2010 have been used in revised approaches. This analysis supersedes all previous GBD CRA results by providing a complete revised time-series of attributable burden from 1990 to 2013, for 188 countries, with consistent definitions and methods. This CRA also allows us to explore how much of the burden of disease around the world is not explained by the behavioural, environmental and occupational, and metabolic risks included in this study.

\section{Methods \\ Overview}

In general, this analysis follows the CRA methods used in GBD 2010. ${ }^{1}$ Conceptually, the CRA approach evaluates how much of the burden of disease observed in a given year can be attributed to past exposure to a risk. Attributable burden is estimated by comparing observed health outcomes to those that would have been observed if a counterfactual level of exposure had occurred in the past. Given that different risks lead to different health

\section{Research in context}

\section{Evidence before this study}

As part of the Global Burden of Disease (GBD) 2010 study a revision of the global comparative risk assessment was undertaken, with an expanded list of 67 risks and risk clusters by 21 world regions, and comparable estimates made for the time period 1990-2010. Quantification of the burden that can be attributed to risk factors is important information to set priorities in prevention.

\section{Added value of this study}

The GBD 2013 comparative risk assessment is a further update to the GBD 2010 study in several ways: (1) addition of new risk factors (handwashing practices, occupational exposure to trichloroethylene, childhood wasting, childhood stunting, unsafe sex, and low glomerular filtration rate); (2) new data for exposure; (3) assumption of a lognormal rather than a normal distribution for most of the continuous risk factors to better represent the observed population distributions; (4) updates to the systematic reviews and meta-analyses of relative risks; (5) aggregation of the burden at multiple levels of risk factors, including the combined effect of all GBD risk factors and aggregates of three large classes-ie, behavioural, environmental and occupational, and metabolic risk factors; (6) systematic inclusion of mediation between major risk

factors in the quantification of the burden associated with joint risks; and (7) quantification of the risk burden for 188 countries. Furthermore, several major improvements to specific risk factors were implemented, such as use of the latest analytical instruments for multilevel analysis of exposure (DisMod-MR), as well as production of burden estimates for 5 -year intervals from 1990-2010 plus 2013.

\section{Implications of all the available evidence}

Comparative risk assessment enables policy makers to prioritise prevention by addressing the most important risk factors at the population level. The burden by aggregations of risk categories, such as air pollution or dietary risks, provides the broad view of investment priorities, whereras the size of burden for individual risks can inform the potential elements of a broader intervention package. In 2013, we explain $41 \%$ of burden by the 79 GBD risk factors with a slight increase since 1990 . This proportion varies between $28 \%$ and $61 \%$ between countries, highlighting the importance of making country estimates as the opportunities for intervention will vary accordingly. Unless new risk factors are identified, the proportion of burden that is not explained by GBD risk factors is likely to be less amenable to primary prevention but more of a concern for curative or rehabilitative services. 
outcomes, assessments are undertaken separately for specific risk-outcome pairs.

For most risk-outcome pairs, we estimated the attributable burden using the following equations.

$A B_{\text {jasct }}=\sum^{\mathfrak{W}} D A L Y_{\text {oasct }} P A F_{\text {josst }}$

Where $A B_{\text {jast }}$ is the attributable burden for risk factor $j$ in age group a, sex $s$, country $c$ and year $t$. $D A L Y_{\text {oast }}$ is disability-adjusted life-years (DALYs) for cause $o$ (of $w$ relevant outcomes for risk factor $j$ ) in age group $a$, sex $s$, country $c$ and year $t$. $P A F_{\text {josst }}$ is the population attributable fraction (PAF) for cause $o$ due to risk factor $j$ in age group $a$, sex $s$, country $c$ and year $t$. Attributable deaths, years of life lost (YLLs), or years lived with disability (YLDs) are computed by substituting in the equation these metrics for DALYs.

Risks fall into three categories on the basis of how exposure is measured: dichotomous, polytomous, and continuous. High systolic blood pressure is an example of a risk measured on a continuous scale. The $P A F_{\text {josst }}$ for a continuous risk factor in each country is defined as: $:^{16}$

$P A F_{\text {joasct }}=\frac{\int_{x=l}^{u} R R_{\text {joasc }}(x) P_{\text {jasct }}(x) d x-R R_{\text {joasc }}\left(T M R E L_{\text {jas }}\right)}{\int_{x=l}^{u} R R_{\text {joasc }}(x) P_{\text {jasct }}(x) d x}$

$R R_{\text {joasc }}(x)$ is the relative risk as a function of exposure level $x$ for risk factor $j$, cause $o$, age-group $a$, sex $s$, and country $c . l$ is the lowest level of exposure and $u$ is the highest level of exposure observed. $P_{\text {jast }}(x)$ is the distribution of exposure for risk $j$ in age-group $a$, sex $s$, country $c$, and year $t$. TMREL $L_{j a s}$ is the theoretical minimum risk exposure level for risk factor $j$, age group $a$, and sex $s$. The discrete version of this equation for polytomous and dichotomous risks is provided in the appendix (p 2).

The equations highlight the four key components by cause, age, sex, country, and year that go into estimations of the burden attributable to a risk factor: the number of deaths, YLLs, YLDs, or DALYs; exposure levels for a risk factor; relative risk of a given outcome due to exposure; and the counterfactual level of risk factor exposure. In the CRA approach, the counterfactual level of risk exposure is selected to be the risk exposure that is theoretically possible and minimises overall risk (theoretical minimum risk exposure level [TMREL]). ${ }^{17}$ The intention is to quantify how much disease burden could be lowered by shifting the distribution of a risk to the level that would lead to the greatest improvement in population health. GBD 2013 provides the rates of mortality, YLLs, YLDs, and DALYs by cause. ${ }^{18,19}$ We focus here on the data and methods used to estimate 79 behavioural, environmental and occupational, and metabolic risks and clusters of these risks, levels of exposure, relative risks, and the choice of TMREL (a more detailed presentation of methods is provided in appendix [pp 2-23]).

\section{Risk-outcome pairs and risk factor hierarchy}

In this analysis, we focus on three groups of risk factors: behavioural, environmental and occupational, and metabolic. Figure 1 shows a more complete causal web (not all the arrows detailing possible interconnections have been drawn) that recognises the role of four other sets of risks: genes; the microbiome and other host factors; public health and medical care interventions; and social, economic, and cultural factors. It is currently beyond the scope of this study to quantify these other categories of risks or causes; however, in future iterations of the GBD we intend to broaden the analysis to include at least some of these broader causes.

For the current assessment focused on behavioural, environmental and occupational, and metabolic risk factors, risk-outcome pairs have been included based on four criteria. These criteria take into account the importance of each risk factor to either disease burden, policy, or both; the availability of sufficient data to estimate risk factor exposure; evidence from epidemiological studies supporting a causal relation between risk factor exposure and the outcome and available data to estimate effect sizes per unit of exposure increase; and evidence that these effects can be applied to a general population. Following GBD 2010, we have adopted the World Cancer Research Fund grading of evidence supporting the causal relation between risk factor exposure and an outcome. They defined four levels of evidence: convincing, probable, possible, and insufficient. Only risk-outcome pairs judged to meet the criteria of convincing or probable were included. Convincing evidence is defined as "evidence based on epidemiological studies showing consistent associations between exposure and disease, with little or no evidence to the contrary. The available evidence is based on a substantial number of studies including prospective observational studies and where relevant, randomised controlled trials of sufficient size, duration, and quality showing consistent effects. The association should be biologically plausible." Probable evidence is defined as "evidence based on epidemiological studies showing

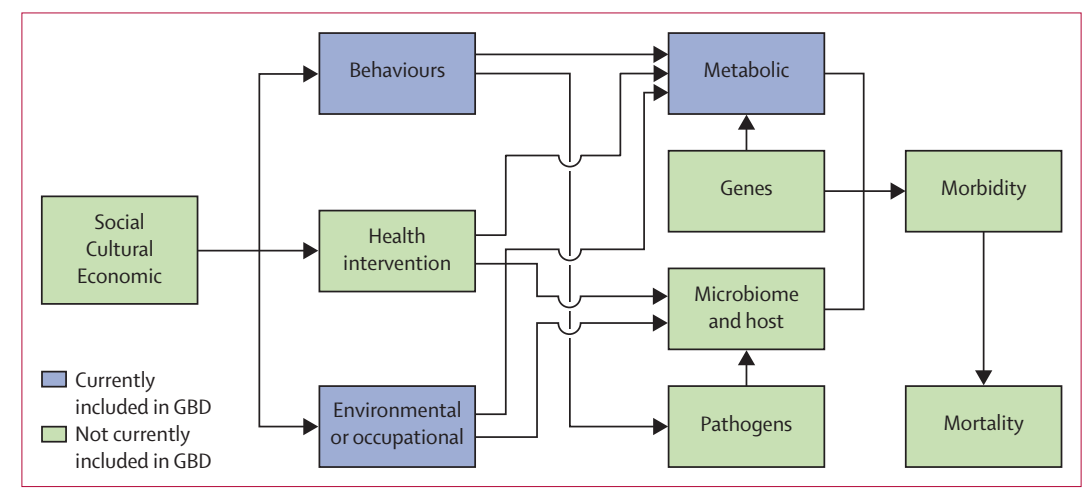

Figure 1: A more general causal web of the causes of health outcomes Categories of causes included in this analysis shown in blue. GBD=Global Burden of Disease. 
Exposure definition
Theoretical minimum risk exposure level

\begin{tabular}{ll}
\hline $\begin{array}{l}\text { All risk factors } \\
\text { Environmental and } \\
\text { occupational risks } \\
\text { Unsafe water, sanitation, } \\
\text { and handwashing }\end{array}$ &.. \\
\hline \multicolumn{1}{|l}{ Unsafe water source } & $\begin{array}{l}\text { Proportion of households with access to different water } \\
\text { sources (unimproved, improved except piped, piped water } \\
\text { supply) and reported use of household water treatment } \\
\text { methods (boiling or filtering; chlorinating or solar filtering; no } \\
\text { treatment) }\end{array}$ \\
\hline
\end{tabular}

Unsafe sanitation

No handwashing with

soap

Air pollution

Ambient particulate

matter pollution

Household air pollution

from solid fuels

Other environmental risks

Residential radon

Lead exposure

Occupational risks

Occupational carcinogens

Occupational exposure

to asbestos

Occupational exposure

to arsenic

Occupational exposure to benzene

Occupational exposure to beryllium

Occupational exposure to cadmium

Occupational exposure to chromium

Occupational exposure to diesel engine exhaust

Occupational exposure to second-hand smoke

Occupational exposure to formaldehyde

Occupational exposure to nickel

Proportion of the population with cumulative exposure to asbestos through their occupation

Proportion of the population ever exposed to benzene at work/through their occupation

Proportion of the population ever exposed to beryllium at work/through their occupation

Proportion of the population ever exposed to cadmium at work/through their occupation

Proportion of the population ever exposed to chromium at work/through their occupation

Proportion of the population ever exposed to diesel engine exhaust at work/through their occupation

Proportion of the population ever exposed to second-hand smoke at work/through their occupation

Proportion of the population ever exposed to formaldehyde at work/through their occupation

Proportion of the population ever exposed to nickel at work/ through their occupation
Seasonal (3 month) hourly maximum ozone concentrations, measured in parts per billion ( $\mathrm{ppb}$ )

Proportion of households with access to different sanitation facilities (unimproved, improved except sewer, sewer connection)

Proportion of individuals who wash their hands with soap and water after potential faecal contact

Annual average daily exposure to outdoor air concentrations of particulate matter (PM) with an aerodynamic diameter smaller than $2.5 \mu \mathrm{m}$, measured in $\mu \mathrm{g} / \mathrm{m}^{3}$

Annual average daily exposure to household concentrations of No households are exposed to excess particulate matter (PM) with an aerodynamic diameter smaller indoor concentration of particles from than $2.5 \mu \mathrm{m}$, measured in $\mu \mathrm{g} / \mathrm{m}^{3}$ from solid fuel use (coal, wood, charcoal, dung, and agricultural residues)

All households have access to water from a piped water supply that is also boiled or filtered before drinking

All households have access to toilets with sewer connection

All individuals wash hands with soap and water after potential faecal contact

Uniform distribution between

$5.9 \mu \mathrm{g} / \mathrm{m}^{3}$ and $8.7 \mu \mathrm{g} / \mathrm{m}^{3}$ solid fuel use (assuming concentration of particulate matters, aerodynamic diameter smaller than $2.5 \mu \mathrm{g} / \mathrm{m}^{3}$, measured in $\mu \mathrm{g} / \mathrm{m}^{3}$ in no fuel use is consistent with a TMREL of 5.9-8.7)

Uniform distribution between $33.3 \mu \mathrm{g} / \mathrm{m}^{3}$ and $41.9 \mu \mathrm{g} / \mathrm{m}^{3}$, according to minimum $/ 5$ th percentile concentrations

Average daily exposure to indoor air radon levels measured in becquerels (radon disintegrations per s) per cubic metre $\left(\mathrm{Bq} / \mathrm{m}^{3}\right)$

Blood lead levels in $\mu \mathrm{g} / \mathrm{dL}$ of blood, bone lead levels in $\mu \mathrm{g} / \mathrm{g}$ of bone

\section{$10 \mathrm{~Bq} / \mathrm{m}^{3}$, corresponding to the outdoor}

concentration of radon

$2 \mu \mathrm{g} / \mathrm{dL}$, corresponding to lead levels in pre-industrial humans as natural sources of lead prevent the feasibility of zero exposure

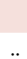

No occupational exposure to asbestos

Proportion of the population ever exposed to arsenic at work/ No occupational exposure to arsenic

Data representativeness index

\begin{tabular}{llrl}
\hline$<1998$ & $1998-2005$ & $2006-13$ & Total \\
\hline $100 \cdot 0 \%$ & $100 \cdot 0 \%$ & $100 \cdot 0 \%$ & $100 \cdot 0 \%$ \\
$100 \cdot 0 \%$ & $100 \cdot 0 \%$ & $100 \cdot 0 \%$ & $100 \cdot 0 \%$
\end{tabular}

$59 \cdot 0 \% \quad 72 \cdot 3 \% \quad 60 \cdot 6 \% \quad 80 \cdot 3 \%$

$\begin{array}{llll}69.6 \% & 84.2 \% & 68.4 \% & 91.8 \%\end{array}$

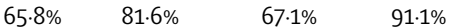

$\begin{array}{llll}1 \cdot 1 \% & 10 \cdot 1 \% & 25 \cdot 5 \% & 29 \cdot 3 \%\end{array}$

$100 \cdot 0 \% \quad 100 \cdot 0 \% \quad 100 \cdot 0 \% \quad 100 \cdot 0 \%$

$99 \cdot 5 \% \quad 99 \cdot 5 \% \quad 99.5 \% \quad 99.5 \%$

$47 \cdot 8 \% \quad 83 \cdot 3 \% \quad 71 \cdot 7 \% \quad 94 \cdot 2 \%$

$100.0 \%-100.0 \% \quad 100.0 \%-100.0 \%$

$34.0 \% \quad 38.8 \% \quad 26.6 \% \quad 49 \cdot 5 \%$

$19 \cdot 7 \% \quad 27 \cdot 1 \% \quad 31 \cdot 7 \% \quad 38 \cdot 3 \%$

$29.3 \%-27 \cdot 1 \% \quad 20.2 \% \quad 39.9 \%$

$\begin{array}{llll}\mathbf{5 6} \cdot \mathbf{4} \% & \mathbf{6 4} \cdot \mathbf{4} \% & \mathbf{5 5} \cdot 3 \% & \mathbf{7 2} \cdot \mathbf{3} \% \\ \mathbf{3 4} \cdot 0 \% & 56 \cdot 9 \% & 51 \cdot 6 \% & 62 \cdot 8 \%\end{array}$




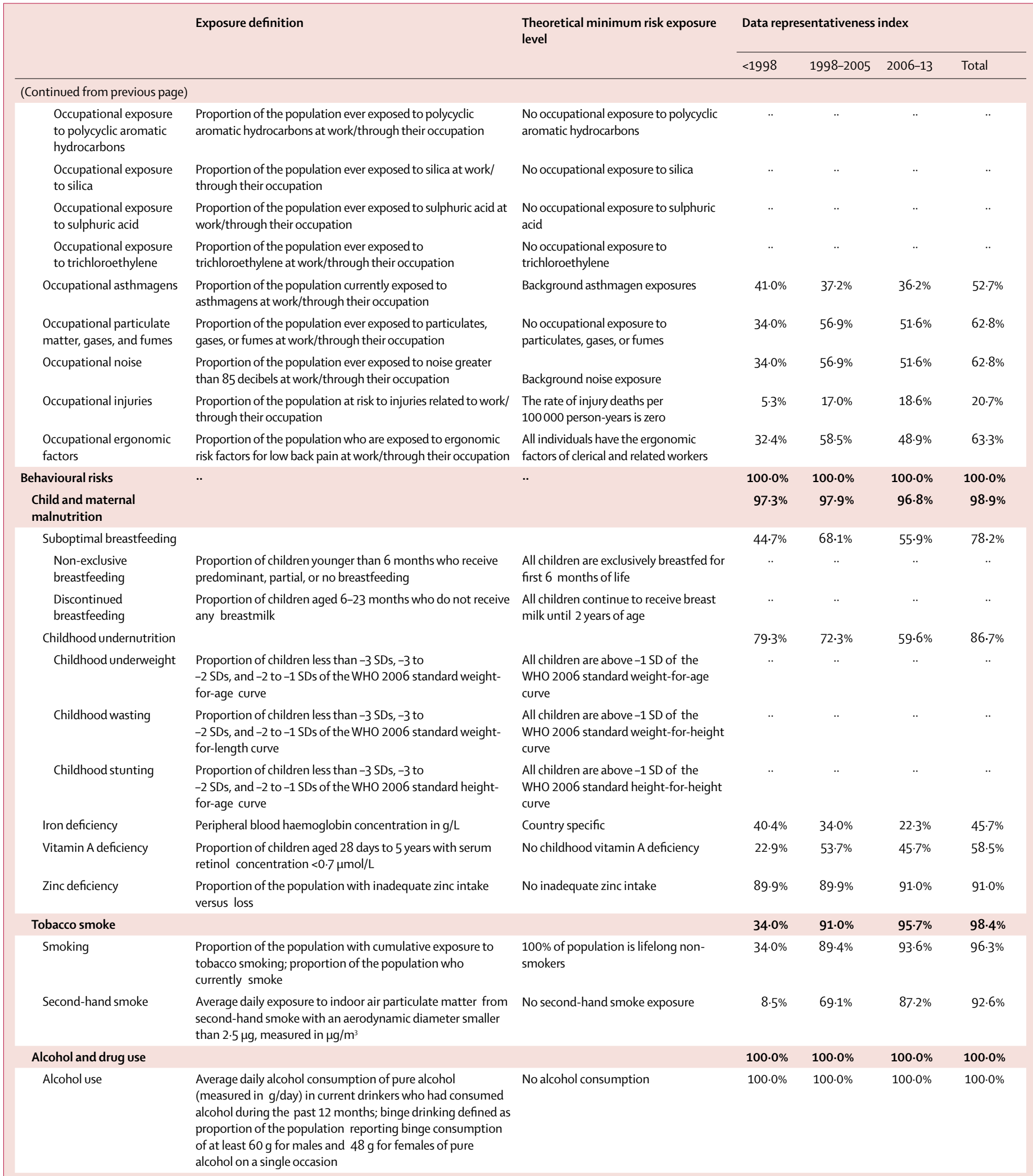




\begin{tabular}{|c|c|c|c|c|c|c|}
\hline & \multirow[t]{2}{*}{ Exposure definition } & \multirow{2}{*}{$\begin{array}{l}\text { Theoretical minimum risk exposure } \\
\text { level }\end{array}$} & \multicolumn{4}{|c|}{ Data representativeness index } \\
\hline & & & $<1998$ & 1998-2005 & $2006-13$ & Total \\
\hline \multicolumn{7}{|l|}{ (Continued from previous page) } \\
\hline Drug use & $\begin{array}{l}\text { Proportion of the population dependent on opioids, } \\
\text { cannabis, cocaine, or amphetamines; proportion of the } \\
\text { population who have ever injected drugs }\end{array}$ & No use & $28 \cdot 7 \%$ & $50 \cdot 5 \%$ & $54 \cdot 3 \%$ & $67 \cdot 0 \%$ \\
\hline Dietary risks & & & $89 \cdot 9 \%$ & $93 \cdot 1 \%$ & $92 \cdot 0 \%$ & $94 \cdot 1 \%$ \\
\hline Diet low in fruits & $\begin{array}{l}\text { Average daily consumption of fruits (fresh, frozen, cooked, } \\
\text { canned, or dried, excluding fruit juices and salted or pickled } \\
\text { fruits) }\end{array}$ & $\begin{array}{l}\text { Consumption of fruit between } 200 \mathrm{~g} \\
\text { and } 400 \mathrm{~g} \text { per day }\end{array}$ & $19 \cdot 1 \%$ & $38.8 \%$ & $22 \cdot 9 \%$ & $56 \cdot 4 \%$ \\
\hline Diet low in vegetables & $\begin{array}{l}\text { Average daily consumption of vegetables (fresh, frozen, } \\
\text { cooked, canned, or dried vegetables, including legumes but } \\
\text { excluding salted or pickled vegetables, juices, nuts and seeds, } \\
\text { and starchy vegetables such as potatoes or corn) }\end{array}$ & $\begin{array}{l}\text { Consumption of vegetables between } \\
350 \mathrm{~g} \text { and } 450 \mathrm{~g} \text { per day }\end{array}$ & $88 \cdot 8 \%$ & $92 \cdot 6 \%$ & $90 \cdot 4 \%$ & $93 \cdot 6 \%$ \\
\hline Diet low in whole grains & $\begin{array}{l}\text { Average daily consumption of whole grains (bran, germ, and } \\
\text { endosperm in their natural proportion) from breakfast } \\
\text { cereals, bread, rice, pasta, biscuits, muffins, tortillas, } \\
\text { pancakes, and other sources }\end{array}$ & $\begin{array}{l}\text { Consumption of whole grains between } \\
100 \mathrm{~g} \text { and } 150 \mathrm{~g} \text { per day }\end{array}$ & $87 \cdot 8 \%$ & $89 \cdot 9 \%$ & $89 \cdot 4 \%$ & $89 \cdot 9 \%$ \\
\hline Diet low in nuts and seeds & Average daily consumption of nut and seed foods & $\begin{array}{l}\text { Consumption of nuts and seeds } \\
\text { between } 12 \mathrm{~g} \text { and } 20 \mathrm{~g} \text { per day }\end{array}$ & $78 \cdot 7 \%$ & $85 \cdot 1 \%$ & $83 \cdot 0 \%$ & $86 \cdot 7 \%$ \\
\hline Diet low in milk & $\begin{array}{l}\text { Average daily consumption of milk, including non-fat, low- } \\
\text { fat, and full-fat milk, excluding soy milk and other plant } \\
\text { derivatives }\end{array}$ & $\begin{array}{l}\text { Consumption of milk between } 425 \mathrm{~g} \\
\text { and } 475 \mathrm{~g} \text { per day }\end{array}$ & $88 \cdot 8 \%$ & $91 \cdot 0 \%$ & $89 \cdot 4 \%$ & $91 \cdot 0 \%$ \\
\hline Diet high in red meat & $\begin{array}{l}\text { Average daily consumption of red meat (beef, pork, lamb, } \\
\text { and, goat but excluding poultry, fish, eggs, and all processed } \\
\text { meats) }\end{array}$ & $\begin{array}{l}\text { Consumption of red meat between } \\
11.4 \mathrm{~g} \text { and } 17.1 \mathrm{~g} \text { per day }\end{array}$ & $88 \cdot 8 \%$ & $91 \cdot 0 \%$ & $89 \cdot 4 \%$ & $91 \cdot 0 \%$ \\
\hline $\begin{array}{l}\text { Diet high in processed } \\
\text { meat }\end{array}$ & $\begin{array}{l}\text { Average daily consumption of meat preserved by smoking, } \\
\text { curing, salting, or addition of chemical preservatives }\end{array}$ & $\begin{array}{l}\text { Consumption of processed meat } \\
\text { between } 0 \mathrm{~g} \text { and } 14.3 \mathrm{~g} \text { per day }\end{array}$ & $14 \cdot 4 \%$ & $24 \cdot 5 \%$ & $6 \cdot 9 \%$ & $28 \cdot 2 \%$ \\
\hline $\begin{array}{l}\text { Diet high in sugar- } \\
\text { sweetened beverages }\end{array}$ & $\begin{array}{l}\text { Average daily consumption of beverages with } \geq 50 \mathrm{kcal} \text { per } \\
226.8 \mathrm{~g} \text { serving, including carbonated beverages, sodas, } \\
\text { energy drinks, and fruit drinks, but excluding } 100 \% \text { fruit and } \\
\text { vegetable juices }\end{array}$ & $\begin{array}{l}\text { Consumption of sugar-sweetened } \\
\text { beverages between } 0 \mathrm{~g} \text { and } 64.3 \mathrm{~g} \\
\text { per day }\end{array}$ & $13 \cdot 8 \%$ & $23 \cdot 9 \%$ & $7 \cdot 4 \%$ & $27 \cdot 1 \%$ \\
\hline Diet low in fibre & $\begin{array}{l}\text { Average daily intake of fibre from all sources including fruits, } \\
\text { vegetables, grains, legumes, and pulses }\end{array}$ & $\begin{array}{l}\text { Consumption of fibre between } 28 \mathrm{~g} \\
\text { and } 32 \mathrm{~g} \text { per day }\end{array}$ & $12 \cdot 8 \%$ & $19 \cdot 7 \%$ & $9 \cdot 0 \%$ & $27 \cdot 1 \%$ \\
\hline Diet suboptimal in calcium & $\begin{array}{l}\text { Average daily intake of calcium from all sources, including } \\
\text { milk, yogurt, and cheese }\end{array}$ & $\begin{array}{l}\text { Consumption of calcium between } 0 \mathrm{~g} \\
\text { and } 0.77 \mathrm{~g} \text { per day }\end{array}$ & $15 \cdot 4 \%$ & $20 \cdot 7 \%$ & $11 \cdot 2 \%$ & $31 \cdot 4 \%$ \\
\hline $\begin{array}{l}\text { Diet low in seafood } \\
\text { omega-3 fatty } \\
\text { acids }\end{array}$ & $\begin{array}{l}\text { Average daily intake of eicosapentaenoic acid and } \\
\text { docosahexaenoic acid }\end{array}$ & $\begin{array}{l}\text { Consumption of seafood omega-3 } \\
\text { fatty acids between } 200 \mathrm{mg} \text { and } \\
300 \mathrm{mg} \text { per day }\end{array}$ & $87 \cdot 7 \%$ & $90 \cdot 4 \%$ & $88 \cdot 8 \%$ & $90 \cdot 4 \%$ \\
\hline $\begin{array}{l}\text { Diet low in } \\
\text { polyunsaturated fatty } \\
\text { acids }\end{array}$ & $\begin{array}{l}\text { Average daily intake of omega- } 6 \text { fatty acids from all sources, } \\
\text { mainly liquid vegetable oils, including soybean oil, corn oil, } \\
\text { and safflower oil }\end{array}$ & $\begin{array}{l}\text { Consumption of polyunsaturated fatty } \\
\text { acids between } 10 \% \text { and } 15 \% \text { of total } \\
\text { daily energy }\end{array}$ & $9 \cdot 0 \%$ & $12 \cdot 2 \%$ & $5 \cdot 3 \%$ & $17 \cdot 0 \%$ \\
\hline $\begin{array}{l}\text { Diet high in trans fatty } \\
\text { acids }\end{array}$ & $\begin{array}{l}\text { Average daily intake of trans fat from all sources, mainly } \\
\text { partially hydrogenated vegetable oils and ruminant } \\
\text { products }\end{array}$ & $\begin{array}{l}\text { Consumption of trans fatty acids } \\
\text { between } 0 \% \text { and } 0.8 \% \text { of total daily } \\
\text { energy }\end{array}$ & $8 \cdot 5 \%$ & $42 \cdot 0 \%$ & $42 \cdot 0 \%$ & $42 \cdot 0 \%$ \\
\hline Diet high in sodium & $24 \mathrm{~h}$ urinary sodium measured in mg per day & $\begin{array}{l}\text { Consumption of sodium between } 1 \mathrm{~g} \\
\text { and } 5 \mathrm{~g} \text { per day }\end{array}$ & $25 \cdot 0 \%$ & $18.6 \%$ & $11 \cdot 7 \%$ & $33 \cdot 5 \%$ \\
\hline Sexual abuse and violence & & & $17 \cdot 6 \%$ & $45 \cdot 7 \%$ & $53 \cdot 2 \%$ & $66 \cdot 0 \%$ \\
\hline Childhood sexual abuse & $\begin{array}{l}\text { Proportion of the population who have ever experienced } \\
\text { one or more acts of childhood sexual abuse, defined as the } \\
\text { experience with an older person of unwanted non-contact, } \\
\text { contact abuse, or intercourse, when aged } 15 \text { years or } \\
\text { younger }\end{array}$ & No childhood sexual abuse & $9 \cdot 0 \%$ & $25 \cdot 5 \%$ & $17 \cdot 6 \%$ & $37 \cdot 8 \%$ \\
\hline Intimate partner violence & $\begin{array}{l}\text { Proportion of the population who have ever experienced } \\
\text { one or more acts of physical or sexual violence by a present } \\
\text { or former intimate partner since age } 15 \text { years }\end{array}$ & No intimate partner violence & $13 \cdot 8 \%$ & $44 \cdot 1 \%$ & $47 \cdot 3 \%$ & $61 \cdot 7 \%$ \\
\hline Unsafe sex & $\begin{array}{l}\text { Proportion of the population with exposure to sexual } \\
\text { encounters that convey the risk of disease }\end{array}$ & $\begin{array}{l}\text { No exposure to a disease agent } \\
\text { through sex }\end{array}$ & $14 \cdot 4 \%$ & $17 \cdot 0 \%$ & $43 \cdot 1 \%$ & $43 \cdot 6 \%$ \\
\hline \multirow[t]{2}{*}{ Low physical activity } & $\begin{array}{l}\text { Average weekly physical activity at work, home, } \\
\text { transport-related, and recreational measured by } \\
\text { metabolic equivalent (MET) mins per week }\end{array}$ & $\begin{array}{l}\text { Highly active, } \geq 8000 \text { MET min } \\
\text { per week }\end{array}$ & $0.0 \%$ & $50 \cdot 5 \%$ & $31 \cdot 4 \%$ & $63 \cdot 3 \%$ \\
\hline & & & & \multicolumn{3}{|c|}{ (Table 1 continues on next page) } \\
\hline
\end{tabular}




\begin{tabular}{|c|c|c|c|c|c|c|}
\hline & \multirow[t]{2}{*}{ Exposure definition } & \multirow{2}{*}{$\begin{array}{l}\text { Theoretical minimum risk exposure } \\
\text { level }\end{array}$} & \multicolumn{4}{|c|}{ Data representativeness index } \\
\hline & & & $<1998$ & $1998-2005$ & 2006-13 & Total \\
\hline \multicolumn{7}{|l|}{ (Continued from previous page) } \\
\hline Metabolic risks & .. & .. & $68.1 \%$ & $89.9 \%$ & $87.8 \%$ & $97.9 \%$ \\
\hline High fasting plasma glucose & Serum fasting plasma glucose, measured in $\mathrm{mmol} / \mathrm{L}$ & $4 \cdot 8-5 \cdot 4$ & $31 \cdot 4 \%$ & $38 \cdot 3 \%$ & $23 \cdot 4 \%$ & $54 \cdot 3 \%$ \\
\hline High total cholesterol & Serum total cholesterol, measured in $\mathrm{mmol} / \mathrm{L}$ & $3 \cdot 0-4 \cdot 8$ & $23.9 \%$ & $27.7 \%$ & $22 \cdot 3 \%$ & $46.8 \%$ \\
\hline High systolic blood pressure & Systolic blood pressure, measured in $\mathrm{mm} \mathrm{Hg}$ & $107-119$ & $36 \cdot 2 \%$ & $45.7 \%$ & $36 \cdot 2 \%$ & $71.8 \%$ \\
\hline High body-mass index & Body-mass index, measured in $\mathrm{kg} / \mathrm{m}^{2}$ & $21-23$ & $57 \cdot 4 \%$ & $87.8 \%$ & $86 \cdot 2 \%$ & $97 \cdot 3 \%$ \\
\hline Low bone mineral density & $\begin{array}{l}\text { Standardised mean bone mineral density values measured } \\
\text { at the femoral neck in } \mathrm{g} / \mathrm{cm}^{2}\end{array}$ & $\begin{array}{l}\text { 99th percentile of NHANES 2005-10 } \\
\text { by age and sex }\end{array}$ & $14.9 \%$ & $19 \cdot 7 \%$ & $6.9 \%$ & $25 \cdot 5 \%$ \\
\hline $\begin{array}{l}\text { Low glomerular filtration } \\
\text { rate }\end{array}$ & $\begin{array}{l}\text { Proportion of the population with a GFR }<60 \mathrm{~mL} \text { per min } \\
\text { per } 1.73 \mathrm{~m}^{2} \text {, and excluding end-stage renal disease }\end{array}$ & $>60 \mathrm{~mL}$ per min per $1.73 \mathrm{~m}^{2}$ & $5 \cdot 3 \%$ & $12 \cdot 2 \%$ & $14 \cdot 4 \%$ & $21.8 \%$ \\
\hline
\end{tabular}

fairly consistent associations between exposure and disease, but for which there are perceived shortcomings in the available evidence or some evidence to the contrary, which precludes a more definite judgment. Shortcomings in the evidence may be any of the following: insufficient duration of trials (or studies); insufficient trials (or studies) available; inadequate sample sizes; or incomplete follow-up. Laboratory evidence is usually supportive. The association should be biologically plausible."

Table 1 summarises the included risk factors; there are, counting risks and clusters of risks, 79 different risks in the hierarchy, including 13 level 2 groupings of risk factors and 63 individual risks. We have quantified the burden of each of the level 1, level 2, and level 3 groupings and an overall estimate of all risk factors combined. Risks are organised into a hierarchy with blocks of behavioural, environmental and occupational, and metabolic risks at the first level of the hierarchy. The next level in the hierarchy includes nine clusters of related risks and two individual risks, with more detail provided at levels 3 and 4 of the hierarchy. New risk-outcome pairs were added for risks already included in GBD 2010 due to new evidence, and some risk-outcome pairs were excluded because they did not meet the quality of evidence criteria.

\section{Estimating risk factor exposure}

Data and exposure categories

For each risk factor exposure, we began with the GBD 2010 sources and supplemented those by identifying and using published studies through systematic reviews of the literature, household survey data, census data, and satellite data (used for PM2.5 estimation). Our analyses for the GBD 2013 of tobacco smoking prevalence and obesity have been published. ${ }^{20,21}$ For some risks such as diet and alcohol consumption, we have also used administrative record systems. Appendix pp 88-475 provides citations for all sources used for estimating risk factor exposure organised by country.
We have computed a data representativeness index (DRI) for risk factor exposure estimation. The DRI for a risk factor is the fraction of countries for which we have identified any data for the risk factor. Table 1 also provides the DRI for the entire period 1985-2013 and the DRI calculated for three intervals: pre-1997, 1998-2005, and from 2006 to 2013. The overall DRI ranges from $17 \%$ for diet low in polyunsaturated fatty acids to $100 \%$ for ambient ozone pollution and ambient particulate matter pollution. The DRI for PM2. 5 is $100 \%$ because data are available for all countries and all years, although direct satellite observations are unavailable before 1998 .

Modelling strategies for exposure levels

Appendix pp 49-51 lists the modelling strategy used to estimate exposure for every risk factor. For 23 risks, we used DisMod-MR 2.0, which is a Bayesian metaregression method used extensively in estimating the prevalence of diseases for GBD 2013. See Vos and colleagues $^{19}$ for a detailed description of the likelihood used for estimation and an explanation of improvements in DisMod-MR 2.0 compared with DisMod-MR 1.0, used in GBD 2010. In brief, DisMod-MR 2.0 shows improvements over DisMod-MR 1.0 in computational speed, geographical disaggregation, and display capabilities. The advantage of DisMod-MR 2.0 is that it estimates both the age-sex pattern of a risk as well as different levels over time based on estimation for 1990 , 1995, 2000, 2005, 2010, and 2013. For 12 risk factors modelled with DisMod-MR 2.0, we conducted crossvalidation tests (appendix pp 476-78).

For 34 risks, we used spatiotemporal Gaussian process regression (ST-GPR), which was also used for multiple risk factors in GBD 2010. ${ }^{21}$ ST-GPR has been used for risk factors for which the data density is sufficient to estimate a very flexible time trend that does not vary over age. If the tabulated data were in standard age groups or at the household level, such as access to different levels of improved water and sanitation, exposure to radon, or 
available zinc intake, we used ST-GPR; but if the data were available by different age intervals or mixed sex groups, we used DisMod-MR 2.0 because of its ability to integrate over age and adjust for different exposure definitions in the data.

For PM2.5, estimates of annual concentrations were generated by combining data from atmospheric chemistry transport models and satellite retrievals of aerosols in the atmosphere. ${ }^{22}$ The combined PM2 5 concentrations were then calibrated against observations from ground-level monitoring of particles from more than 75 countries. For modelling the burden attributable to tobacco smoking, we used the smoking impact ratio (SIR) developed by Peto, Lopez, and colleagues ${ }^{23}$ for cancers and chronic respiratory disease, and 5-year lagged smoking prevalence for all cardiovascular outcomes, tuberculosis, diabetes, and asthma. The SIR is used to reflect past exposure, duration, and intensity of smoking in a population. ${ }^{23}$ Alcohol exposure estimation used both administrative and survey data to estimate levels of abstainers, former drinkers, binge drinkers, and drinks per day for regular drinkers. Physical activity exposure was modelled in terms of four categories of metabolic equivalent (MET) min per week (ratio of metabolic rate during a specific physical activity to a resting metabolic rate): inactivity, less than 600 MET min per week; low activity, 600-3999; moderate activity, 4000-7999; and high activity, greater than 8000. Exposure to occupational risks was estimated with data from labour force surveys and censuses on the economically active population available from the International Labour Organization (ILO; Geneva, Switzerland). The distribution of the economically active population across nine industries or eight occupational groups was used to measure exposure to occupational asthmagens, particulate matter, noise, and ergonomic factors.

To calculate the burden of every continuous risk factor, the distribution of exposure needs to be estimated, which includes central tendency and dispersion parameters. We modelled mean and SD because these can be derived from nearly all published studies. In GBD 2010, for computational simplicity, all continuous risks were assumed to be normally distributed, so mean and SD were used to simulate the population distribution in the PAF calculation. Considerable evidence suggests that most risks are not normally distributed, so we have devoted substantial effort to choosing appropriate distribution for each risk factor. ${ }^{24-27}$ First, we modelled the natural log of the SD using observed data as a function of the mean and fixed effects on risk and super-region. Second, we evaluated the likelihood value of fitting normal, lognormal, gamma, beta, and inverse Gaussian distributions to the US National Health and Nutrition Examination Survey (NHANES) micro-data for systolic blood pressure, body-mass index (BMI), fasting plasma glucose, and cholesterol. We found that the lognormal distribution fit the available data best for all but three risk factors. For iron deficiency and low bone mineral density, the normal distribution had the best fit. For high BMI, we used a beta distribution for which BMI is first transformed to be on a 0 to 1 scale, and the $\alpha$ and beta parameters for the distribution are fit to the mean and SD with the constraint that skewness cannot be negative.

Relative risks for systolic blood pressure have been corrected for regression dilution bias. ${ }^{28}$ To be consistent with the adjusted relative risks for regression dilution bias, we have corrected exposure SDs for a measure of intertemporal variance in blood pressure observed in cohort studies; this effectively ensures that our values reflect usual systolic blood pressure.

\section{Estimating the effects of risk factors on disease and injury outcomes}

For 59 component risk factors, for which we estimate attributable burden using the relative risk and exposure formula, we estimated relative risks of mortality and morbidity based on either published meta-analyses, meta-analyses updated with new studies, or new metaregressions that include covariates such as age, sex, or country-level predictors for the GBD 2013.

For every risk factor, relevant outcomes meeting the World Cancer Research Fund criteria of convincing or probable evidence for a causal association were identified. We used almost all outcomes from GBD 2010 and added 35 new outcomes (appendix p 10) to them through a comprehensive review of the list. For risk-outcome pairs for which evidence is only available on either mortality or morbidity, we assumed that the estimated relative risks applied equally to both. Where there was evidence of statistically different relative risks for mortality and morbidity, we used different relative risks for each. Of note, relative risks were not consistently higher or lower for mortality compared with morbidity. Appendix pp 479-614 summarise the relative risks used by age and sex for each risk factor and outcome pair, and appendix pp 615-709 provide citations for all sources used for relative risks. We used relative risks from studies controlled for confounding but not controlling for factors along the causal pathway between exposure and outcome.

We used an updated meta-regression for water, sanitation, and handwashing with results from recently published studies. ${ }^{11,12}$ We conducted a new meta-regression for physical activity by converting the activity levels for which relative risk data are available to total MET mins of activity per week. DisMod-MR 2.0 was used to generate a continuous risk curve for every outcome as a function of MET mins activity per week. We updated the relative risks for childhood underweight, stunting, and wasting using a recently published study that did a pooled analysis of children enrolled in ten prospective cohorts in Africa, Asia, and South America. ${ }^{29,30}$ The updated relative risks for all three anthropometric indicators showed that they have no significant effect on malaria. Finally, we assumed that $100 \%$ of the burden of protein-energy malnutrition 
was attributable to childhood underweight and wasting. The integrated exposure-response curve was used as a framework for ambient particulate matter pollution, household air pollution, secondhand smoke, and tobacco smoking in GBD 2010. ${ }^{31}$ For GBD 2013, we re-estimated these relations with recently published studies of relative risk and also extended their use to estimate the burden from secondhand smoke and household air pollution for chronic obstructive pulmonary disease. ${ }^{31-39}$

In some cases, evidence of the direct relation between a risk factor and a disease outcome was lacking or extremely sparse. For three risk factors (lead, sugar-sweetened beverages, and sodium), we estimated relative risks through a two-stage process. ${ }^{40-42}$ For sodium and disease outcomes other than gastric cancer, we first estimated the relation between 24-h sodium excretion and change in systolic blood pressure. Second, we estimated the relation between change in blood pressure and disease outcomes to estimate the effect of sodium on outcomes. This twostage approach was also used for chronic lead exposure on adults (effect of bone lead through blood pressure) and sugar-sweetened beverages (through BMI).

Alcohol and high BMI are the only risk factors included in our current analysis that show a significant protective effect for selected outcomes, and the protective effects are restricted to certain groups (ie, premenopausal women for high BMI) or levels of intake (ie, alcohol). ${ }^{43,44}$ Recent studies confirmed previous meta-analyses that indicated a protective effect of high BMI on breast cancer in premenopausal women outside Asia-Pacific countries. ${ }^{45,46}$ These protective effects were estimated and included as negative attributable burden in our calculations.

\section{Theoretical minimum risk exposure level (TMREL)}

In the CRA framework, attributable burden is calculated with respect to a counterfactual risk exposure (see equation 2). In GBD 2010, we used the exposure distribution that minimises risk for the population, termed the theoretical minimum risk exposure distribution (TMRED). ${ }^{17}$ Based on a consultation with risk factor epidemiologists, we have chosen to simplify the TMRED and to choose a single level of risk exposure that minimises risk from all causes of DALYs combined, which we term the theoretical minimum risk exposure level (TMREL). The TMREL by its definition should

Figure 2: Tree maps of global deaths (A) and global DALYs (B) for GBD level 2 causes for all ages, both sexes combined in 2013 The fraction of each cause attributable to all risk factors combined is shown with dark shading. DALYs=disability-adjusted life-years. GBD=Global Burden of Disease.

Chr Resp=chronic respiratory diseases. Diab + Urog + Haem=diabetes, urogenital, blood, and endocrine diseases. Diar $+\mathrm{LRI}+\mathrm{Oth}=$ diarrhoea, lower respiratory, and other common infectious diseases. HIV + TB=HIV/AIDS and tuberculosis.

Mental=mental and substance use disorders. $M S K=$ musculoskeletal disorders. Neuro=neurological disorders. Nutr Def=nutritional deficiencies. Oth $N C D=$ other

non-communicable diseases. Other group $\mathrm{I}=$ other communicable, maternal neonatal, and nutritional diseases. NTD + Malaria=neglected tropical diseases and malaria. Self-harm + IPV=self-harm and interpersonal violence. Trans Inj=transportation injuries. Unint Inj=unintentional injuries.

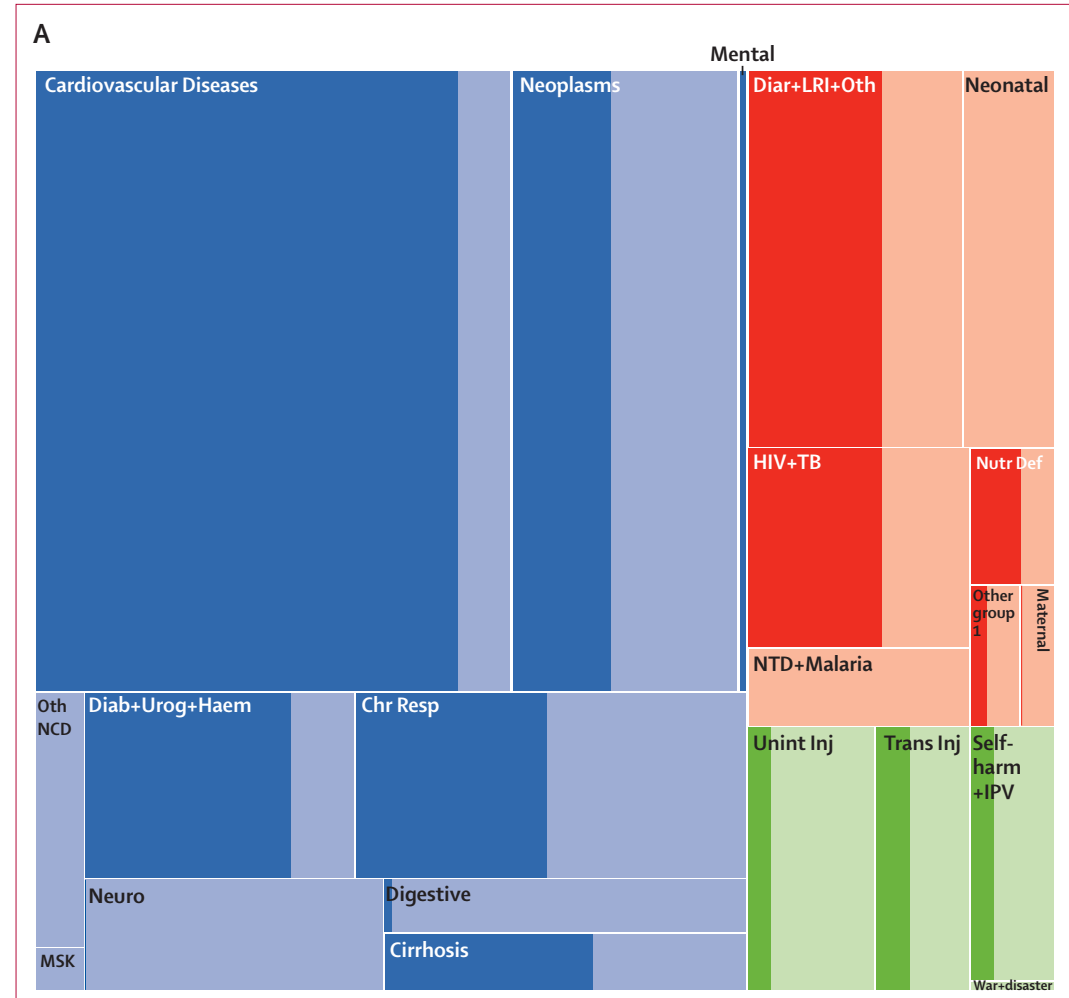

B

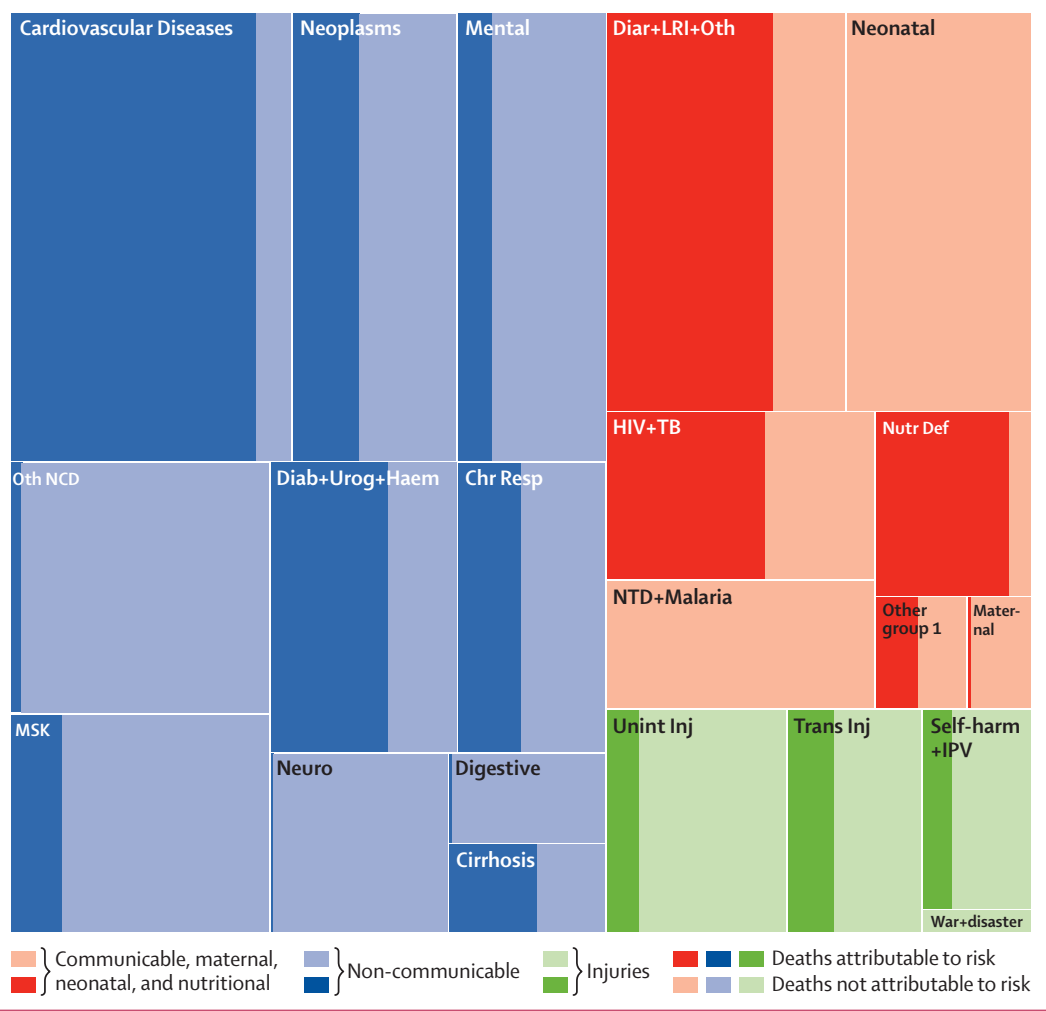


minimise individual (and population level) risk and be theoretically possible to achieve, but not necessarily affordable or feasible to achieve. Table 1 shows the TMREL for each risk factor. In some cases, such as sodium consumption, the evidence supporting the selection of the TMREL is uncertain. In these cases, we include in the uncertainty estimation sampling a uniform distribution of different TMRELs.

As part of GBD 2013, we have modified the TMREL to be households with piped water connections and those who also boil or filter their water before drinking for unsafe water. Similarly, the TMREL for unsafe sanitation is now defined by the proportion of households that have access to sewer-connected toilet facilities.

In GBD 2010, a TMRED with a mean of $1 \mathrm{~g}$ per day of urinary sodium excretion was used for sodium intake. This value was supported by randomised clinical trials which showed that systolic blood pressure falls continuously as sodium is lowered to concentrations as low as $1 \mathrm{~g}$ per day. ${ }^{47}$ The 2013 Institute of Medicine report, Sodium Intake in Populations: Assessment of Evidence, argued that the evidence of the benefit of lowering sodium below $2.3 \mathrm{~g}$ per day was unclear. $^{48}$ The PURE cohort study found a J-shaped association between urinary sodium excretion, mortality, and major cardiovascular events, with minimum risk of death and major cardiovascular events observed between $3 \mathrm{~g}$ and $6 \mathrm{~g}$ of sodium excretion per day. ${ }^{49}$ Taking into account the potential overestimation of the Kawasaki formula used to estimate sodium excretion in PURE, the upper bound of minimum risk seems closer to $5 \mathrm{~g}$ per day. To account for the uncertainty surrounding the concentration of sodium that most minimises risk, we sampled a uniform distribution ranging from $1 \mathrm{~g}$ to $5 \mathrm{~g}$ per day to generate the TMREL. This choice, however, was controversial across the GBD investigators, with several diet collaborators proposing an uncertainty interval of 1-3 g per day. Following the GBD Study Protocol, the GBD Scientific Council made the final decision to use an uncertainty interval of 1-5 g per day.

For bone mineral density, we used the 99th percentile of age-sex subgroups of NHANES III studies between 2005 and 2010 data instead of 90 th percentiles from NHANES III (used in GBD 2010). Use of the 99th percentile enables us to consider the bone density decrease by age, while capturing the excess risk of fracture caused by lower bone mineral density observed in elderly populations.

Attributable burden estimated using other approaches For unsafe sex and occupational injuries for all outcomes, we did not use the relative risk and exposure method to estimate attributable burden. Because of absence of reliable relative risk estimates associating different occupations with injury outcomes, we used data for rates of fatal injuries reported by industry as related to occupation to calculate the PAF. This implicitly assumes that the TMREL would be zero for occupation-related fatal injuries. In view of the difficulty of fitting unsafe sex in the exposure-risk framework, we took a direct attribution approach and modelled the PAFs directly in DisMod-MR 2.0 for HIV. Direct attribution was also used for intimate partner violence and homicide, as well as drug use and hepatitis B and C.

\section{Burden attributable to clusters of risk factors}

There is interest in what fraction of the burden of disease is attributable to various combinations of risk factors or to all risk factors combined..$^{50,51}$ To compute the joint risk factor burden for metabolic risks and combinations of metabolic risk factors with other behavioural or environmental risk factors requires assumptions about how one risk factor is mediated through other risk factors-for example, what fraction of the hazard associated with obesity is mediated through blood pressure or cholesterol? Recent studies have examined the fraction of high BMI mediated through elevated cholesterol and systolic blood pressure. ${ }^{52}$ Consistent with this approach for every two risk factors for an outcome, we estimated the fraction of risk that is mediated through the other risk based on published studies (appendix pp 710-11). Using this matrix of parameters carrying every two by two combination of the risk factors, we have computed the aggregated burden of disease for every level including behavioural, environmental and occupational, and metabolic risks, and finally for all risk factors using the following formula:

$$
P A F_{\text {joasct }}=1-\prod_{j=1}^{J}\left(1-P A F_{\text {joasct }} \prod_{i=1}^{J}\left(1-M F_{j i 0}\right)\right)
$$

Where $J$ is a set of risk factors for aggregation, $P A F_{\text {joasc }}$ is the population attributable fraction for risk factor $i, M F_{j i o}$ is mediation factor for risk factor $i$ mediated through $j$, cause $o$, age-group $a$ and sex s, country $c$, and time $t$.

We estimated the joint burden of childhood wasting, stunting, and underweight. Published relative risks for wasting, stunting, and underweight, however, do not control for each other. We adjusted the published confounded relative risks for each indicator for the effect of the other two anthropometric indicators. ${ }^{29}$ Using the adjusted relative risks for all three anthropometric indicators, we have calculated the joint PAF for all three indicators assuming they were independent.

\section{Role of the funding source}

The funder of the study had no role in the study design, data collection, data analysis, data interpretation, or writing of the report. The authors had access to the data in the study and the final responsibility to submit the paper.

\section{Results}

The risk factors included in this analysis are estimated to account for a widely varying proportion of deaths and DALYs across causes at the global level. Figure 2 uses tree 
maps to represent the PAFs for all risks combined for each disease and injury for level 2 causes in the GBD hierarchical cause list for deaths and DALYs. Across the level 2 causes, the attributable fractions for deaths range from $0 \%$ for neonatal disorders to $88.7 \%$ (95\% UI 86.6-90.6) for cardiovascular and circulatory diseases. The next highest attributable fractions are $76.4 \%$ (95\% UI 70.1-80.1) for diabetes, urogenital, blood, and endocrine disorders and 63.6\% (61.2-66.1) for diarrhoea, lower respiratory infections, and other common infectious diseases. Table 2 shows that the attributable fraction for deaths due to all causes combined for all risk factors is $57 \cdot 2 \%(95 \%$ UI $55 \cdot 8-58 \cdot 5)$ and the fraction for DALYs is $41 \cdot 6 \%(40 \cdot 1-43 \cdot 0)$. The attributable fraction for YLDs due to non-communicable diseases for all risk factors combined $(25 \cdot 8 \%$ [24.0-27.6]) is much lower than for deaths or YLLs because some of the leading causes of YLDs such as mental and substance abuse disorders, musculoskeletal disorders, and other non-communicable diseases have low attributable fractions for the set of risks included in this study. For DALYs, in 2013 all risks explained a variable fraction ranging from $25 \cdot 8 \%(95 \%$ UI $24 \cdot 0-27 \cdot 6)$ for injuries, to $43 \cdot 8 \%(41 \cdot 1-46 \cdot 3)$ for non-communicable diseases, and $42 \cdot 3 \%(40 \cdot 6-44 \cdot 1)$ for communicable, maternal, neonatal, and nutritional diseases. Within each broad disease and injury group, there is also substantial variation. Risks account for only $5 \cdot 8 \%$ (95\% UI 2 -6-8 - 6) for maternal disorders and $0 \%$ for neonatal disorders, but $87.0(84 \cdot 6-89 \cdot 3)$ for nutritional deficiencies. Within non-communicable diseases, all risks account for less than $6 \%$ of DALYs for digestive diseases, neurological disorders, and other non-communicable diseases.

To help quantify how each large group of risk factors interacts, figure 3 shows the fraction of burden for different outcomes that is explained by eight exclusive groupings: not explained by risks included in this study; behavioural risks alone; behavioural risks and environmental and occupational risks; behavioural risks and metabolic risks; environmental and occupational risks alone; environmental and occupational and metabolic risks; metabolic risks alone; and the intersection of all three groups of risks (ie, behavioural, environmental and occupational, and metabolic). For all

\begin{tabular}{|c|c|c|c|c|}
\hline & Deaths 2013 & YLLs 2013 & YLDs 2013 & DALYs 2013 \\
\hline All causes & $57 \cdot 2 \%(55 \cdot 8-58 \cdot 5)$ & $47 \cdot 9 \%(46 \cdot 6-49 \cdot 0)$ & $27 \cdot 6 \%(26 \cdot 6-28 \cdot 5)$ & $41 \cdot 6 \%(40 \cdot 1-43 \cdot 0)$ \\
\hline $\begin{array}{l}\text { Communicable, maternal, neonatal, and nutritional } \\
\text { diseases }\end{array}$ & $44 \cdot 1 \%(42 \cdot 4-46 \cdot 0)$ & $40 \cdot 8 \%(39 \cdot 0-42 \cdot 7)$ & $51 \cdot 8 \%(49 \cdot 0-54 \cdot 1)$ & $42 \cdot 3 \%(40 \cdot 6-44 \cdot 1)$ \\
\hline HIV/AIDS and tuberculosis & $59 \cdot 8 \%(55 \cdot 7-63 \cdot 9)$ & $58 \cdot 5 \%(55 \cdot 3-62 \cdot 0)$ & $62 \cdot 5 \%(58 \cdot 8-66 \cdot 0)$ & $58 \cdot 7 \%(55 \cdot 5-62 \cdot 2)$ \\
\hline $\begin{array}{l}\text { Diarrhoea, lower respiratory, and other common } \\
\text { infectious diseases }\end{array}$ & $62 \cdot 4 \%(60 \cdot 0-64 \cdot 8)$ & $70 \cdot 4 \%(67 \cdot 6-73 \cdot 0)$ & $50 \cdot 1 \%(41 \cdot 3-57 \cdot 6)$ & $69 \cdot 3 \%(66 \cdot 5-71 \cdot 9)$ \\
\hline Neglected tropical diseases and malaria & 0 & 0 & 0 & 0 \\
\hline Maternal disorders & $6 \cdot 1 \%(2 \cdot 7-9 \cdot 1)$ & $6 \cdot 1 \%(2 \cdot 8-9 \cdot 1)$ & $1.4 \%(0.5-2 \cdot 5)$ & $5 \cdot 8 \%(2 \cdot 6-8 \cdot 6)$ \\
\hline Neonatal disorders & 0 & 0 & 0 & 0 \\
\hline Nutritional deficiencies & $56 \cdot 8 \%(50 \cdot 2-65 \cdot 2)$ & $78 \cdot 2 \%(73 \cdot 7-82 \cdot 7)$ & $94 \cdot 2 \%(93 \cdot 2-95 \cdot 0)$ & $87 \cdot 0 \%(84 \cdot 6-89 \cdot 3)$ \\
\hline $\begin{array}{l}\text { Other communicable, maternal, neonatal, and } \\
\text { nutritional diseases }\end{array}$ & $33 \cdot 0 \%(23 \cdot 5-43 \cdot 3)$ & $47 \cdot 6 \%(35 \cdot 1-59 \cdot 6)$ & $38 \cdot 0 \%(32 \cdot 8-46 \cdot 1)$ & $46 \cdot 5 \%(35 \cdot 3-57 \cdot 6)$ \\
\hline Non-communicable diseases & $64 \cdot 0 \%(62 \cdot 3-65 \cdot 7)$ & $58 \cdot 9 \%(56 \cdot 8-60 \cdot 7)$ & $23 \cdot 1 \%(21 \cdot 8-24 \cdot 3)$ & $43 \cdot 8 \%(41 \cdot 1-46 \cdot 3)$ \\
\hline Neoplasms & $45 \cdot 0 \%(42 \cdot 1-47 \cdot 7)$ & $42 \cdot 5 \%(39 \cdot 8-45 \cdot 1)$ & $32 \cdot 0 \%(29 \cdot 9-34 \cdot 0)$ & $42 \cdot 1 \%(39 \cdot 4-44 \cdot 7)$ \\
\hline Cardiovascular diseases & $88 \cdot 5 \%(86 \cdot 3-90 \cdot 5)$ & $88 \cdot 7 \%(87 \cdot 4-90 \cdot 0)$ & $76 \cdot 5 \%(73 \cdot 5-79 \cdot 5)$ & $87 \cdot 9 \%(86 \cdot 5-89 \cdot 3)$ \\
\hline Chronic respiratory diseases & $49 \cdot 3 \%(43 \cdot 2-54 \cdot 7)$ & $45 \cdot 3 \%(39 \cdot 6-50 \cdot 3)$ & $44 \cdot 1 \%(39 \cdot 3-49 \cdot 2)$ & $44 \cdot 9 \%(40 \cdot 2-49 \cdot 2)$ \\
\hline Cirrhosis & $57 \cdot 3 \%(50 \cdot 2-62 \cdot 1)$ & $56 \cdot 8 \%(49 \cdot 1-61 \cdot 5)$ & $44 \cdot 3 \%(40 \cdot 7-47 \cdot 3)$ & $56 \cdot 6 \%(49 \cdot 0-61 \cdot 3)$ \\
\hline Digestive diseases & $2 \cdot 0 \%(1 \cdot 0-2 \cdot 8)$ & $2 \cdot 7 \%(1 \cdot 4-3 \cdot 8)$ & $1 \cdot 3 \%(0 \cdot 7-1 \cdot 8)$ & $2 \cdot 4 \%(1 \cdot 3-3 \cdot 3)$ \\
\hline Neurological disorders & $0.6 \%(0.4-0.7)$ & $1.9 \%(1 \cdot 2-2 \cdot 5)$ & $1 \cdot 3 \%(0 \cdot 8-1 \cdot 7)$ & $1.5 \%(1.0-1.9)$ \\
\hline Mental and substance use disorders & $93 \cdot 7 \%(90 \cdot 8-94 \cdot 8)$ & $95 \cdot 3 \%(93 \cdot 1-96 \cdot 0)$ & $17 \cdot 6 \%(16 \cdot 0-19 \cdot 4)$ & $22 \cdot 8 \%(20 \cdot 7-25 \cdot 4)$ \\
\hline Diabetes, urogenital, blood, and endocrine diseases & $77 \cdot 6 \%(73 \cdot 0-80 \cdot 9)$ & $64 \cdot 5 \%(53 \cdot 1-72 \cdot 7)$ & $64 \cdot 8 \%(60 \cdot 0-68 \cdot 9)$ & $64 \cdot 5 \%(57 \cdot 6-69 \cdot 6)$ \\
\hline Musculoskeletal disorders & 0 & 0 & $19 \cdot 9 \%(17 \cdot 9-21 \cdot 9)$ & $19 \cdot 4 \%(17 \cdot 5-21 \cdot 4)$ \\
\hline Other non-communicable diseases & 0 & 0 & $6 \cdot 3 \%(5 \cdot 4-7 \cdot 3)$ & $4 \cdot 4 \%(3 \cdot 6-5 \cdot 2)$ \\
\hline Injuries & $26 \cdot 9 \%(25 \cdot 4-28 \cdot 6)$ & $23 \cdot 3 \%(21 \cdot 7-25 \cdot 1)$ & $38 \cdot 7 \%(35 \cdot 1-41 \cdot 3)$ & $25 \cdot 8 \%(24 \cdot 0-27 \cdot 6)$ \\
\hline Transport injuries & $36 \cdot 8 \%(34 \cdot 3-39 \cdot 5)$ & $34 \cdot 0 \%(31 \cdot 2-37 \cdot 0)$ & $44 \cdot 3 \%(42 \cdot 1-46 \cdot 7)$ & $35 \cdot 4 \%(32 \cdot 7-38 \cdot 4)$ \\
\hline Unintentional injuries & $20 \cdot 0 \%(17 \cdot 8-21 \cdot 9)$ & $12 \cdot 3 \%(10 \cdot 8-14 \cdot 0)$ & $43 \cdot 3 \%(41 \cdot 5-45 \cdot 2)$ & $19 \cdot 1 \%(16 \cdot 8-21 \cdot 4)$ \\
\hline Self-harm and interpersonal violence & $27 \cdot 9 \%(25 \cdot 2-31 \cdot 0)$ & $28 \cdot 2 \%(25 \cdot 4-31 \cdot 4)$ & $26 \cdot 6 \%(24 \cdot 9-28 \cdot 7)$ & $28 \cdot 1 \%(25 \cdot 4-31 \cdot 3)$ \\
\hline Forces of nature, war, and legal intervention & $0 \cdot 3 \%(0 \cdot 2-0 \cdot 3)$ & $0.1 \%(0 \cdot 1-0 \cdot 2)$ & $1 \cdot 5 \%(0 \cdot 9-2 \cdot 4)$ & $1.0 \%(0 \cdot 6-1 \cdot 5)$ \\
\hline
\end{tabular}




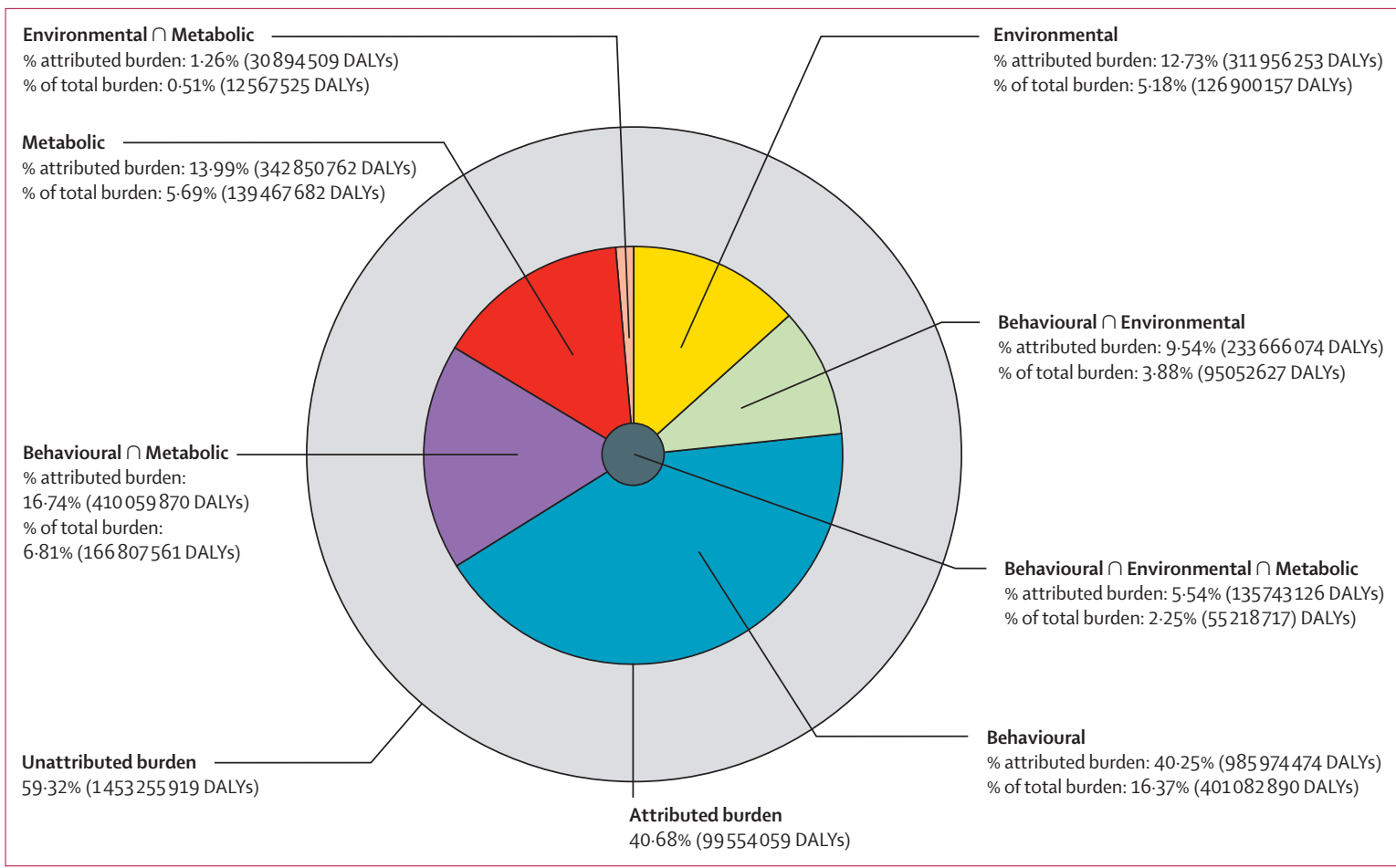

Figure 3: Proportion of all-cause DALYs attributable to behavioural, environmental and occupational, and metabolic risk factors and their overlaps for all ages in 2013 DALYs=disability-adjusted life-years. $\cap=$ interaction.

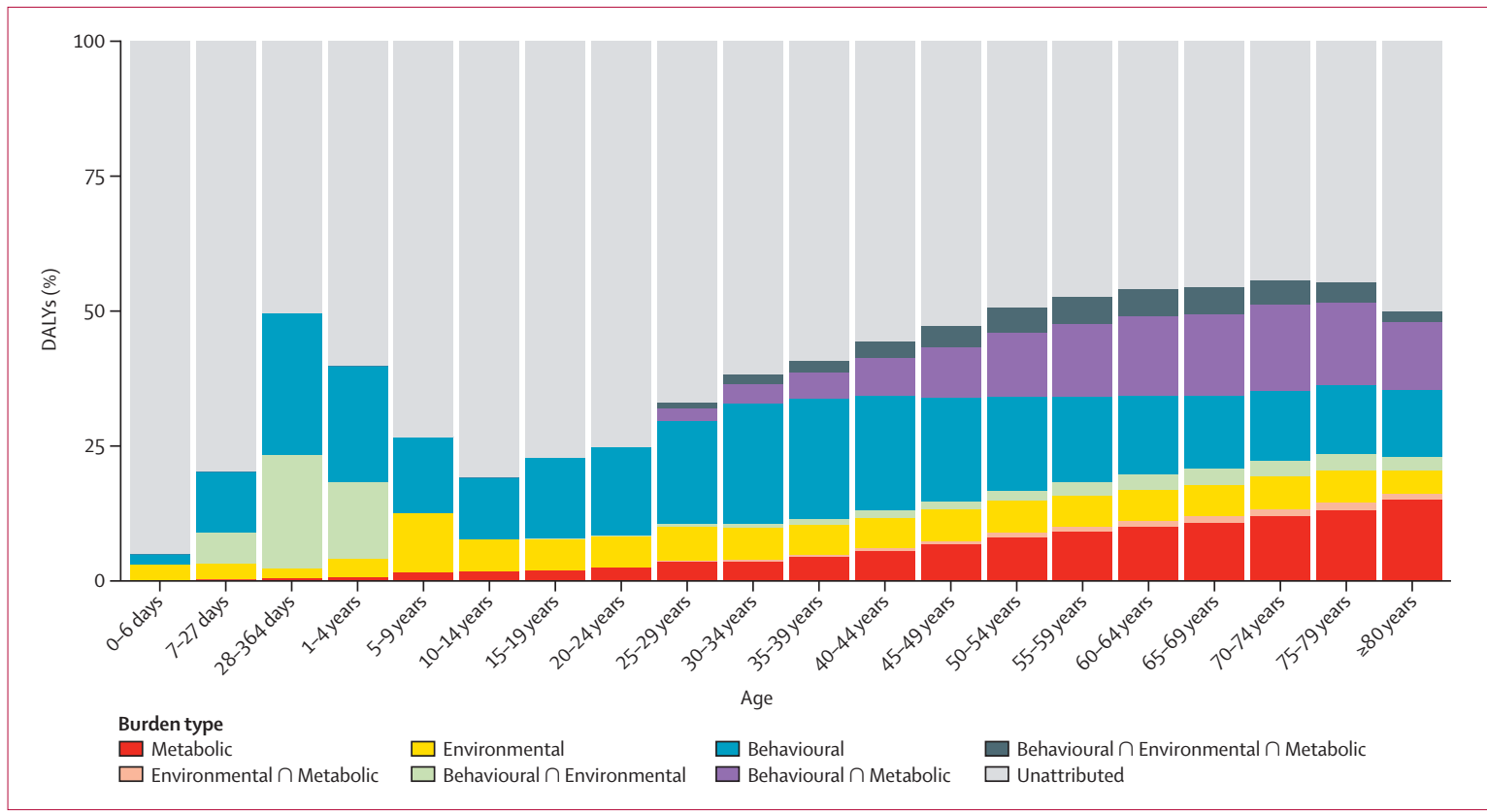

Figure 4: Proportion of global all-cause DALYs attributable to behavioural, environmental and occupational, and metabolic risk factors and their overlaps, by age for both sexes combined in 2013

DALYs=disability-adjusted life-years. $\cap=$ interaction

causes, all three primary clusters of risks have substantial overlap with the smallest proportional overlap being for environmental and occupational and metabolic risks. By contrast, cardiovascular diseases are dominated by metabolic risks and their considerable overlap with behavioural risks and environmental and occupational risks plays a much smaller role. Behavioural risks with a substantial overlap with environmental risks are the key 


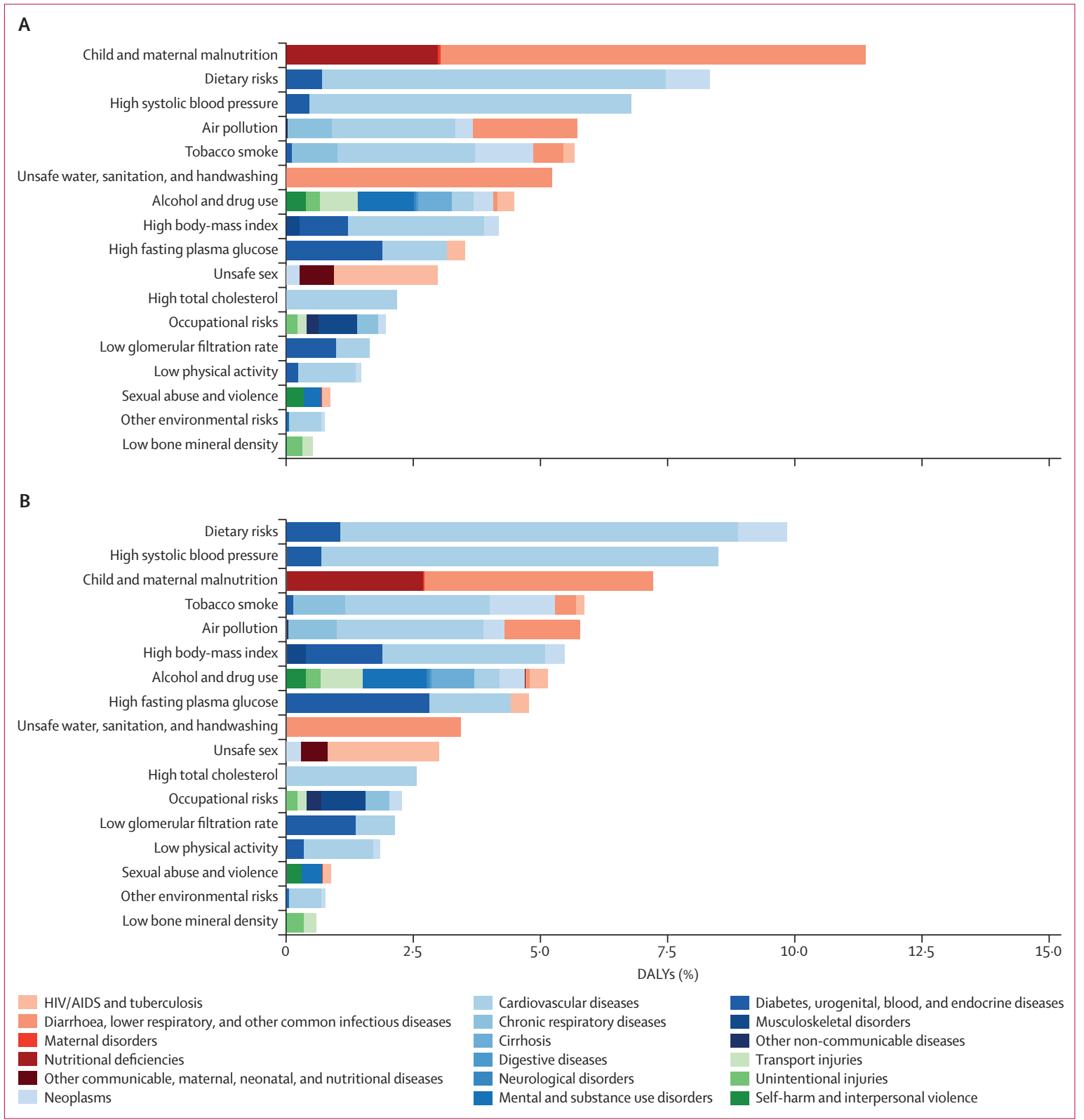

Figure 5: Global DALYs attributed to level 2 risk factors in 2000 for both sexes combined (A) and global DALYs attributed to level 2 risk factors in 2013 for both sexes combined (B)

DALYs=disability-adjusted life-years.

explanations for neoplasms. For the category of diarrhoea, lower respiratory infections, and other common infections, there is no contribution from the metabolic risks included in this study but environmental and occupational and behavioural risks are nearly equal with substantial overlap. Figure 4 shows the same breakdown of the overlap of the three clusters of risk factors by age. Because we have included no risk factors for major neonatal causes in this analysis, the fraction explained by the three clusters rises rapidly with age in children. The fraction explained declines again to a low at 10-14 years.
In young adults, behavioural risks are the dominant risks with an increasing component related to metabolic risks at older ages. Environmental risks explain a relatively constant share of burden in all age groups.

The leading risk factors globally have changed substantially from 2000 to 2013 (figure 5; see appendix pp 712-20 for 1990 and for results for males and females separately). In 2000, the leading cause of attributable DALYs (level 2 in the risk hierarchy) was child and maternal malnutrition for both males and females, accounting for more than one in ten DALYs. Other risks 


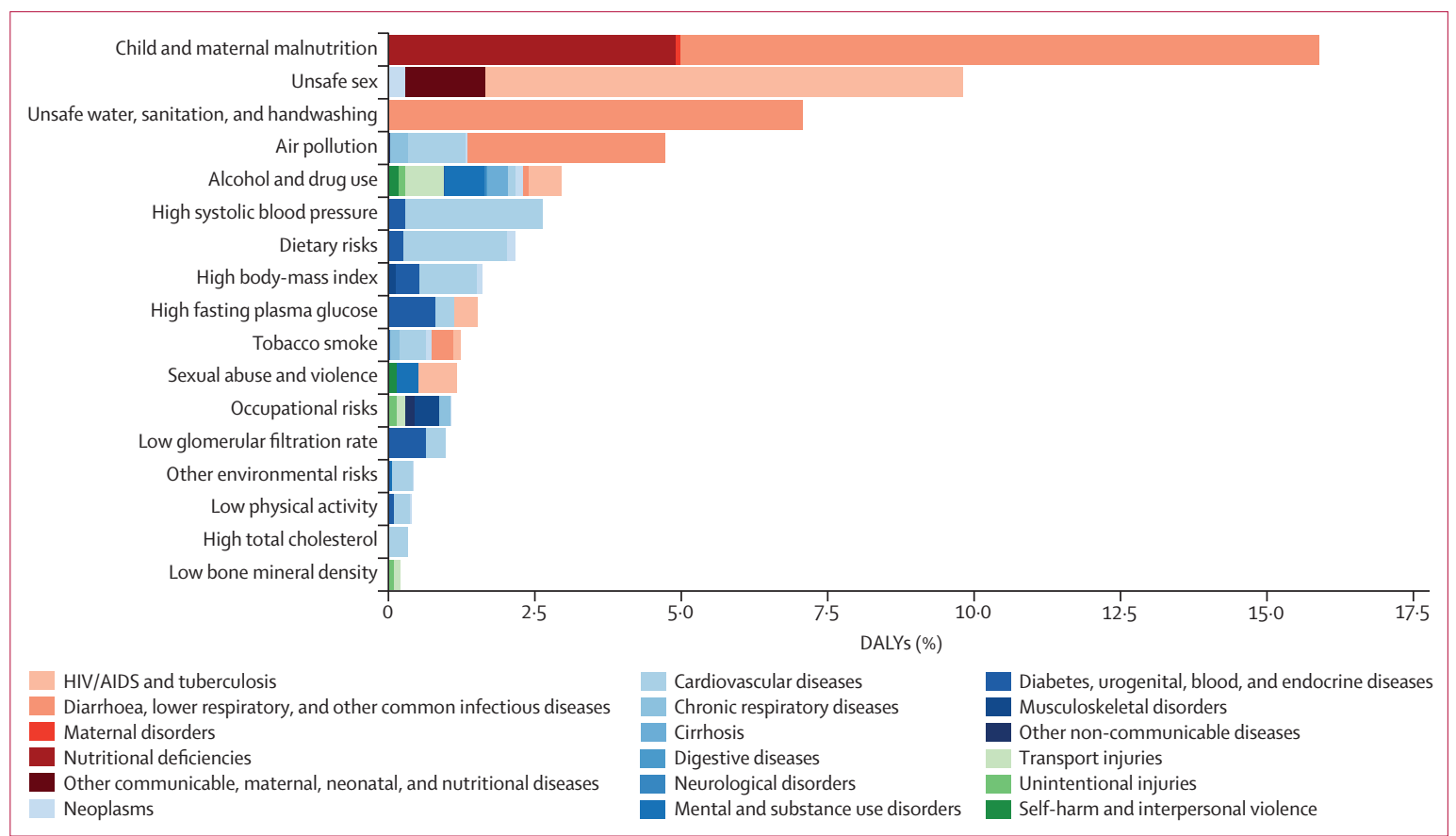

Figure 6: Global DALYs attributed to level 2 risk factors in 2013 for sub-Saharan Africa for both sexes combined

DALYs=disability-adjusted life-years.

that are characteristic of poor communities including unsafe water, unsafe sanitation and handwashing, and air pollution caused nearly $5 \%$ each of DALYs for males and females. By 2013, child and maternal malnutrition had dropped from $10 \cdot 4 \%$ in males and $12.5 \%$ in females in 2000 to $6 \cdot 55 \%$ and $8 \cdot 02 \%$, respectively. Risks for males at the global level in 2013 accounting for more than 5\% of DALYs were the aggregation of dietary risks, high systolic blood pressure, tobacco smoke, alcohol and drug use, child and maternal malnutrition, air pollution, high fasting plasma glucose, and high BMI. In females, the risks in 2013 accounting for more than 5\% of DALYs were dietary risks, child and maternal malnutrition, high systolic blood pressure, high BMI, and air pollution. Other risks that account for more than $2 \%$ of global DALYs in men and women include high fasting plasma glucose, unsafe water, unsafe sanitation, lack of handwashing, unsafe sex, and high cholesterol. The most notable differences in the magnitude of risk factors between males and females are the more prominent role for females of child and maternal malnutrition, high BMI, and sexual abuse and violence; whereas in males, tobacco, alcohol, and drug use are much more prominent than in females.

The global pattern masks tremendous regional variation in the profile of risks, particularly in sub-Saharan Africa compared with the rest of the developing and developed world. Figure 6 shows the leading risk factors in terms of attributable DALYs for sub-Saharan Africa in 2013 for both sexes combined: child and maternal malnutrition, unsafe sex, and unsafe water, sanitation, and handwashing practices. In females, the next most important is air pollution (in this case mostly household air pollution) and high systolic blood pressure. In males, alcohol and drug use is also an important risk factor.

The period 2000-13 was characterised by a major shift in the size and relative magnitude of many risk factors (figure 7). Childhood undernutrition went from the number one global risk factor in terms of attributable DALYS to the fourth in 2013, a drop of $45 \%(39-51)$ in the number of DALYs. Unsafe water declined 37\% (30-44) dropping from fourth to eighth; likewise unsafe sanitation dropped from ninth to 16th. Suboptimal breastfeeding declined 40\% (32-47) from rank 11 to rank 19. Unsafe sex went from 10th to 9th from 2000 to 2013; it should be noted that the peak attributable burden associated with unsafe sex was in 2005. Several risks related to non-communicable diseases have risen in prominence. High systolic blood pressure increased from second to first. Smoking increased from third to second. High BMI increased from fifth to third and high fasting plasma glucose also increased from eighth to fifth. Ambient particulate matter pollution increased 6\% (1-12) leading to a rank increase from 13th to 12th. Several diet components-most notably low fruit, high sodium, and low whole grains-increased in rank and absolute attributable burden over the period. We can isolate the impact of changes in population size and age composition by examining the change in the number of attributable DALYs compared with the change in the agestandardised rate of attributable DALYs. In fact, only five risk factors had increases in the age-standardised attributable DALY rate: unsafe sex, diet high in red meat, 


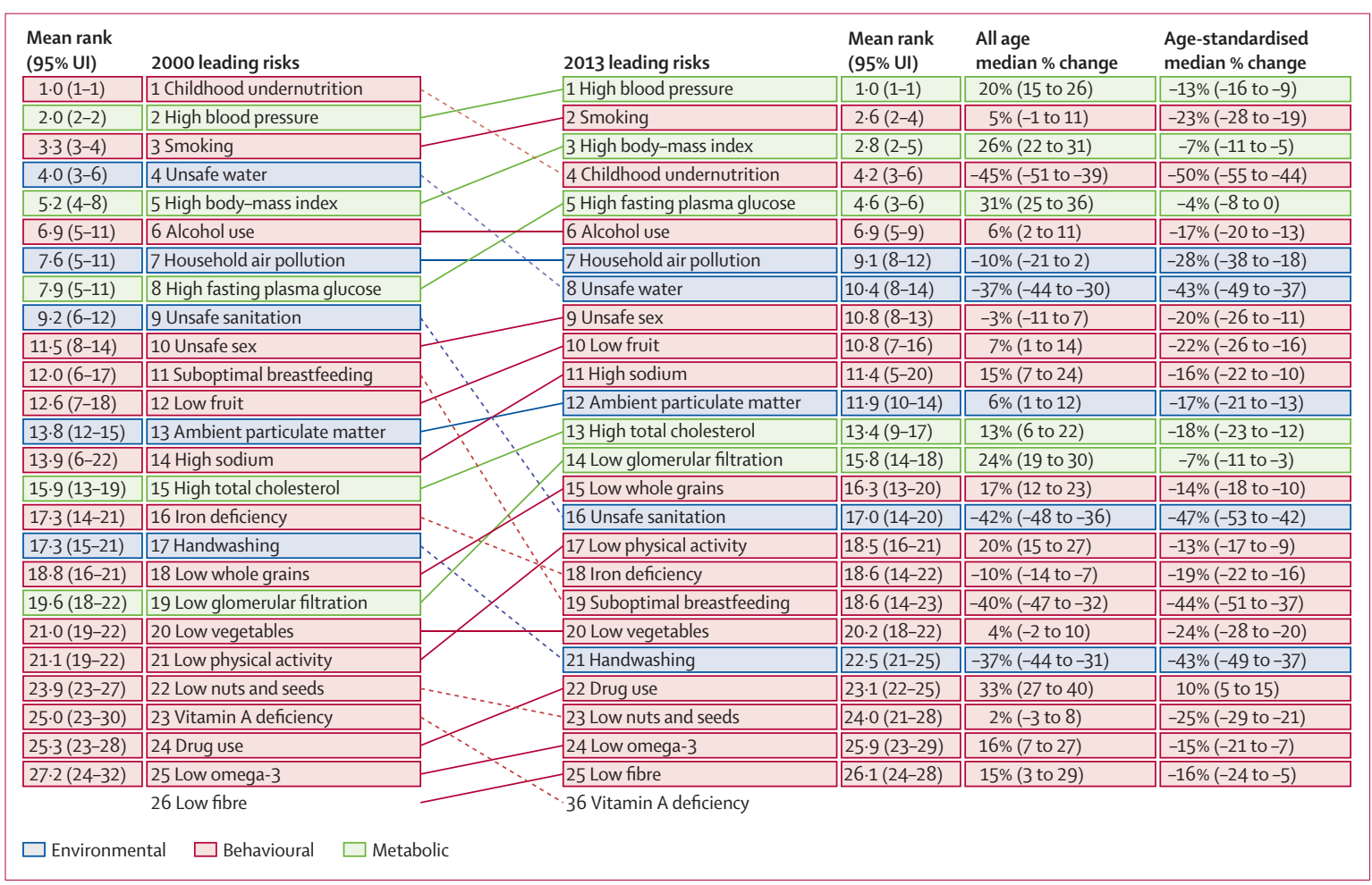

Figure 7: The 25 leading level 3 global risk factors for DALYs in both sexes combined in 2000 and 2013

diet high in sugar-sweetened beverages, occupational carcinogens, and drug use. In terms of the number of attributable DALYs, seven risks declined: vitamin A deficiency, childhood undernutrition, unsafe sanitation, secondhand smoke, no handwashing with soap, unsafe water, and suboptimal breastfeeding. Among the components of unsafe water, sanitation, and handwashing, the most important is unsafe water followed by unsafe sanitation and then no handwashing with soap.

Deaths and DALYs for all ages and both sexes combined for the full risk factor hierarchy are provided in table 3 . Appendix pp 52-87 provides a further breakdown for each risk-outcome pair. All risk factors combined accounted for $25 \cdot 1$ million deaths in 1990 , increasing by more than one-fifth to $30 \cdot 8$ million deaths in 2013 . Although the number of deaths attributed to all risks increased substantially, the global all-risk all-cause PAF increased only 3.4 percentage points from $52.8 \%$ to $56 \cdot 2 \%$. The trends in DALYs attributed to all risk factors are quite different than those for deaths: total DALYs did not change from 1990 to 2013 and the PAF decreased by 0.05 of a percentage point. For most risks that affect non-communicable diseases, the number of deaths or DALYs that are attributable to those risks increased; however, the age-standardised PAF increased by more than $10 \%$ for a subset of risks, including most occupational carcinogens, occupational noise, occupational ergonomic factors, alcohol use, drug use, diet low in whole grains, diet low in milk, diet high in red meat, diet high in processed meat, diet high in sugarsweetened beverages, diet with suboptimal calcium, intimate partner violence, unsafe sex, low physical activity, high fasting plasma glucose, high systolic blood pressure, high BMI, and low glomerular filtration rate.

In most cases, the trend in the number of deaths attributed to a risk factor is similar to the trend in the number of DALYs attributable to the same risk from 1990 to 2013. Differences in the rates reflect the age pattern of the attributable events for a risk. An unusual case is air pollution, for which the number of attributable deaths increased but attributable DALYs declined. This finding is due to the trends for ambient particulate matter pollution, for which deaths increased from $2 \cdot 2$ million to 2.9 million deaths, and household air pollution from solid fuels for which deaths remained constant at 2.9 million. Because deaths due to household air pollution on average occur at much younger ages, the trend in this risk drives the overall trend in the joint risk of air pollution.

The combined effect of air pollution was 5.5 million deaths in 2013 and 141.5 million DALYs. There were roughly equal contributions from household air pollution (2.9 million deaths and 81.1 million DALYs in 2013) and ambient particulate matter pollution (2.9 million deaths and 69.7 million DALYs in 2013). Lead exposure accounted 


\begin{tabular}{|c|c|c|c|c|c|c|c|c|}
\hline & $\begin{array}{l}1990 \text { deaths (in } \\
\text { thousands) }\end{array}$ & $\begin{array}{l}2013 \text { deaths (in } \\
\text { thousands) }\end{array}$ & $\begin{array}{l}\text { Median percent } \\
\text { change deaths }\end{array}$ & $\begin{array}{l}\text { Median percent } \\
\text { change of age- } \\
\text { standardised } \\
\text { deaths PAF }\end{array}$ & $\begin{array}{l}1990 \text { DALYs (in } \\
\text { thousands) }\end{array}$ & $\begin{array}{l}2013 \text { DALYs (in } \\
\text { thousands) }\end{array}$ & $\begin{array}{l}\text { Median percent } \\
\text { change DALYs }\end{array}$ & $\begin{array}{l}\text { Median percent } \\
\text { change of age- } \\
\text { standardised } \\
\text { DALYs PAF }\end{array}$ \\
\hline All risk factors & $\begin{array}{l}25085 \\
\text { (24385 to 25821) }\end{array}$ & $\begin{array}{l}30839 \\
\text { (29719 to 31949) }\end{array}$ & $\begin{array}{c}23.0 \% \\
(19 \cdot 0 \text { to } 27 \cdot 3)\end{array}$ & $\begin{array}{c}0.6 \% \\
(-1.0 \text { to } 2 \cdot 0)\end{array}$ & $\begin{array}{l}1035987 \\
\text { (980813 to } 1092478)\end{array}$ & $\begin{array}{l}996554 \\
\text { (927157 to 1072340) }\end{array}$ & $\begin{array}{c}-3.8 \% \\
(-7.7 \text { to }-0.1)\end{array}$ & $\begin{array}{c}-3.8 \% \\
(-6.0 \text { to }-1.8)\end{array}$ \\
\hline Environmental risks & $\begin{array}{l}8492 \\
\text { (8036 to 8953) }\end{array}$ & $\begin{array}{c}8181 \\
\text { (7651 to } 8726)\end{array}$ & $\begin{array}{c}-3.7 \% \\
(-9.6 \text { to } 2 \cdot 4)\end{array}$ & $\begin{array}{l}-15 \cdot 5 \% \\
(-19 \cdot 8 \text { to } 11 \cdot 1)\end{array}$ & $\begin{array}{l}400345 \\
\text { (374489 to } 424432 \text { ) }\end{array}$ & $\begin{array}{l}289517 \\
\text { (265778 to } 312094)\end{array}$ & $\begin{array}{l}-27 \cdot 7 \% \\
(-32 \cdot 1 \text { to }-23 \cdot 2)\end{array}$ & $\begin{array}{l}-22 \cdot 6 \% \\
(-26 \cdot 1 \text { to }-19 \cdot 1)\end{array}$ \\
\hline $\begin{array}{l}\text { Unsafe water, } \\
\text { sanitation, and } \\
\text { handwashing }\end{array}$ & $\begin{array}{l}2727 \\
\text { (2530 to 2952) }\end{array}$ & $\begin{array}{l}1399 \\
\text { (1237 to 1576) }\end{array}$ & $\begin{array}{l}-48 \cdot 8 \% \\
(-53 \cdot 6 \text { to }-43 \cdot 7)\end{array}$ & $\begin{array}{l}-44 \cdot 9 \% \\
(-49 \cdot 6 \text { to }-40 \cdot 0)\end{array}$ & $\begin{array}{l}190423 \\
\text { (174685 to 208033) }\end{array}$ & $\begin{array}{l}83867 \\
\text { (72879 to } 95568)\end{array}$ & $\begin{array}{l}-56.0 \% \\
(-60.6 \text { to }-50.9)\end{array}$ & $\begin{array}{l}-45 \cdot 6 \% \\
(-50 \cdot 8 \text { to }-40 \cdot 1)\end{array}$ \\
\hline Unsafe water source & $\begin{array}{l}2434 \\
\text { (1971 to 2763) }\end{array}$ & $\begin{array}{l}1246 \\
\text { (989 to } 1464)\end{array}$ & $\begin{array}{l}-48 \cdot 8 \% \\
(-53 \cdot 7 \text { to }-43 \cdot 9)\end{array}$ & $\begin{array}{l}-45 \cdot 0 \% \\
(-49 \cdot 7 \text { to }-40 \cdot 1)\end{array}$ & $\begin{array}{l}170053 \\
\text { (137216 to } 193963)\end{array}$ & $\begin{array}{l}75125 \\
\text { (59952 to 89756) }\end{array}$ & $\begin{array}{l}-55.9 \% \\
(-60.4 \text { to }-50.8)\end{array}$ & $\begin{array}{l}-45 \cdot 5 \% \\
(-50 \cdot 7 \text { to }-40 \cdot 0)\end{array}$ \\
\hline Unsafe sanitation & $\begin{array}{c}1785 \\
\text { (1613 to } 1959)\end{array}$ & $\begin{array}{c}816 \\
\text { (707 to 921) }\end{array}$ & $\begin{array}{l}-54 \cdot 4 \% \\
(-58.8 \text { to }-49.8)\end{array}$ & $\begin{array}{l}-51 \cdot 1 \% \\
(-55 \cdot 5 \text { to }-46 \cdot 9)\end{array}$ & $\begin{array}{l}124049 \\
\text { (111394 to } 137303)\end{array}$ & $\begin{array}{l}49039 \\
\text { (41770 to } 56227)\end{array}$ & $\begin{array}{l}-60 \cdot 5 \% \\
(-64 \cdot 8 \text { to }-56 \cdot 0)\end{array}$ & $\begin{array}{l}-51 \cdot 3 \% \\
(-56 \cdot 3 \text { to }-46 \cdot 4)\end{array}$ \\
\hline $\begin{array}{l}\text { No handwashing } \\
\text { with soap }\end{array}$ & $\begin{array}{c}1010 \\
\text { (798 to } 1204)\end{array}$ & $\begin{array}{c}517 \\
\text { (408 to } 621)\end{array}$ & $\begin{array}{l}-48 \cdot 9 \% \\
(-53 \cdot 7 \text { to }-43 \cdot 8)\end{array}$ & $\begin{array}{l}-45 \cdot 0 \% \\
(-49 \cdot 8 \text { to }-40 \cdot 2)\end{array}$ & $\begin{array}{c}70389 \\
\text { (55414 to } 84417)\end{array}$ & $\begin{array}{c}30721 \\
\text { (24281 to } 37626)\end{array}$ & $\begin{array}{l}-56 \cdot 4 \% \\
(-60 \cdot 9 \text { to }-51 \cdot 6)\end{array}$ & $\begin{array}{l}-46 \cdot 1 \% \\
(-51 \cdot 3 \text { to }-40 \cdot 5)\end{array}$ \\
\hline Air pollution & $\begin{array}{l}4808 \\
\text { (4459 to 5157) }\end{array}$ & $\begin{array}{l}5527 \\
\text { (5109 to 5944) }\end{array}$ & $\begin{array}{l}14 \cdot 8 \% \\
(5 \cdot 8 \text { to } 25 \cdot 3)\end{array}$ & $\begin{array}{l}-8.0 \% \\
(-15 \cdot 0 \text { to }-0.2)\end{array}$ & $\begin{array}{l}157831 \\
\text { (145269 to } 171007)\end{array}$ & $\begin{array}{l}141456 \\
(130071 \text { to } 153652)\end{array}$ & $\begin{array}{l}-10 \cdot 5 \% \\
(-17 \cdot 4 \text { to }-2 \cdot 8)\end{array}$ & $\begin{array}{l}-12 \cdot 7 \% \\
(-19 \cdot 2 \text { to }-5 \cdot 7)\end{array}$ \\
\hline $\begin{array}{l}\text { Ambient particulate } \\
\text { matter pollution }\end{array}$ & $\begin{array}{c}2238 \\
\text { (2154 to 2317) }\end{array}$ & $\begin{array}{l}2926 \\
\text { (2777 to 3066) }\end{array}$ & $\begin{array}{l}30 \cdot 7 \% \\
(25 \cdot 2 \text { to } 36 \cdot 5)\end{array}$ & $\begin{array}{c}2 \cdot 9 \% \\
\text { (0.7 to } 5 \cdot 1)\end{array}$ & $\begin{array}{c}68120 \\
\text { (64972 to } 71405)\end{array}$ & $\begin{array}{l}69673 \\
\text { (65585 to } 73552)\end{array}$ & $\begin{array}{c}2 \cdot 3 \% \\
(-3 \cdot 4 \text { to } 8 \cdot 2)\end{array}$ & $\begin{array}{c}-3.0 \% \\
(-6.6 \text { to } 0.8)\end{array}$ \\
\hline $\begin{array}{l}\text { Household air } \\
\text { pollution from solid } \\
\text { fuels }\end{array}$ & $\begin{array}{l}2857 \\
\text { (2482 to 3216) }\end{array}$ & $\begin{array}{l}2893 \\
\text { (2463 to 3303) }\end{array}$ & $\begin{array}{c}1 \cdot 3 \% \\
(-13 \cdot 4 \text { to } 18 \cdot 8)\end{array}$ & $\begin{array}{l}-17 \cdot 2 \% \\
(-30.0 \text { to }-2 \cdot 8)\end{array}$ & $\begin{array}{l}101643 \\
\text { (88877 to } 115053)\end{array}$ & $\begin{array}{l}81087 \\
\text { (70025 to } 92802)\end{array}$ & $\begin{array}{l}-20 \cdot 2 \% \\
(-29 \cdot 5 \text { to }-9 \cdot 4)\end{array}$ & $\begin{array}{l}-20.4 \% \\
(-30 \cdot 5 \text { to }-9 \cdot 1)\end{array}$ \\
\hline $\begin{array}{l}\text { Ambient ozone } \\
\text { pollution }\end{array}$ & $\begin{array}{c}133 \\
\text { (105 to } 162)\end{array}$ & $\begin{array}{c}217 \\
\text { (161 to 272) }\end{array}$ & $\begin{array}{l}63 \cdot 8 \% \\
(14 \cdot 5 \text { to } 125 \cdot 1)\end{array}$ & $\begin{array}{c}19 \cdot 8 \% \\
(-16 \cdot 3 \text { to } 60 \cdot 6)\end{array}$ & $\begin{array}{c}3038 \\
\text { (2296 to 3814) }\end{array}$ & $\begin{array}{c}5073 \\
\text { (3576 to 6620) }\end{array}$ & $\begin{array}{c}66 \cdot 9 \% \\
(12 \cdot 2 \text { to } 137 \cdot 1)\end{array}$ & $\begin{array}{l}32.5 \% \\
\text { (-11.0 to } 84 \cdot 6)\end{array}$ \\
\hline $\begin{array}{l}\text { Other environmental } \\
\text { risks }\end{array}$ & $\begin{array}{c}731 \\
\text { (523 to 965) }\end{array}$ & $\begin{array}{c}945 \\
\text { (663 to 1279) }\end{array}$ & $\begin{array}{l}29 \cdot 2 \% \\
(17 \cdot 1 \text { to } 40 \cdot 5)\end{array}$ & $\begin{array}{c}-1 \cdot 9 \% \\
(-9 \cdot 2 \text { to } 4 \cdot 7)\end{array}$ & $\begin{array}{c}17015 \\
\text { (12567 to 22173) }\end{array}$ & $\begin{array}{l}18822 \\
\text { (13300 to 25407) }\end{array}$ & $\begin{array}{c}10.5 \% \\
(0.4 \text { to } 20.1)\end{array}$ & $\begin{array}{c}-9 \cdot 4 \% \\
(-16 \cdot 6 \text { to }-2 \cdot 3)\end{array}$ \\
\hline Residential radon & $\begin{array}{c}63 \\
\text { (41 to } 86)\end{array}$ & $\begin{array}{c}92 \\
\text { (61 to } 128)\end{array}$ & $\begin{array}{l}46 \cdot 3 \% \\
\text { (13.1 to } 87.9)\end{array}$ & $\begin{array}{l}13 \cdot 8 \% \\
(-11 \cdot 7 \text { to } 44 \cdot 3)\end{array}$ & $\begin{array}{c}1503 \\
\text { (984 to 2086) }\end{array}$ & $\begin{array}{c}1979 \\
\text { (1331 to 2768) }\end{array}$ & $\begin{array}{c}31.7 \% \\
(2 \cdot 4 \text { to } 67.6)\end{array}$ & $\begin{array}{c}7 \cdot 1 \% \\
(-17 \cdot \text { to }-36 \cdot 9)\end{array}$ \\
\hline Lead exposure & $\begin{array}{c}668 \\
\text { (465 to 899) }\end{array}$ & $\begin{array}{c}853 \\
\text { (572 to } 1181 \text { ) }\end{array}$ & $\begin{array}{c}27 \cdot 6 \% \\
\text { (15.1 to } 39 \cdot 1)\end{array}$ & $\begin{array}{c}-3 \cdot 3 \% \\
(-10 \cdot 8 \text { to } 3 \cdot 7)\end{array}$ & $\begin{array}{c}15512 \\
\text { (10967 to 20727) }\end{array}$ & $\begin{array}{c}16843 \\
\text { (11494 to 23505) }\end{array}$ & $\begin{array}{c}8.5 \% \\
\text { (-2.4 to } 18 \cdot 3)\end{array}$ & $\begin{array}{l}-10.9 \% \\
(-18.9 \text { to }-3.8)\end{array}$ \\
\hline Occupational risks & $\begin{array}{c}562 \\
\text { (509 to 629) }\end{array}$ & $\begin{array}{c}717 \\
\text { (641 to } 803 \text { ) }\end{array}$ & $\begin{array}{l}27 \cdot 7 \% \\
(13 \cdot 4 \text { to } 42 \cdot 5)\end{array}$ & $\begin{array}{c}4.0 \% \\
(-5 \cdot 7 \text { to } 14 \cdot 0)\end{array}$ & $\begin{array}{c}43879 \\
\text { (35819 to } 52859)\end{array}$ & $\begin{array}{l}55352 \\
\text { (44589 to } 67890)\end{array}$ & $\begin{array}{c}26 \cdot 2 \% \\
(16 \cdot 3 \text { to } 36 \cdot 1)\end{array}$ & $\begin{array}{c}10 \cdot 2 \% \\
(2.9 \text { to } 18 \cdot 0)\end{array}$ \\
\hline $\begin{array}{l}\text { Occupational } \\
\text { carcinogens }\end{array}$ & $\begin{array}{c}152 \\
\text { (135 to 174) }\end{array}$ & $\begin{array}{c}304 \\
\text { (263 to 341) }\end{array}$ & $\begin{array}{l}100 \cdot 7 \% \\
\text { (78.5 to } 116 \cdot 2)\end{array}$ & $\begin{array}{c}52 \cdot 4 \% \\
(36 \cdot 1 \text { to } 63.6)\end{array}$ & $\begin{array}{c}3149 \\
\text { (2789 to 3543) }\end{array}$ & $\begin{array}{c}5803 \\
\text { (5076 to 6526) }\end{array}$ & $\begin{array}{l}84.7 \% \\
\text { (66.2 to } 101 \cdot 4)\end{array}$ & $\begin{array}{c}48 \cdot 5 \% \\
(34 \cdot 2 \text { to } 60.8)\end{array}$ \\
\hline $\begin{array}{l}\text { Occupational } \\
\text { exposure to } \\
\text { asbestos }\end{array}$ & $\begin{array}{c}94 \\
\text { (76 to 116) }\end{array}$ & $\begin{array}{c}194 \\
\text { (155 to } 233)\end{array}$ & $\begin{array}{l}109 \cdot 6 \% \\
\text { (72.4 to } 132 \cdot 2)\end{array}$ & $\begin{array}{c}56 \cdot 2 \% \\
\text { (28.9 to } 74 \cdot 2)\end{array}$ & $\begin{array}{c}1773 \\
\text { (1425 to 2211) }\end{array}$ & $\begin{array}{c}3402 \\
\text { (2725 to 4113) }\end{array}$ & $\begin{array}{l}93 \cdot 4 \% \\
(63.5 \text { to } 117 \cdot 3)\end{array}$ & $\begin{array}{c}53 \cdot 4 \% \\
(29.9 \text { to } 72 \cdot 4)\end{array}$ \\
\hline $\begin{array}{l}\text { Occupational } \\
\text { exposure to } \\
\text { polycyclic } \\
\text { aromatic } \\
\text { hydrocarbons }\end{array}$ & (2 to 3$)^{3}$ & $\begin{array}{r}6 \\
\text { (5 to } 7)\end{array}$ & $\begin{array}{l}120 \cdot 2 \% \\
\text { (101.8 to } 139 \cdot 3)\end{array}$ & $\begin{array}{c}71 \cdot 4 \% \\
(58 \cdot 4 \text { to } 85 \cdot 1)\end{array}$ & $\begin{array}{r}60 \\
\text { (51 to } 71)\end{array}$ & $\begin{array}{c}125 \\
(102 \text { to } 146)\end{array}$ & $\begin{array}{l}105 \cdot 9 \% \\
\text { (88.3 to } 126 \cdot 2)\end{array}$ & $\begin{array}{c}67 \cdot 4 \% \\
(52 \cdot 8 \text { to } 82 \cdot 7)\end{array}$ \\
\hline $\begin{array}{l}\text { Occupational } \\
\text { exposure to silica }\end{array}$ & $\begin{array}{c}11 \\
\text { (10 to } 12)\end{array}$ & $\begin{array}{c}21 \\
\text { (19 to } 24)\end{array}$ & $\begin{array}{l}95 \cdot 8 \% \\
\text { (78.9 to } 112.6)\end{array}$ & $\begin{array}{c}52 \cdot 8 \% \\
(41 \cdot 3 \text { to } 64 \cdot 1)\end{array}$ & $\begin{array}{c}248 \\
\text { (223 to } 274)\end{array}$ & $\begin{array}{c}454 \\
\text { (404 to } 509 \text { ) }\end{array}$ & $\begin{array}{l}83.0 \% \\
(67 \cdot 3 \text { to } 100 \cdot 1)\end{array}$ & $\begin{array}{c}49.0 \% \\
(35.8 \text { to } 61.9)\end{array}$ \\
\hline $\begin{array}{l}\text { Occupational } \\
\text { exposure to } \\
\text { sulphuric acid }\end{array}$ & $\begin{array}{r}3 \\
\text { (2 to } 4)^{2}\end{array}$ & $\begin{array}{r}4 \\
\text { (3 to } 5)\end{array}$ & $\begin{array}{c}29 \cdot 6 \% \\
(16 \cdot 8 \text { to } 48 \cdot 3)\end{array}$ & $\begin{array}{c}0.8 \% \\
\text { (-8.8 to } 13 \cdot 1)\end{array}$ & $\begin{array}{r}68 \\
\text { (49 to } 91 \text { ) }\end{array}$ & $\begin{array}{c}83 \\
\text { (60 to } 113)\end{array}$ & $\begin{array}{c}21 \cdot 3 \% \\
\text { (9.6 to } 40 \cdot 5)\end{array}$ & $\begin{array}{c}-1.5 \% \\
(-11.6 \text { to } 12.1 \%)\end{array}$ \\
\hline $\begin{array}{l}\text { Occupational } \\
\text { exposure to } \\
\text { trichloroethylene }\end{array}$ & $\begin{array}{r}0 \\
\text { (0 to } 0)\end{array}$ & $\begin{array}{r}0 \\
(0 \text { to } 0)\end{array}$ & $\begin{array}{l}100 \cdot 2 \% \\
\text { (88.5 to } 112 \cdot 2)\end{array}$ & $\begin{array}{c}54 \cdot 3 \% \\
\text { (46.1 to } 62 \cdot 7)\end{array}$ & $(0 \text { to } 2)^{1}$ & $(0 \text { to } 3)^{2}$ & $\begin{array}{l}88 \cdot 5 \% \\
\text { (77.3 to 100.2) }\end{array}$ & $\begin{array}{c}51 \cdot 7 \% \\
(42 \cdot 9 \text { to } 61 \cdot 1)\end{array}$ \\
\hline $\begin{array}{l}\text { Occupational } \\
\text { exposure to } \\
\text { arsenic }\end{array}$ & $\begin{array}{r}2 \\
\text { (2 to } 3)^{2}\end{array}$ & $\begin{array}{r}4 \\
\text { (3 to } 4)\end{array}$ & $\begin{array}{l}72 \cdot 7 \% \\
\text { (56.4 to } 90.8)\end{array}$ & $\begin{array}{c}34.7 \% \\
\text { (23.4 to } 46.8)\end{array}$ & $\begin{array}{r}47 \\
\text { (38 to } 58)\end{array}$ & $\begin{array}{r}76 \\
\text { (60 to } 94)\end{array}$ & $\begin{array}{c}61 \cdot 3 \% \\
\text { (46.0 to } 79 \cdot 3)\end{array}$ & $\begin{array}{l}31 \cdot 3 \% \\
(18.6 \text { to } 44.9)\end{array}$ \\
\hline $\begin{array}{l}\text { Occupational } \\
\text { exposure to } \\
\text { benzene }\end{array}$ & $\begin{array}{r}2 \\
(1 \text { to } 2)^{2}\end{array}$ & $\begin{array}{r}3 \\
\text { (2 to } 3)^{2}\end{array}$ & $\begin{array}{c}66 \cdot 2 \% \\
\text { (57.2 to } 75 \cdot 5)\end{array}$ & $\begin{array}{c}32 \cdot 3 \% \\
\text { (25.8 to } 37.8)\end{array}$ & $\begin{array}{r}59 \\
\text { (51 to } 68)\end{array}$ & $\begin{array}{c}95 \\
\text { (81 to } 108)\end{array}$ & $\begin{array}{c}59 \cdot 4 \% \\
\text { (50.3 to } 69 \cdot 1)\end{array}$ & $\begin{array}{c}36 \cdot 8 \% \\
\text { (29.1 to } 44 \cdot 4)\end{array}$ \\
\hline $\begin{array}{l}\text { Occupational } \\
\text { exposure to } \\
\text { beryllium }\end{array}$ & $\begin{array}{r}0 \\
\text { (0 to } 0)\end{array}$ & $\begin{array}{r}0 \\
\text { (0 to } 0)\end{array}$ & $\begin{array}{l}44 \cdot 3 \% \\
\text { (30.6 to } 62 \cdot 7 \text { ) }\end{array}$ & $\begin{array}{c}12 \cdot 6 \% \\
(3 \cdot 0 \text { to } 25 \cdot 3)\end{array}$ & $(2 \text { to } 3)^{2}$ & $(3 \text { to } 4)^{3}$ & $\begin{array}{c}34 \cdot 7 \% \\
\text { (21.6 to } 53 \cdot 2 \text { ) }\end{array}$ & $\begin{array}{c}9.1 \% \\
(-2 \cdot 0 \text { to } 22 \cdot 3 \%)\end{array}$ \\
\hline
\end{tabular}




\begin{tabular}{|c|c|c|c|c|c|c|c|c|}
\hline & $\begin{array}{l}1990 \text { deaths (in } \\
\text { thousands) }\end{array}$ & $\begin{array}{l}2013 \text { deaths (in } \\
\text { thousands) }\end{array}$ & $\begin{array}{l}\text { Median percent } \\
\text { change deaths }\end{array}$ & $\begin{array}{l}\text { Median percent } \\
\text { change of age- } \\
\text { standardised } \\
\text { deaths PAF }\end{array}$ & $\begin{array}{l}1990 \text { DALYs (in } \\
\text { thousands) }\end{array}$ & $\begin{array}{l}2013 \text { DALYs (in } \\
\text { thousands) }\end{array}$ & $\begin{array}{l}\text { Median percent } \\
\text { change DALYs }\end{array}$ & $\begin{array}{l}\text { Median percent } \\
\text { change of age- } \\
\text { standardised } \\
\text { DALYs PAF }\end{array}$ \\
\hline \multicolumn{9}{|c|}{ (Continued from previous page) } \\
\hline $\begin{array}{l}\text { Occupational } \\
\text { exposure to } \\
\text { cadmium }\end{array}$ & $\begin{array}{l}0 \\
(0 \text { to } 0)\end{array}$ & $\begin{array}{l}1 \\
\text { (1 to } 1)\end{array}$ & $\begin{array}{l}116 \cdot 6 \% \\
(97 \cdot 0 \text { to } 137 \cdot 4 \%)\end{array}$ & $\begin{array}{c}68.6 \% \\
(54.9 \text { to } 82 \cdot 2)\end{array}$ & (7to 9) & $\begin{array}{r}16 \\
(13 \text { to } 19)\end{array}$ & $\begin{array}{l}102 \cdot 8 \% \\
(84 \cdot 4 \text { to } 123 \cdot 2)\end{array}$ & $\begin{array}{c}64 \cdot 9 \% \\
(49 \cdot 7 \text { to } 80 \cdot 1)\end{array}$ \\
\hline $\begin{array}{l}\text { Occupational } \\
\text { exposure to } \\
\text { chromium }\end{array}$ & $\begin{array}{l}1 \\
\text { (1 to } 1)\end{array}$ & $\begin{array}{l}3 \\
\text { (2 to } 3 \text { ) }\end{array}$ & $\begin{array}{l}116 \cdot 2 \% \\
\text { (96.7 to } 136 \cdot 7)\end{array}$ & $\begin{array}{c}68 \cdot 3 \% \\
\text { (54.8 to 81.4) }\end{array}$ & $\begin{array}{r}28 \\
\text { (25 to 32) }\end{array}$ & $\begin{array}{r}57 \\
(50 \text { to } 65)\end{array}$ & $\begin{array}{l}102 \cdot 3 \% \\
(83 \cdot 8 \text { to } 123 \cdot 6)\end{array}$ & $\begin{array}{c}64 \cdot 6 \% \\
(48.9 \text { to } 80 \cdot 4)\end{array}$ \\
\hline $\begin{array}{l}\text { Occupational } \\
\text { exposure to diesel } \\
\text { engine exhaust }\end{array}$ & $\begin{array}{l}17 \\
\text { (15 to } 20)\end{array}$ & $\begin{array}{l}37 \\
\text { (32 to 43) }\end{array}$ & $\begin{array}{l}116 \cdot 6 \% \\
\text { (99.4 to } 134 \cdot 9 \text { ) }\end{array}$ & $\begin{array}{c}69 \cdot 1 \% \\
(57 \cdot 2 \text { to } 81 \cdot 3)\end{array}$ & $\begin{array}{c}394 \\
\text { (343 to 449) }\end{array}$ & $\begin{array}{c}797 \\
\text { (690 to 913) }\end{array}$ & $\begin{array}{l}102 \cdot 0 \% \\
(84 \cdot 6 \text { to } 120 \cdot 8)\end{array}$ & $\begin{array}{c}64 \cdot 4 \% \\
(50 \cdot 5 \text { to } 78 \cdot 5)\end{array}$ \\
\hline $\begin{array}{l}\text { Occupational } \\
\text { exposure to } \\
\text { second-hand } \\
\text { smoke }\end{array}$ & $\begin{array}{l}19 \\
\text { (17 to } 20)\end{array}$ & $\begin{array}{l}34 \\
\text { (31 to 37) }\end{array}$ & $\begin{array}{l}80 \cdot 5 \% \\
(66.8 \text { to } 94.8)\end{array}$ & $\begin{array}{c}40 \cdot 6 \% \\
(31 \cdot 5 \text { to } 50 \cdot 0)\end{array}$ & $\begin{array}{c}431 \\
\text { (393 to 465) }\end{array}$ & $\begin{array}{c}725 \\
\text { (660 to } 794)\end{array}$ & $\begin{array}{c}68 \cdot 1 \% \\
(54 \cdot 7 \text { to } 83 \cdot 8)\end{array}$ & $\begin{array}{c}36 \cdot 7 \% \\
(26 \cdot 0 \text { to } 48 \cdot 3)\end{array}$ \\
\hline $\begin{array}{l}\text { Occupational } \\
\text { exposure to } \\
\text { formaldehyde }\end{array}$ & $\begin{array}{l}1 \\
(0 \text { to } 1)\end{array}$ & $\begin{array}{l}1 \\
\text { (1 to } 1)\end{array}$ & $\begin{array}{c}51 \cdot 1 \% \\
(34 \cdot 2 \text { to } 67 \cdot 8)\end{array}$ & $\begin{array}{c}20 \cdot 9 \% \\
\text { (9.3 to } 32 \cdot 2)\end{array}$ & $\begin{array}{r}20 \\
(16 \text { to } 25)\end{array}$ & $\begin{array}{r}29 \\
(23 \text { to } 35)\end{array}$ & $\begin{array}{c}43 \cdot 3 \% \\
(26 \cdot 9 \text { to } 59 \cdot 7)\end{array}$ & $\begin{array}{c}21 \cdot 3 \% \\
\text { (8.6 to } 34 \cdot 3)\end{array}$ \\
\hline $\begin{array}{l}\text { Occupational } \\
\text { exposure to } \\
\text { nickel }\end{array}$ & $\begin{array}{l}6 \\
\text { (4 to 8) }\end{array}$ & $\begin{array}{l}12 \\
\text { (9 to } 16)\end{array}$ & $\begin{array}{l}103 \cdot 0 \% \\
(82 \cdot 2 \text { to } 123 \cdot 6)\end{array}$ & $\begin{array}{c}58 \cdot 0 \% \\
(42 \cdot 7 \text { to } 73 \cdot 1)\end{array}$ & $\begin{array}{c}135 \\
\text { (103 to } 173)\end{array}$ & $\begin{array}{c}257 \\
(193 \text { to } 326)\end{array}$ & $\begin{array}{c}90 \cdot 5 \% \\
\text { (70.8 to } 110 \cdot 7 \text { ) }\end{array}$ & $\begin{array}{c}54 \cdot 6 \% \\
(38.4 \text { to } 71 \cdot 0)\end{array}$ \\
\hline $\begin{array}{l}\text { Occupational } \\
\text { asthmagens }\end{array}$ & $\begin{array}{l}63 \\
\text { (48 to 93) }\end{array}$ & $\begin{array}{l}52 \\
\text { (42 to } 70 \text { ) }\end{array}$ & $\begin{array}{l}-18 \cdot 4 \% \\
(-32 \cdot 9 \text { to } 5 \cdot 2)\end{array}$ & $\begin{array}{l}-34 \cdot 2 \% \\
(-46 \cdot 8 \text { to }-17 \cdot 1)\end{array}$ & $\begin{array}{c}2903 \\
\text { (2310 to 3909) }\end{array}$ & $\begin{array}{c}2771 \\
\text { (2227 to 3521) }\end{array}$ & $\begin{array}{c}-4 \cdot 7 \% \\
(-18 \cdot 1 \text { to } 12 \cdot 0)\end{array}$ & $\begin{array}{l}-18 \cdot 1 \% \\
(-30 \cdot 5 \text { to }-4 \cdot 4)\end{array}$ \\
\hline $\begin{array}{l}\text { Occupational } \\
\text { particulate matter, } \\
\text { gases, and fumes }\end{array}$ & $\begin{array}{l}197 \\
(161 \text { to } 236)\end{array}$ & $\begin{array}{l}205 \\
(164 \text { to } 251)\end{array}$ & $\begin{array}{c}3 \cdot 7 \% \\
(-7 \cdot 6 \text { to } 17 \cdot 6)\end{array}$ & $\begin{array}{l}-18 \cdot 8 \% \\
(-26 \cdot 7 \text { to }-9 \cdot 9)\end{array}$ & $\begin{array}{c}7212 \\
(5877 \text { to } 8545)\end{array}$ & $\begin{array}{c}8802 \\
\text { (7012 to } 10740)\end{array}$ & $\begin{array}{c}22 \cdot 0 \% \\
(10 \cdot 9 \text { to } 34 \cdot 0)\end{array}$ & $\begin{array}{c}-0.6 \% \\
(-8.4 \text { to } 8.0)\end{array}$ \\
\hline Occupational noise &.. &.. &. &.. & $\begin{array}{c}5039 \\
\text { (3268 to } 7193)\end{array}$ & $\begin{array}{c}7119 \\
\text { (4549 to } 10329)\end{array}$ & $\begin{array}{c}41 \cdot 4 \% \\
(33 \cdot 9 \text { to } 48.0)\end{array}$ & $\begin{array}{c}21 \cdot 4 \% \\
(15 \cdot 1 \text { to } 27 \cdot 8)\end{array}$ \\
\hline $\begin{array}{l}\text { Occupational } \\
\text { injuries }\end{array}$ & $\begin{array}{l}151 \\
(122 \text { to } 197)\end{array}$ & $\begin{array}{l}159 \\
(127 \text { to } 206)\end{array}$ & $\begin{array}{c}4 \cdot 4 \% \\
(-24 \cdot 6 \text { to } 49 \cdot 2)\end{array}$ & $\begin{array}{l}-4 \cdot 7 \% \\
(-32 \cdot 6 \text { to } 34 \cdot 2)\end{array}$ & $\begin{array}{c}9776 \\
\text { (7809 to } 12884)\end{array}$ & $\begin{array}{c}9947 \\
\text { (7886 to } 12927)\end{array}$ & $\begin{array}{c}1 \cdot 3 \% \\
(-26 \cdot 0 \text { to } 42 \cdot 5)\end{array}$ & $\begin{array}{c}-2 \cdot 9 \% \\
(-29 \cdot 9 \text { to } 34 \cdot 2)\end{array}$ \\
\hline $\begin{array}{l}\text { Occupational } \\
\text { ergonomic factors }\end{array}$ &.. &.. &.. &.. & $\begin{array}{c}15944 \\
\text { (10747 to } 22276)\end{array}$ & $\begin{array}{l}21109 \\
\text { (14206 to 29304) }\end{array}$ & $\begin{array}{c}32 \cdot 2 \% \\
\text { (28.0 to } 37 \cdot 7)\end{array}$ & $\begin{array}{c}16 \cdot 2 \% \\
(11 \cdot 2 \text { to } 21 \cdot 8)\end{array}$ \\
\hline Behavioural risks & $\begin{array}{l}18453 \\
\text { (17419 to } 19480)\end{array}$ & $\begin{array}{l}21909 \\
\text { (20446 to 23383) }\end{array}$ & $\begin{array}{c}18 \cdot 7 \% \\
(14 \cdot 5 \text { to } 23 \cdot 1)\end{array}$ & $\begin{array}{c}-0.7 \% \\
(-2 \cdot 4 \text { to } 1.0)\end{array}$ & $\begin{array}{l}799073 \\
\text { (753589 to } 844178)\end{array}$ & $\begin{array}{l}717608 \\
\text { (667831 to } 771924)\end{array}$ & $\begin{array}{l}-10 \cdot 2 \% \\
(-14 \cdot 1 \text { to }-6 \cdot 1)\end{array}$ & $\begin{array}{l}-7 \cdot 4 \% \\
(-9 \cdot 8 \text { to }-5 \cdot 1)\end{array}$ \\
\hline $\begin{array}{l}\text { Child and maternal } \\
\text { malnutrition }\end{array}$ & $\begin{array}{c}4254 \\
\text { (3937 to } 4555)\end{array}$ & $\begin{array}{l}1665 \\
\text { (1487 to } 1840)\end{array}$ & $\begin{array}{l}-60 \cdot 8 \% \\
(-65 \cdot 0 \text { to }-57 \cdot 1)\end{array}$ & $\begin{array}{l}-50 \cdot 5 \% \\
(-55 \cdot 9 \text { to }-45 \cdot 5)\end{array}$ & $\begin{array}{l}403951 \\
\text { (371608 to } 432910)\end{array}$ & $\begin{array}{l}176859 \\
\text { (156431 to } 199831)\end{array}$ & $\begin{array}{l}-56 \cdot 1 \% \\
(-60 \cdot 6 \text { to }-52 \cdot 2)\end{array}$ & $\begin{array}{l}-43 \cdot 2 \% \\
(-47 \cdot 9 \text { to } \\
-38 \cdot 9)\end{array}$ \\
\hline $\begin{array}{l}\text { Childhood } \\
\text { undernutrition }\end{array}$ & $\begin{array}{c}3635 \\
\text { (3341 to 3888) }\end{array}$ & $\begin{array}{c}1327 \\
(1169 \text { to } 1481)\end{array}$ & $\begin{array}{l}-63 \cdot 4 \% \\
(-67 \cdot 6 \text { to }-59 \cdot 6)\end{array}$ & $\begin{array}{l}-53 \cdot 2 \% \\
(-58 \cdot 6 \text { to }-48 \cdot 1)\end{array}$ & $\begin{array}{c}317851 \\
\text { (292 } 419 \text { to } 339549)\end{array}$ & $\begin{array}{l}119802 \\
(106565 \text { to } 133359)\end{array}$ & $\begin{array}{l}-62 \cdot 2 \% \\
(-66 \cdot 3 \text { to }-58 \cdot 5)\end{array}$ & $\begin{array}{l}-49 \cdot 9 \% \\
(-55 \cdot 1 \text { to }-45 \cdot 0)\end{array}$ \\
\hline $\begin{array}{l}\text { Childhood } \\
\text { underweight }\end{array}$ & $\begin{array}{l}1080 \\
\text { (886 to } 1288)\end{array}$ & $\begin{array}{c}386 \\
\text { (309 to 463) }\end{array}$ & $\begin{array}{l}-64 \cdot 2 \% \\
(-70 \cdot 5 \text { to }-57 \cdot 9)\end{array}$ & $\begin{array}{l}-54 \cdot 0 \% \\
(-62 \cdot 1 \text { to }-45 \cdot 8)\end{array}$ & $\begin{array}{l}95709 \\
\text { (79 } 446 \text { to } 113315)\end{array}$ & $\begin{array}{l}35806 \\
\text { (29108 to 42575) }\end{array}$ & $\begin{array}{l}-62 \cdot 5 \% \\
(-68 \cdot 9 \text { to }-56 \cdot 3)\end{array}$ & $\begin{array}{l}-50 \cdot 2 \% \\
(-58 \cdot 3 \text { to }-42 \cdot 4)\end{array}$ \\
\hline $\begin{array}{l}\text { Childhood } \\
\text { wasting }\end{array}$ & $\begin{array}{l}3295 \\
\text { (2802 to } 3696)\end{array}$ & $\begin{array}{c}1247 \\
(1034 \text { to } 1413)\end{array}$ & $\begin{array}{l}-62 \cdot 0 \% \\
(-66 \cdot 5 \text { to }-57 \cdot 4)\end{array}$ & $\begin{array}{l}-51 \cdot 4 \% \\
(-57 \cdot 1 \text { to }-45 \cdot 2)\end{array}$ & $\begin{array}{l}288145 \\
\text { (246038 to } 322526)\end{array}$ & $\begin{array}{l}112350 \\
\text { (94437 to } 127169 \text { ) }\end{array}$ & $\begin{array}{l}-60 \cdot 9 \% \\
(-65 \cdot 4 \text { to }-56 \cdot 3)\end{array}$ & $\begin{array}{l}-48 \cdot 2 \% \\
(-53 \cdot 8 \text { to }-42 \cdot 2)\end{array}$ \\
\hline $\begin{array}{l}\text { Childhood } \\
\text { stunting }\end{array}$ & $\begin{array}{c}848 \\
\text { (474 to 1339) }\end{array}$ & $\begin{array}{c}218 \\
(107 \text { to } 389)\end{array}$ & $\begin{array}{l}-74 \cdot 6 \% \\
(-79 \cdot 5 \text { to }-68 \cdot 9)\end{array}$ & $\begin{array}{l}-67 \cdot 3 \% \\
(-73 \cdot 9 \text { to }-60 \cdot 0)\end{array}$ & $\begin{array}{c}73355 \\
\text { (40848 to } 115668)\end{array}$ & $\begin{array}{c}19291 \\
\text { (9581 to 34208) }\end{array}$ & $\begin{array}{l}-73.9 \% \\
(-79.0 \text { to }-68.6)\end{array}$ & $\begin{array}{l}-65 \cdot 4 \% \\
(-72 \cdot 2 \text { to }-58 \cdot 1)\end{array}$ \\
\hline $\begin{array}{l}\text { Suboptimal } \\
\text { breastfeeding }\end{array}$ & $\begin{array}{l}1344 \\
\text { (904 to 1834) }\end{array}$ & $\begin{array}{c}501 \\
\text { (318 to 697) }\end{array}$ & $\begin{array}{l}-62 \cdot 8 \% \\
(-67 \cdot 5 \text { to }-58 \cdot 0)\end{array}$ & $\begin{array}{l}-52 \cdot 1 \% \\
(-58 \cdot 3 \text { to }-45 \cdot 5)\end{array}$ & $\begin{array}{c}116801 \\
\text { (78740 to } 158958)\end{array}$ & $\begin{array}{l}44203 \\
(28205 \text { to } 61650)\end{array}$ & $\begin{array}{l}-62 \cdot 3 \% \\
(-66 \cdot 8 \text { to }-57 \cdot 6)\end{array}$ & $\begin{array}{l}-49 \cdot 6 \% \\
(-55 \cdot 7 \text { to }-43 \cdot 4)\end{array}$ \\
\hline $\begin{array}{l}\text { Non-exclusive } \\
\text { breastfeeding }\end{array}$ & $\begin{array}{c}1155 \\
\text { (743 to } 1606)\end{array}$ & $\begin{array}{c}442 \\
\text { (264 to } 641)\end{array}$ & $\begin{array}{l}-61 \cdot 9 \% \\
(-66 \cdot 8 \text { to }-56 \cdot 9)\end{array}$ & $\begin{array}{l}-50 \cdot 7 \% \\
(-57 \cdot 3 \text { to }-43 \cdot 9)\end{array}$ & $\begin{array}{c}99927 \\
\text { (64457 to } 138645)\end{array}$ & $\begin{array}{l}38502 \\
\text { (23037 to 55565) }\end{array}$ & $\begin{array}{l}-61 \cdot 7 \% \\
(-66 \cdot 5 \text { to }-56 \cdot 7)\end{array}$ & $\begin{array}{l}-48 \cdot 7 \% \\
(-55 \cdot 1 \text { to }-42 \cdot 1)\end{array}$ \\
\hline $\begin{array}{l}\text { Discontinued } \\
\text { breastfeeding }\end{array}$ & $\begin{array}{c}191 \\
\text { (65 to 349) }\end{array}$ & $\begin{array}{c}59 \\
\text { (20 to } 110)\end{array}$ & $\begin{array}{l}-69 \cdot 3 \% \\
(-74 \cdot 6 \text { to }-63 \cdot 0)\end{array}$ & $\begin{array}{l}-60 \cdot 5 \% \\
(-67 \cdot 3 \text { to }-52 \cdot 5)\end{array}$ & $\begin{array}{c}17046 \\
\text { (5804 to } 31059 \text { ) }\end{array}$ & $\begin{array}{c}5722 \\
\text { (1898 to 10599) }\end{array}$ & $\begin{array}{l}-66 \cdot 6 \% \\
(-71 \cdot 7 \text { to }-60 \cdot 5)\end{array}$ & $\begin{array}{l}-55 \cdot 4 \% \\
(-62 \cdot 1 \text { to }-47 \cdot 6)\end{array}$ \\
\hline Iron deficiency & $\begin{array}{c}241 \\
(169 \text { to } 344)\end{array}$ & $\begin{array}{c}199 \\
(137 \text { to } 275)\end{array}$ & $\begin{array}{l}-17 \cdot 1 \% \\
(-33 \cdot 7 \text { to }-0 \cdot 5)\end{array}$ & $\begin{array}{l}-21 \cdot 8 \% \\
(-35 \cdot 6 \text { to }-7 \cdot 7)\end{array}$ & $\begin{array}{c}53019 \\
(38674 \text { to } 71446)\end{array}$ & $\begin{array}{c}44651 \\
\text { (31844 to 62304) }\end{array}$ & $\begin{array}{l}-15 \cdot 6 \% \\
(-21 \cdot 5 \text { to }-11 \cdot 5)\end{array}$ & $\begin{array}{l}-6 \cdot 5 \% \\
(-11 \cdot 3 \text { to }-2 \cdot 0)\end{array}$ \\
\hline $\begin{array}{l}\text { Vitamin A } \\
\text { deficiency }\end{array}$ & $\begin{array}{c}377 \\
\text { (247 to 522) }\end{array}$ & $\begin{array}{c}85 \\
\text { (51 to } 125)\end{array}$ & $\begin{array}{l}-77 \cdot 4 \% \\
(-82 \cdot 9 \text { to }-71 \cdot 5)\end{array}$ & $\begin{array}{l}-71 \cdot 0 \% \\
(-78 \cdot 2 \text { to }-63 \cdot 7)\end{array}$ & $\begin{array}{c}32920 \\
\text { (21694 to } 45629)\end{array}$ & $\begin{array}{c}7875 \\
\text { (4758 to 11541) }\end{array}$ & $\begin{array}{l}-76 \cdot 1 \% \\
(-81 \cdot 6 \text { to }-70 \cdot 3)\end{array}$ & $\begin{array}{l}-68 \cdot 3 \% \\
(-75 \cdot 6 \text { to }-60 \cdot 9)\end{array}$ \\
\hline \multirow[t]{2}{*}{ Zinc deficiency } & $\begin{array}{c}221 \\
\text { (15 to 491) }\end{array}$ & $\begin{array}{c}66 \\
\text { (4 to } 153)\end{array}$ & $\begin{array}{l}-70 \cdot 1 \% \\
(-76 \cdot 3 \text { to }-62 \cdot 7)\end{array}$ & $\begin{array}{l}-61 \cdot 2 \% \\
(-69 \cdot 8 \text { to }-52 \cdot 4)\end{array}$ & $\begin{array}{c}19188 \\
\text { (1816 to 41961) }\end{array}$ & $\begin{array}{c}5996 \\
\text { (745 to } 13267)\end{array}$ & $\begin{array}{l}-68 \cdot 4 \% \\
(-74 \cdot 4 \text { to }-56 \cdot 7)\end{array}$ & $\begin{array}{l}-57 \cdot 3 \% \\
(-66 \cdot 1 \text { to }-42 \cdot 6)\end{array}$ \\
\hline & & & & & & & \multicolumn{2}{|c|}{ (Table 3 continues on next page) } \\
\hline
\end{tabular}




\begin{tabular}{|c|c|c|c|c|c|c|c|c|}
\hline & $\begin{array}{l}1990 \text { deaths (in } \\
\text { thousands) }\end{array}$ & $\begin{array}{l}2013 \text { deaths (in } \\
\text { thousands) }\end{array}$ & $\begin{array}{l}\text { Median percent } \\
\text { change deaths }\end{array}$ & $\begin{array}{l}\text { Median percent } \\
\text { change of age- } \\
\text { standardised } \\
\text { deaths PAF }\end{array}$ & $\begin{array}{l}1990 \text { DALYs (in } \\
\text { thousands) }\end{array}$ & $\begin{array}{l}2013 \text { DALYs (in } \\
\text { thousands) }\end{array}$ & $\begin{array}{l}\text { Median percent } \\
\text { change DALYs }\end{array}$ & $\begin{array}{l}\text { Median percent } \\
\text { change of age- } \\
\text { standardised } \\
\text { DALYs PAF }\end{array}$ \\
\hline \multicolumn{9}{|c|}{ (Continued from previous page) } \\
\hline Tobacco smoke & $\begin{array}{l}5229 \\
(4816 \text { to } 5681)\end{array}$ & $\begin{array}{l}6149 \\
\text { (5587 to 6762) }\end{array}$ & $\begin{array}{l}17.8 \% \\
(10.9 \text { to } 23.9)\end{array}$ & $\begin{array}{c}-9 \cdot 6 \% \\
(-13 \cdot 2 \text { to }-6 \cdot 3)\end{array}$ & $\begin{array}{l}142341 \\
\text { (131399 to } 153920)\end{array}$ & $\begin{array}{l}143512 \\
\text { (129979 to 159147) }\end{array}$ & $\begin{array}{c}0.7 \% \\
(-5 \cdot 5 \text { to } 7 \cdot 5)\end{array}$ & $\begin{array}{l}-14.5 \% \\
(-18.9 \text { to }-10 \cdot 2)\end{array}$ \\
\hline Smoking & $\begin{array}{l}4634 \\
(4222 \text { to } 5079)\end{array}$ & $\begin{array}{l}5818 \\
\text { (5258 to } 6435)\end{array}$ & $\begin{array}{l}25 \cdot 7 \% \\
(17 \cdot 9 \text { to } 32.6)\end{array}$ & $\begin{array}{c}-5 \cdot 1 \% \\
(-9 \cdot 3 \text { to }-1 \cdot 3)\end{array}$ & $\begin{array}{l}115910 \\
\text { (105383 to } 127110)\end{array}$ & $\begin{array}{l}134196 \\
\text { (120872 to } 149759)\end{array}$ & $\begin{array}{c}15 \cdot 8 \% \\
(8 \cdot 6 \text { to } 23 \cdot 6)\end{array}$ & $\begin{array}{c}-7 \cdot 4 \% \\
(-12 \cdot 4 \text { to }-2 \cdot 2)\end{array}$ \\
\hline Second hand smoke & $\begin{array}{c}595 \\
\text { (540 to } 654)\end{array}$ & $\begin{array}{c}331 \\
\text { (308 to 355) }\end{array}$ & $\begin{array}{l}-44 \cdot 4 \% \\
(-48 \cdot 2 \text { to }-40 \cdot 0)\end{array}$ & $\begin{array}{l}-50 \cdot 9 \% \\
(-53 \cdot 6 \text { to }-48 \cdot 2)\end{array}$ & $\begin{array}{c}26431 \\
\text { (22494 to } 30676)\end{array}$ & $\begin{array}{c}9316 \\
\text { (8417 to } 10,277)\end{array}$ & $\begin{array}{l}-64 \cdot 7 \% \\
(-68 \cdot 3 \text { to }-60 \cdot 8)\end{array}$ & $\begin{array}{l}-60 \cdot 2 \% \\
(-63.3 \text { to }-56.9)\end{array}$ \\
\hline Alcohol and drug use & $\begin{array}{l}2092 \\
\text { (1671 to 2438) }\end{array}$ & $\begin{array}{l}3163 \\
\text { (2537 to 3656) }\end{array}$ & $\begin{array}{l}51 \cdot 3 \% \\
(44 \cdot 3 \text { to } 58 \cdot 4)\end{array}$ & $\begin{array}{c}19 \cdot 4 \% \\
\text { (15.3 to 23.7) }\end{array}$ & $\begin{array}{l}89844 \\
\text { (76788 to } 101767)\end{array}$ & $\begin{array}{l}126053 \\
\text { (107154 to } 142356)\end{array}$ & $\begin{array}{l}40 \cdot 2 \% \\
\text { (34.8 to } 46 \cdot 3)\end{array}$ & $\begin{array}{c}23 \cdot 5 \% \\
\text { (18.9 to 28.3) }\end{array}$ \\
\hline Alcohol use & $\begin{array}{c}1977 \\
\text { (1555 to 2329) }\end{array}$ & $\begin{array}{l}2786 \\
\text { (2146 to 3287) }\end{array}$ & $\begin{array}{l}40 \cdot 9 \% \\
\text { (33.2 to } 47 \cdot 9)\end{array}$ & $\begin{array}{c}11 \cdot 1 \% \\
(6 \cdot 9 \text { to } 14 \cdot 8)\end{array}$ & $\begin{array}{c}76029 \\
\text { (63443 to } 87186)\end{array}$ & $\begin{array}{l}99278 \\
\text { (81295 to } 113616)\end{array}$ & $\begin{array}{c}30.5 \% \\
(23.9 \text { to } 37.0)\end{array}$ & $\begin{array}{c}13 \cdot 6 \% \\
\text { (8.6 to } 18 \cdot 1)\end{array}$ \\
\hline Drug use & $\begin{array}{c}132 \\
\text { (109 to } 155)\end{array}$ & $\begin{array}{c}429 \\
\text { (381 to } 480)\end{array}$ & $\begin{array}{l}224.8 \% \\
(188.0 \text { to } 273.4)\end{array}$ & $\begin{array}{l}179 \cdot 5 \% \\
\text { (147.0 to } 222 \cdot 3)\end{array}$ & $\begin{array}{c}14481 \\
\text { (11607 to } 17286)\end{array}$ & $\begin{array}{l}28578 \\
\text { (24505 to 33104) }\end{array}$ & $\begin{array}{l}97 \cdot 4 \% \\
(83 \cdot 2 \text { to } 114 \cdot 8)\end{array}$ & $\begin{array}{l}89 \cdot 3 \% \\
\text { (74.3 to } 107 \cdot 1)\end{array}$ \\
\hline Dietary risks & $\begin{array}{l}8068 \\
\text { (6991 to 9159) }\end{array}$ & $\begin{array}{l}11274 \\
\text { (9656 to } 12957)\end{array}$ & $\begin{array}{l}39 \cdot 6 \% \\
\text { (34.1 to } 46 \cdot 2)\end{array}$ & $\begin{array}{c}2.9 \% \\
\text { (0.3 to } 5 \cdot 8)\end{array}$ & $\begin{array}{l}177408 \\
\text { (154661 to 200097) }\end{array}$ & $\begin{array}{l}241351 \\
\text { (209634 to 273339) }\end{array}$ & $\begin{array}{c}35.9 \% \\
(29 \cdot 8 \text { to } 43 \cdot 0)\end{array}$ & $\begin{array}{c}7 \cdot 7 \% \\
(4 \cdot 1 \text { to } 12 \cdot 0)\end{array}$ \\
\hline Diet low in fruits & $\begin{array}{l}2540 \\
(1686 \text { to 3367) }\end{array}$ & $\begin{array}{l}3413 \\
\text { (2207 to 4546) }\end{array}$ & $\begin{array}{c}33 \cdot 9 \% \\
(25 \cdot 6 \text { to } 43 \cdot 3)\end{array}$ & $\begin{array}{c}0.1 \% \\
(-5 \cdot 2 \text { to } 5 \cdot 9)\end{array}$ & $\begin{array}{l}58710 \\
\text { (39575 to } 76928)\end{array}$ & $\begin{array}{l}74797 \\
\text { (49434 to 98791) }\end{array}$ & $\begin{array}{c}27.0 \% \\
(19 \cdot 0 \text { to } 36 \cdot 0)\end{array}$ & $\begin{array}{c}1.7 \% \\
(-3 \cdot 8 \text { to } 7 \cdot 9)\end{array}$ \\
\hline $\begin{array}{l}\text { Diet low in } \\
\text { vegetables }\end{array}$ & $\begin{array}{c}1381 \\
\text { (1094 to } 1684)\end{array}$ & $\begin{array}{c}1782 \\
\text { (1405 to 2173) }\end{array}$ & $\begin{array}{c}28 \cdot 9 \% \\
\text { (22.3 to } 36 \cdot 6)\end{array}$ & $\begin{array}{c}-4.8 \% \\
(-9.4 \text { to }-0.1)\end{array}$ & $\begin{array}{c}31283 \\
\text { (24692 to } 38039)\end{array}$ & $\begin{array}{l}39176 \\
\text { (31050 to 47658) }\end{array}$ & $\begin{array}{c}25 \cdot 2 \% \\
(17 \cdot 9 \text { to } 33 \cdot 2)\end{array}$ & $\begin{array}{c}-0 \cdot 4 \% \\
(-5 \cdot 4 \text { to } 5 \cdot 1)\end{array}$ \\
\hline $\begin{array}{l}\text { Diet low in whole } \\
\text { grains }\end{array}$ & $\begin{array}{l}1396 \\
\text { (1066 to 1728) }\end{array}$ & $\begin{array}{l}2049 \\
(1575 \text { to } 2525)\end{array}$ & $\begin{array}{l}46 \cdot 8 \% \\
(40.8 \text { to } 54 \cdot 2)\end{array}$ & $\begin{array}{c}9 \cdot 2 \% \\
(5 \cdot 9 \text { to } 13 \cdot 1)\end{array}$ & $\begin{array}{c}34807 \\
\text { (26736 to } 43078)\end{array}$ & $\begin{array}{l}51411 \\
\text { (39500 to 63286) }\end{array}$ & $\begin{array}{c}47.6 \% \\
(40.9 \text { to } 56.0)\end{array}$ & $\begin{array}{c}18.0 \% \\
\text { (13.9 to 22.9) }\end{array}$ \\
\hline $\begin{array}{l}\text { Diet low in nuts and } \\
\text { seeds }\end{array}$ & $\begin{array}{c}1012 \\
\text { (725 to } 1304)\end{array}$ & $\begin{array}{c}1195 \\
\text { (816 to } 1578)\end{array}$ & $\begin{array}{c}17 \cdot 7 \% \\
\text { (10.5 to } 25 \cdot 0)\end{array}$ & $\begin{array}{l}-13 \cdot 3 \% \\
(-18.7 \text { to }-8.5)\end{array}$ & $\begin{array}{c}23434 \\
\text { (16643 to } 30134)\end{array}$ & $\begin{array}{l}27109 \\
\text { (18408 to } 36030)\end{array}$ & $\begin{array}{c}15 \cdot 3 \% \\
\text { (8.0 to } 22 \cdot 8)\end{array}$ & $\begin{array}{c}-8 \cdot 5 \% \\
(-13 \cdot 7 \text { to }-3 \cdot 3)\end{array}$ \\
\hline Diet low in milk & $\begin{array}{c}66 \\
\text { (19 to } 111)\end{array}$ & $\begin{array}{c}105 \\
\text { (30 to } 177)\end{array}$ & $\begin{array}{l}58.1 \% \\
\text { (51.9 to } 63.8)\end{array}$ & $\begin{array}{c}18 \cdot 4 \% \\
(14 \cdot 6 \text { to } 22 \cdot 2)\end{array}$ & $\begin{array}{c}1515 \\
\text { (434 to } 2538)\end{array}$ & $\begin{array}{c}2218 \\
\text { (633 to 3713) }\end{array}$ & $\begin{array}{c}46.3 \% \\
\text { (39.8 to } 52.5)\end{array}$ & $\begin{array}{c}17 \cdot 2 \% \\
(12 \cdot 6 \text { to } 21 \cdot 6)\end{array}$ \\
\hline $\begin{array}{l}\text { Diet high in red } \\
\text { meat }\end{array}$ & $\begin{array}{c}62 \\
\text { (55 to } 70 \text { ) }\end{array}$ & $\begin{array}{c}102 \\
\text { (89 to } 116)\end{array}$ & $\begin{array}{l}64.1 \% \\
\text { (52.8 to } 75.8)\end{array}$ & $\begin{array}{c}23.0 \% \\
(14.4 \text { to } 32.0)\end{array}$ & $\begin{array}{c}2201 \\
\text { (1854 to 2585) }\end{array}$ & $\begin{array}{c}4147 \\
\text { (3349 to 5026) }\end{array}$ & $\begin{array}{l}88 \cdot 2 \% \\
\text { (75.9 to 101.6) }\end{array}$ & $\begin{array}{c}50 \cdot 7 \% \\
(41.9 \text { to } 60 \cdot 4)\end{array}$ \\
\hline $\begin{array}{l}\text { Diet high in } \\
\text { processed meat }\end{array}$ & $\begin{array}{c}457 \\
\text { (332 to } 622 \text { ) }\end{array}$ & $\begin{array}{c}644 \\
\text { (467 to } 881 \text { ) }\end{array}$ & $\begin{array}{c}41 \cdot 4 \% \\
\text { (24.1 to } 57 \cdot 9)\end{array}$ & $\begin{array}{c}4.4 \% \\
(-8 \cdot 6 \text { to } 17 \cdot 1)\end{array}$ & $\begin{array}{c}11745 \\
\text { (8676 to } 15897)\end{array}$ & $\begin{array}{l}17380 \\
\text { (12677 to 23925) }\end{array}$ & $\begin{array}{c}47.9 \% \\
(30.9 \text { to } 64.0)\end{array}$ & $\begin{array}{c}17 \cdot 3 \% \\
\text { (3.4 to } 29 \cdot 4)\end{array}$ \\
\hline $\begin{array}{l}\text { Diet high in } \\
\text { sugar-sweetened } \\
\text { beverages }\end{array}$ & $\begin{array}{c}60 \\
\text { (44 to } 82 \text { ) }\end{array}$ & $\begin{array}{c}126 \\
\text { (96 to } 166)\end{array}$ & $\begin{array}{l}110 \cdot 1 \% \\
\text { (88.7 to } 141 \cdot 4)\end{array}$ & $\begin{array}{c}64 \cdot 4 \% \\
\text { (45.7 to } 87 \cdot 2)\end{array}$ & $\begin{array}{c}2712 \\
\text { (2006 to 3635) }\end{array}$ & $\begin{array}{c}6190 \\
\text { (4665 to 8142) }\end{array}$ & $\begin{array}{l}128.4 \% \\
(105 \cdot 4 \text { to } 159.0)\end{array}$ & $\begin{array}{c}89 \cdot 6 \% \\
\text { (70.2 to } 115 \cdot 3)\end{array}$ \\
\hline Diet low in fibre & $\begin{array}{c}716 \\
\text { (587 to } 853 \text { ) }\end{array}$ & $\begin{array}{l}1009 \\
\text { (817 to } 1207)\end{array}$ & $\begin{array}{l}40 \cdot 6 \% \\
\text { (25.3 to } 60.0)\end{array}$ & $\begin{array}{c}4.2 \% \\
(-7 \cdot 4 \text { to } 18.0)\end{array}$ & $\begin{array}{c}16395 \\
\text { (13496 to 19433) }\end{array}$ & $\begin{array}{l}22098 \\
\text { (17996 to 26349) }\end{array}$ & $\begin{array}{c}35.0 \% \\
(18.6 \text { to } 52 \cdot 4)\end{array}$ & $\begin{array}{c}7 \cdot 4 \% \\
(-5 \cdot 1 \text { to } 20 \cdot 6)\end{array}$ \\
\hline $\begin{array}{l}\text { Diet suboptimal in } \\
\text { calcium }\end{array}$ & $\begin{array}{c}85 \\
\text { (74 to } 97 \text { ) }\end{array}$ & $\begin{array}{c}141 \\
\text { (122 to } 160)\end{array}$ & $\begin{array}{l}64 \cdot 6 \% \\
\text { (53.6 to } 80.4)\end{array}$ & $\begin{array}{c}22 \cdot 9 \% \\
(15 \cdot 2 \text { to } 33 \cdot 1)\end{array}$ & $\begin{array}{c}1870 \\
\text { (1605 to 2143) }\end{array}$ & $\begin{array}{c}2876 \\
\text { (2507 to 3258) }\end{array}$ & $\begin{array}{c}53 \cdot 5 \% \\
\text { (42.8 to } 66 \cdot 9)\end{array}$ & $\begin{array}{c}22.9 \% \\
(15 \cdot 5 \text { to } 33.0)\end{array}$ \\
\hline $\begin{array}{l}\text { Diet low in seafood } \\
\text { omega-3 fatty acids }\end{array}$ & $\begin{array}{c}712 \\
\text { (530 to 909) }\end{array}$ & $\begin{array}{c}1031 \\
\text { (769 to } 1304)\end{array}$ & $\begin{array}{c}44 \cdot 6 \% \\
\text { (35.3 to } 57 \cdot 3 \text { ) }\end{array}$ & $\begin{array}{c}7 \cdot 5 \% \\
(1.9 \text { to } 14 \cdot 3)\end{array}$ & $\begin{array}{c}16285 \\
\text { (12321 to } 20657)\end{array}$ & $\begin{array}{l}22448 \\
\text { (16887 to 28205) }\end{array}$ & $\begin{array}{c}37 \cdot 6 \% \\
\text { (27.7 to } 52 \cdot 7)\end{array}$ & $\begin{array}{c}10 \cdot 1 \% \\
(2 \cdot 8 \text { to } 19 \cdot 8)\end{array}$ \\
\hline $\begin{array}{l}\text { Diet low in } \\
\text { polyunsaturated } \\
\text { fatty acids }\end{array}$ & $\begin{array}{c}447 \\
\text { (404 to 493) }\end{array}$ & $\begin{array}{c}581 \\
\text { (512 to } 651)\end{array}$ & $\begin{array}{c}29 \cdot 6 \% \\
(16 \cdot 9 \text { to } 44 \cdot 7)\end{array}$ & $\begin{array}{c}-4 \cdot 5 \% \\
(-13 \cdot 7 \text { to } 5 \cdot 2)\end{array}$ & $\begin{array}{c}10033 \\
\text { (9051 to 11040) }\end{array}$ & $\begin{array}{c}12670 \\
\text { (11103 to } 14342)\end{array}$ & $\begin{array}{c}25 \cdot 9 \% \\
(13 \cdot 0 \text { to } 41 \cdot 8)\end{array}$ & $\begin{array}{c}0.0 \% \\
(-9.8 \text { to } 11.6)\end{array}$ \\
\hline $\begin{array}{l}\text { Diet high in trans } \\
\text { fatty acids }\end{array}$ & $\begin{array}{c}464 \\
\text { (311 to } 650)\end{array}$ & $\begin{array}{c}405 \\
\text { (218 to } 645)\end{array}$ & $\begin{array}{l}-15.0 \% \\
(-34.0 \text { to } 3.7)\end{array}$ & $\begin{array}{l}-38 \cdot 3 \% \\
(-52 \cdot 2 \text { to }-24 \cdot 5)\end{array}$ & $\begin{array}{c}10644 \\
\text { (7131 to } 14859)\end{array}$ & $\begin{array}{c}9875 \\
\text { (5503 to 15228) }\end{array}$ & $\begin{array}{c}-8.5 \% \\
(-29.0 \text { to } 9.6)\end{array}$ & $\begin{array}{l}-28 \cdot 7 \% \\
(-43 \cdot 6 \text { to }-14 \cdot 7)\end{array}$ \\
\hline Diet high in sodium & $\begin{array}{l}2562 \\
\text { (1377 to 4041) }\end{array}$ & $\begin{array}{l}3689 \\
\text { (2028 to 5810) }\end{array}$ & $\begin{array}{l}44 \cdot 1 \% \\
\text { (33.8 to } 57 \cdot 1)\end{array}$ & $\begin{array}{c}7.4 \% \\
\text { (1.3 to } 15 \cdot 5)\end{array}$ & $\begin{array}{c}54620 \\
\text { (29271 to } 86008)\end{array}$ & $\begin{array}{l}74327 \\
\text { (40615 to } 116717)\end{array}$ & $\begin{array}{c}36 \cdot 2 \% \\
\text { (26.5 to } 48 \cdot 7)\end{array}$ & $\begin{array}{c}8.4 \% \\
\text { (1.5 to } 17 \cdot 5)\end{array}$ \\
\hline $\begin{array}{l}\text { Sexual abuse and } \\
\text { violence }\end{array}$ & $\begin{array}{c}163 \\
\text { (141 to } 188)\end{array}$ & $\begin{array}{c}257 \\
\text { (203 to 312) }\end{array}$ & $\begin{array}{l}57.5 \% \\
(30.6 \text { to } 83.7)\end{array}$ & $\begin{array}{c}36.7 \% \\
(14.9 \text { to } 58.9)\end{array}$ & $\begin{array}{c}15133 \\
\text { (12297 to 18621) }\end{array}$ & $\begin{array}{l}21290 \\
\text { (16743 to 26065) }\end{array}$ & $\begin{array}{l}40.6 \% \\
(26.4 \text { to } 55 \cdot 7)\end{array}$ & $\begin{array}{c}31.8 \% \\
(19.1 \text { to } 46 \cdot 0)\end{array}$ \\
\hline $\begin{array}{l}\text { Childhood sexual } \\
\text { abuse }\end{array}$ & $\begin{array}{c}64 \\
\text { (53 to } 78 \text { ) }\end{array}$ & $\begin{array}{c}68 \\
\text { (55 to } 82 \text { ) }\end{array}$ & $\begin{array}{c}5 \cdot 9 \% \\
(-9.3 \text { to } 19 \cdot 9)\end{array}$ & $\begin{array}{c}-7.4 \% \\
(-21.4 \text { to } 3.9)\end{array}$ & $\begin{array}{c}6896 \\
\text { (5364 to 8667) }\end{array}$ & $\begin{array}{c}7682 \\
\text { (5910 to } 9736)\end{array}$ & $\begin{array}{c}11 \cdot 4 \% \\
\text { (4.0 to } 18 \cdot 8)\end{array}$ & $\begin{array}{c}5 \cdot 8 \% \\
(-1 \cdot 6 \text { to } 12 \cdot 6)\end{array}$ \\
\hline $\begin{array}{l}\text { Intimate partner } \\
\text { violence }\end{array}$ & $\begin{array}{c}106 \\
\text { (86 to } 130)\end{array}$ & $\begin{array}{c}197 \\
\text { (146 to 251) }\end{array}$ & $\begin{array}{l}85 \cdot 9 \% \\
\text { (49.6 to } 124 \cdot 8)\end{array}$ & $\begin{array}{c}60.9 \% \\
\text { (30.5 to } 93 \cdot 6)\end{array}$ & $\begin{array}{c}9009 \\
\text { (7076 to 11440) }\end{array}$ & $\begin{array}{l}14454 \\
\text { (11027 to } 18164)\end{array}$ & $\begin{array}{c}60 \cdot 6 \% \\
(39.6 \text { to } 85.1)\end{array}$ & $\begin{array}{c}48 \cdot 8 \% \\
(29 \cdot 3 \text { to } 71 \cdot 7)\end{array}$ \\
\hline Unsafe sex & $\begin{array}{c}679 \\
\text { (561 to 827) }\end{array}$ & $\begin{array}{l}1481 \\
\text { (1383 to 1621) }\end{array}$ & $\begin{array}{l}118.8 \% \\
\text { (86.2 to } 158 \cdot 1)\end{array}$ & $\begin{array}{l}100 \cdot 5 \% \\
\text { (76.6 to } 129 \cdot 3)\end{array}$ & $\begin{array}{c}39761 \\
\text { (30789 to } 52320)\end{array}$ & $\begin{array}{l}73282 \\
\text { (67015 to } 82478)\end{array}$ & $\begin{array}{l}86.1 \% \\
(51 \cdot 7 \text { to } 127 \cdot 0)\end{array}$ & $\begin{array}{c}97 \cdot 6 \% \\
(68 \cdot 3 \text { to } 131 \cdot 3)\end{array}$ \\
\hline
\end{tabular}




\begin{tabular}{|c|c|c|c|c|c|c|c|c|}
\hline & $\begin{array}{l}1990 \text { deaths (in } \\
\text { thousands) }\end{array}$ & $\begin{array}{l}2013 \text { deaths (in } \\
\text { thousands) }\end{array}$ & $\begin{array}{l}\text { Median percent } \\
\text { change deaths }\end{array}$ & $\begin{array}{l}\text { Median percent } \\
\text { change of age- } \\
\text { standardised } \\
\text { deaths PAF }\end{array}$ & $\begin{array}{l}1990 \text { DALYs (in } \\
\text { thousands) }\end{array}$ & $\begin{array}{l}2013 \text { DALYs (in } \\
\text { thousands) }\end{array}$ & $\begin{array}{l}\text { Median percent } \\
\text { change DALYs }\end{array}$ & $\begin{array}{l}\text { Median percent } \\
\text { change of age- } \\
\text { standardised } \\
\text { DALYs PAF }\end{array}$ \\
\hline \multicolumn{9}{|c|}{ (Continued from previous page) } \\
\hline Low physical activity & $\begin{array}{l}1489 \\
(1257 \text { to } 1741)\end{array}$ & $\begin{array}{l}2182 \\
\text { (1858 to 2555) }\end{array}$ & $\begin{array}{l}46.5 \% \\
(40.9 \text { to } 52 \cdot 9)\end{array}$ & $\begin{array}{c}6 \cdot 4 \% \\
(4 \cdot 0 \text { to } 9 \cdot 2)\end{array}$ & $\begin{array}{c}31247 \\
\text { (26556 to } 36521)\end{array}$ & $\begin{array}{l}45143 \\
\text { (38328 to } 52671)\end{array}$ & $\begin{array}{l}44 \cdot 3 \% \\
(37 \cdot 2 \text { to } 52 \cdot 8)\end{array}$ & $\begin{array}{c}13 \cdot 6 \% \\
(9 \cdot 4 \text { to } 18 \cdot 3)\end{array}$ \\
\hline Metabolic risks & $\begin{array}{l}10398 \\
\text { (9811 to } 11003)\end{array}$ & $\begin{array}{l}15723 \\
(14719 \text { to } 16767)\end{array}$ & $\begin{array}{l}51 \cdot 2 \% \\
(46 \cdot 2 \text { to } 57 \cdot 0)\end{array}$ & $\begin{array}{c}10 \cdot 6 \% \\
(8 \cdot 8 \text { to } 12 \cdot 6)\end{array}$ & $\begin{array}{l}250957 \\
\text { (233711 to 267582) }\end{array}$ & $\begin{array}{l}373817 \\
\text { (343978 to } 403889 \text { ) }\end{array}$ & $\begin{array}{l}48.9 \% \\
\text { (43.1 to } 54 \cdot 9)\end{array}$ & $\begin{array}{c}18 \cdot 4 \% \\
(15 \cdot 3 \text { to } 21 \cdot 7)\end{array}$ \\
\hline $\begin{array}{l}\text { High fasting plasma } \\
\text { glucose }\end{array}$ & $\begin{array}{l}2444 \\
\text { (2101 to 2853) }\end{array}$ & $\begin{array}{l}4014 \\
\text { (3499 to 4641) }\end{array}$ & $\begin{array}{l}64 \cdot 4 \% \\
(56 \cdot 3 \text { to } 73 \cdot 4)\end{array}$ & $\begin{array}{c}21.8 \% \\
(17 \cdot 4 \text { to } 26 \cdot 8)\end{array}$ & $\begin{array}{l}68903 \\
(60506 \text { to } 78071)\end{array}$ & $\begin{array}{l}116893 \\
\text { (101592 to 133368) }\end{array}$ & $\begin{array}{l}69.6 \% \\
(60 \cdot 9 \text { to } 78 \cdot 7)\end{array}$ & $\begin{array}{l}37.0 \% \\
(31.6 \text { to } 42 \cdot 6)\end{array}$ \\
\hline High total cholesterol & $\begin{array}{l}2204 \\
\text { (1574 to 3126) }\end{array}$ & $\begin{array}{l}2830 \\
\text { (1966 to 4053) }\end{array}$ & $\begin{array}{l}28.0 \% \\
(19.9 \text { to } 37 \cdot 4)\end{array}$ & $\begin{array}{c}-7 \cdot 4 \% \\
(-11 \cdot 3 \text { to }-2 \cdot 5)\end{array}$ & $\begin{array}{c}49289 \\
(38075 \text { to } 63764)\end{array}$ & $\begin{array}{l}62715 \\
\text { (49244 to } 80986)\end{array}$ & $\begin{array}{c}26 \cdot 9 \% \\
(19 \cdot 8 \text { to } 36 \cdot 3)\end{array}$ & $\begin{array}{c}-0.6 \% \\
(-5.7 \text { to } 5 \cdot 7)\end{array}$ \\
\hline $\begin{array}{l}\text { High systolic blood } \\
\text { pressure }\end{array}$ & $\begin{array}{l}6949 \\
\text { (6182 to } 7665)\end{array}$ & $\begin{array}{l}10364 \\
\text { (9178 to } 11544)\end{array}$ & $\begin{array}{l}49 \cdot 1 \% \\
(43 \cdot 2 \text { to } 55 \cdot 2)\end{array}$ & $\begin{array}{c}8 \cdot 8 \% \\
\text { (6.4 to } 11 \cdot 2)\end{array}$ & $\begin{array}{l}143434 \\
(130053 \text { to } 156023)\end{array}$ & $\begin{array}{l}208129 \\
\text { (188307 to 227509) }\end{array}$ & $\begin{array}{c}45 \cdot 1 \% \\
(38 \cdot 7 \text { to } 52 \cdot 1)\end{array}$ & $\begin{array}{c}14.1 \% \\
(10 \cdot 0 \text { to } 18 \cdot 4)\end{array}$ \\
\hline $\begin{array}{l}\text { High body-mass } \\
\text { index }\end{array}$ & $\begin{array}{l}2724 \\
\text { (2263 to 3187) }\end{array}$ & $\begin{array}{l}4444 \\
\text { (3716 to 5169) }\end{array}$ & $\begin{array}{l}63 \cdot 2 \% \\
(57 \cdot 8 \text { to } 69 \cdot 5)\end{array}$ & $\begin{array}{c}22 \cdot 2 \% \\
(19 \cdot 0 \text { to } 25 \cdot 4)\end{array}$ & $\begin{array}{c}78310 \\
\text { (65436 to } 92006)\end{array}$ & $\begin{array}{l}134048 \\
(112420 \text { to } 156787)\end{array}$ & $\begin{array}{l}71 \cdot 3 \% \\
(64.4 \text { to } 78.0)\end{array}$ & $\begin{array}{c}36 \cdot 3 \% \\
\text { (32.3 to } 40 \cdot 1)\end{array}$ \\
\hline $\begin{array}{l}\text { Low bone mineral } \\
\text { density }\end{array}$ & $\begin{array}{c}176 \\
\text { (164 to } 198)\end{array}$ & $\begin{array}{c}334 \\
\text { (285 to } 361)\end{array}$ & $\begin{array}{l}92 \cdot 1 \% \\
(62 \cdot 8 \text { to } 104 \cdot 0)\end{array}$ & $\begin{array}{c}35 \cdot 4 \% \\
(15 \cdot 4 \text { to } 44 \cdot 6)\end{array}$ & $\begin{array}{c}10903 \\
\text { (8958 to } 13231)\end{array}$ & $\begin{array}{l}14249 \\
\text { (11658 to } 17500)\end{array}$ & $\begin{array}{c}30 \cdot 6 \% \\
(20 \cdot 9 \text { to } 40 \cdot 7)\end{array}$ & $\begin{array}{c}-1.8 \% \\
(-9 \cdot 4 \text { to } 6.9)\end{array}$ \\
\hline $\begin{array}{l}\text { Low glomerular } \\
\text { filtration rate }\end{array}$ & $\begin{array}{c}1310 \\
\text { (1176 to } 1480)\end{array}$ & $\begin{array}{l}2164 \\
\text { (1960 to 2387) }\end{array}$ & $\begin{array}{c}65 \cdot 6 \% \\
(54 \cdot 5 \text { to } 74 \cdot 5)\end{array}$ & $\begin{array}{c}18 \cdot 9 \% \\
\text { (11.1 to } 24.8)\end{array}$ & $\begin{array}{c}34159 \\
\text { (30 499 to 38394) }\end{array}$ & $\begin{array}{l}51906 \\
\text { (46246 to } 57573)\end{array}$ & $\begin{array}{c}52 \cdot 0 \% \\
(43 \cdot 5 \text { to } 59 \cdot 3)\end{array}$ & $\begin{array}{c}25 \cdot 5 \% \\
(18 \cdot 4 \text { to } 31 \cdot 3)\end{array}$ \\
\hline
\end{tabular}

for an increased number of deaths in 2013 as compared with 1990 (853000 compared with 668000). Taken together, occupational carcinogens caused 304000 deaths globally in 2013 and 5.8 million DALYs; asbestos exposure accounted for nearly two-thirds of the burden of all occupational carcinogens. In total, occupational risks accounted for 55.4 million DALYs, of which occupational ergonomic factors accounted for $38 \cdot 1 \%$. As a cluster, childhood undernutrition accounted for 1.3 million child deaths in 2013 and 120 million DALYs. Iron deficiency, vitamin A deficiency, and zinc deficiency each accounted for less than 200000 deaths; however, iron deficiency is a major cause of DALYs due to its crucial role as a cause of anaemia.

The number of deaths attributable to tobacco smoking continued to increase from 4.6 million in 1990 to 5.8 million in 2013, and from 115.9 million DALYs to 134. 2 million DALYs over the same period. Secondhand smoke accounted for an additional 331000 deaths and $9 \cdot 3$ million DALYs. Alcohol use accounted for $2 \cdot 8$ million deaths and 99.3 million DALYs in 2013, with both deaths and DALYs increasing over time. Among the components of diet, the most important in terms of deaths and DALYs in 2013 were diets high in sodium and low in fruit, followed by low whole grains and low vegetables. Among the metabolic risks, high systolic blood pressure is more than twice as important as the next most important factorhigh BMI, followed by high fasting plasma glucose.

One simple way to examine the complex results by country is to examine the leading risk factor in terms of DALYs with risk factors broken down to level 3 in the risk factor hierarchy (figure 8). For men (figure 8A), a large set of countries from North Africa and the Middle East through to south Asia and east Asia and into Eastern
Europe have high systolic blood pressure as their leading risk. Another broad set of countries in west, east, and central sub-Saharan Africa have childhood undernutrition as the leading risk. Unsafe sex is the leading risk in a set of countries in east and southern Africa with large HIV epidemics. Tobacco is the leading risk in most high-income countries and alcohol use is the leading risk in many countries in Latin America. For women (figure 8B), the pattern is notably different. High BMI is the leading risk for most countries in North and South America with only three exceptions (Canada, Guatemala, and Uruguay). High BMI is also the leading risk in Spain, France, Switzerland, Belgium, most of North Africa and the Middle East, Australia, and New Zealand. High systolic blood pressure is the leading risk in most of Central and Eastern Europe, central Asia, south Asia, and east Asia. Cambodia stands out as having household air pollution as the top risk factor for women. In sub-Saharan Africa, the leading risks are undernutrition and unsafe sex for both men and women in sub-Saharan Africa.

Figure 9 provides the ten leading risk factors in terms of attributable DALYs (level 3 in the risk hierarchy) for each country in 2013 for both sexes combined. The top 15 global risks have been coloured to highlight where country and regional patterns diverge from global patterns. In high-income regions, most countries had high BMI, high systolic blood pressure, and smoking as the top three risks. Brunei, Singapore, and Japan had high fasting plasma glucose in the top three. Alcohol use was the second leading risk in South Korea. Low glomerular filtration rate was an important risk in several countries such as Italy. In Central Europe, 


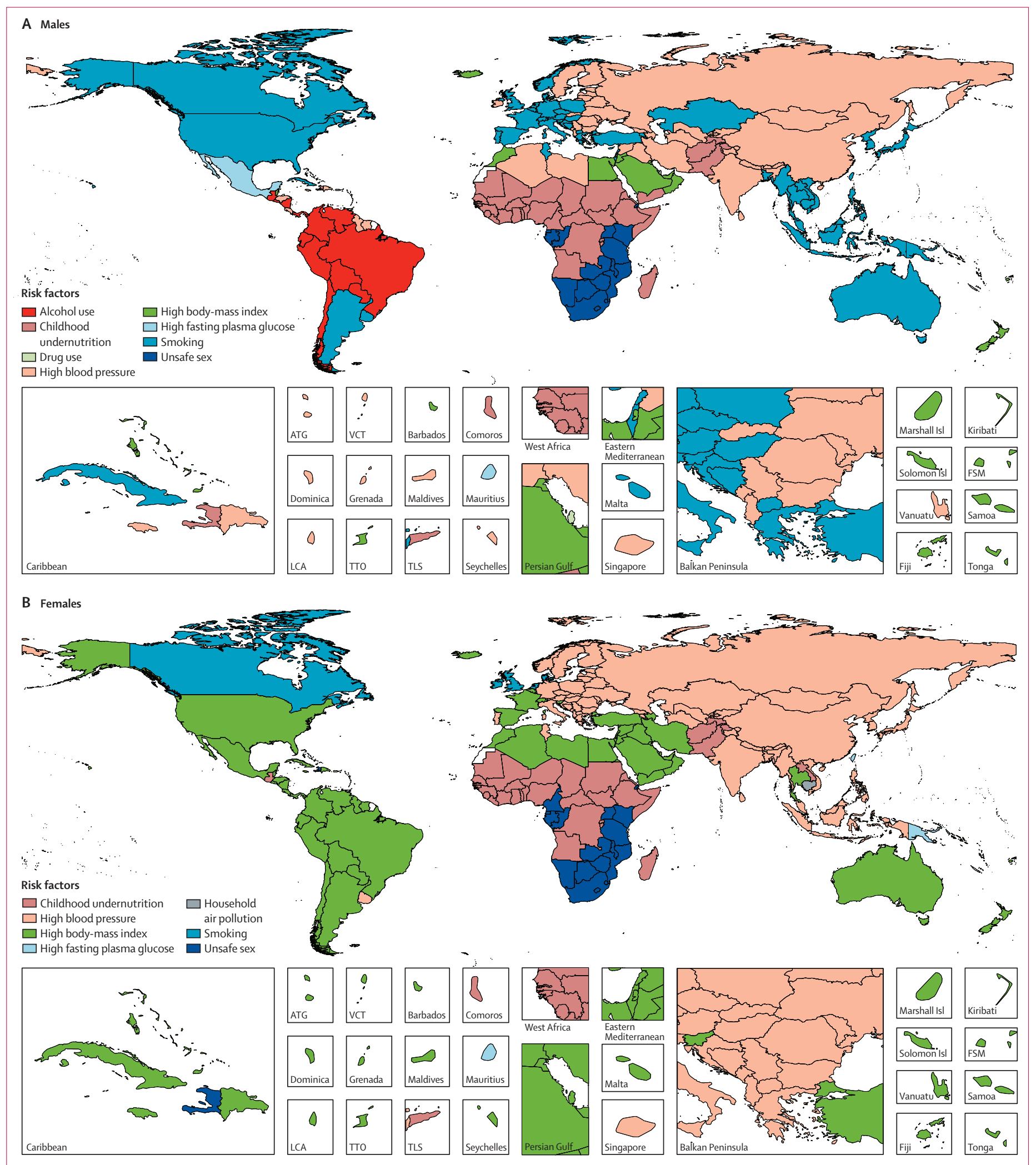

Figure 8: Global maps for level 3 risk factors in 2013 of attributable DALYs for males (A) and females (B)

DALYs=disability-adjusted life-years. ATG=Antigua and Barbuda. VCT=Saint Vincent and the Grenadines. FSM=Federated States of Micronesia. LCA=Saint Lucia. TLS=Timor-Leste. TTO=Trinidad and Tobago. Isl=|slands. 


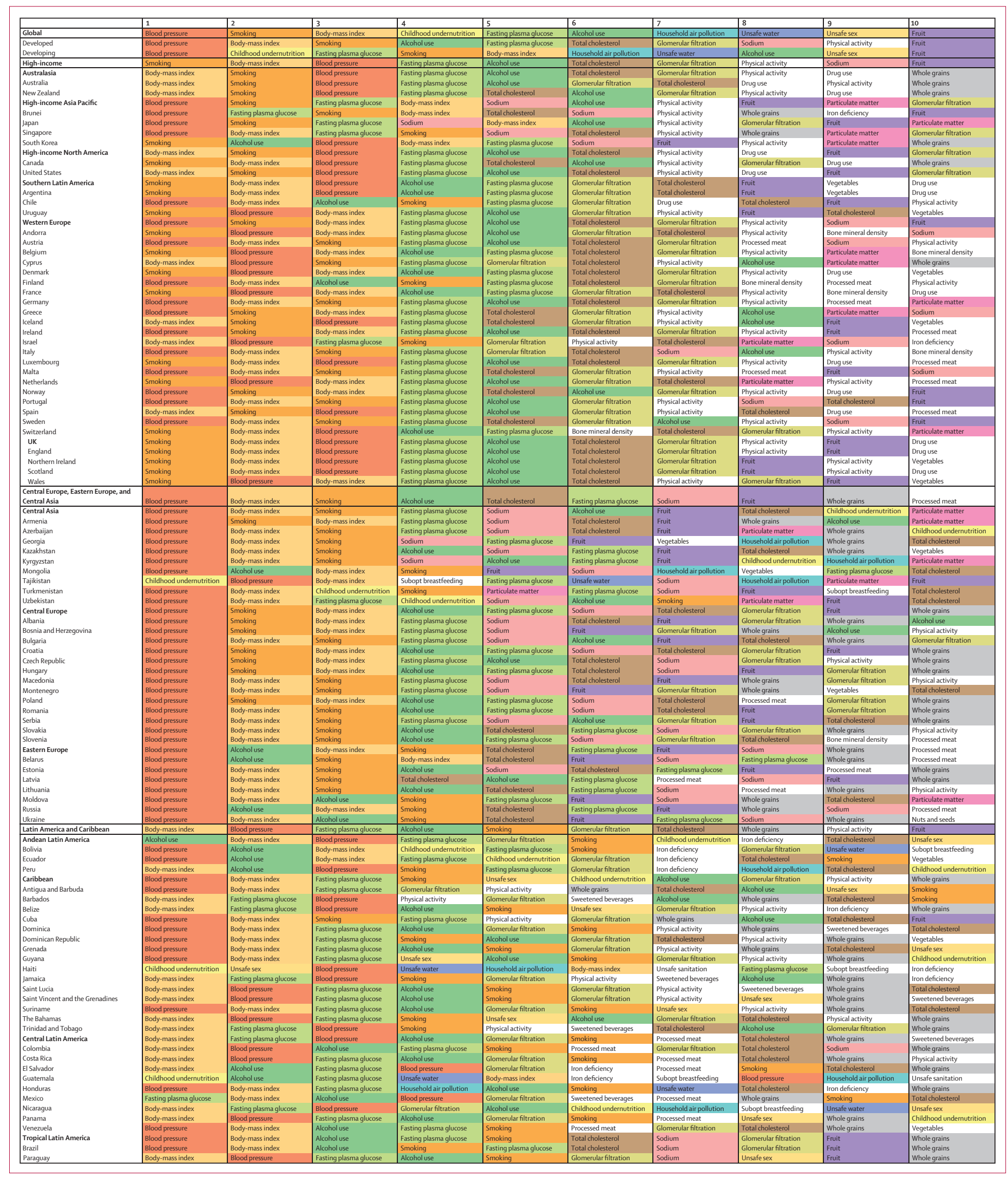

(Figure 9 continued on next page) 
Articles

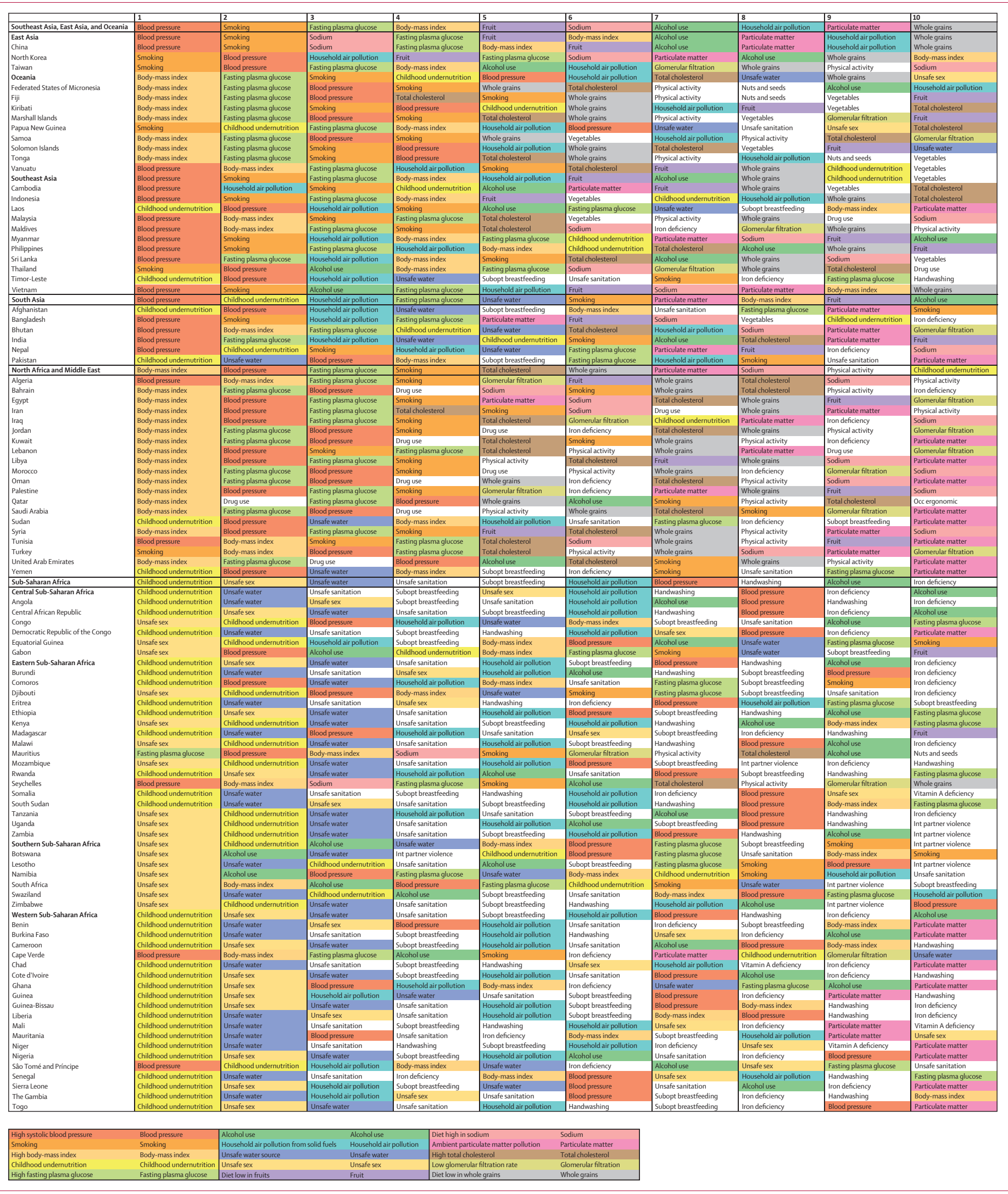


Eastern Europe, and central Asia, the leading risk factor for both sexes combined was high systolic blood pressure, followed by smoking or high BMI. In Mongolia, Belarus, and Russia, alcohol was the second leading risk factor. Childhood undernutrition remained a top five risk in Tajikistan, Turkmenistan, and Uzbekistan. In Latin America and the Caribbean, high systolic blood pressure or high BMI were the leading risks in most countries. Notable exceptions are in Haiti and Guatemala, where childhood undernutrition was the leading risk. Haiti also stands out with unsafe sex as the second leading risk factor. In this region, either high fasting plasma glucose or alcohol use were top five risks in nearly every country. Unsafe water was a top five risk in Haiti and Guatemala. In east Asia, the leading risks were high systolic blood pressure, tobacco smoking, and high sodium intake. In Oceania, high BMI and high fasting plasma glucose were the leading risks in all countries, except in Papua New Guinea where smoking and childhood undernutrition were most important and Vanuatu where high systolic blood pressure was the top risk, followed by high BMI. In southeast Asia, high systolic blood pressure and smoking were dominant risks, except in Laos and Timor-Leste where childhood undernutrition was the leading risk. Household air pollution was a top five risk in many countries in the region. In south Asia, high systolic blood pressure was the leading risk, except for in Afghanistan and Pakistan. In India, high fasting plasma glucose was the second leading risk followed by household air pollution, unsafe water, and childhood undernutrition. In North Africa and the Middle East, high BMI was the leading risk in nearly all countries, and most countries had high fasting plasma glucose and high systolic blood pressure as top three risks. Sudan and Yemen stand out with childhood undernutrition and unsafe water as top three risks. In sub-Saharan Africa, there are four patterns: countries where the leading risks were childhood undernutrition, unsafe water, and unsafe sanitation; countries where the leading risks were unsafe sex, childhood undernutrition, and unsafe water; countries in southern Africa with unsafe sex and alcohol use as leading risks, and island nations such as the Seychelles and Cape Verde with high systolic blood pressure as leading risk. South Africa is notable for the top three risks being unsafe sex, high BMI, and alcohol use.

Figure 9: The ten leading level 3 risks in 2013 in terms of DALYs by location for both sexes combined

The 15 leading risk factors are coloured. Subopt=Suboptimal. Occ=occupational. DALYs=disability-adjusted life-years. Bone mineral density=low bone mineral density. Handwashing=no handwashing with soap. Int partner violence=intimate partner violence. Nuts and seeds=diet low in nuts and seeds. Occ ergonomic=occupational ergonomic factors. Particulate matter=ambient particulate matter pollution. Physical activity=low physical activity. Processed meat=diet high in processed meat. Subopt breastfeeding=suboptimal breastfeeding. Sweetened beverages=diet high in sugar-sweetened beverages. Vegetables=diet low in vegetables.

\section{Discussion}

Our analysis of 79 risks divided into three broad groups of behavioural, environmental and occupational, and metabolic risk factors shows that together they explain slightly greater than $57 \%$ of global deaths and more than $41 \%$ of global DALYs. Each of the risk factors included in this analysis is modifiable, pointing to the huge potential of prevention to improve human health. Globally, behavioural risk factors are the most important followed by metabolic and environmental and occupational risk factors. This pattern varies substantially: in many countries in sub-Saharan Africa, environmental risk factors, mainly water, sanitation, no handwashing, and household air pollution, are more important than metabolic risks. By 2013, the six most important risk factors globally were dietary risks, high systolic blood pressure, child and maternal malnutrition, tobacco, air pollution, and high BMI.

Since 1990, there has been a profound change in risk factors associated with the global epidemiological transition. In 1990, child and maternal malnutrition and unsafe water, sanitation, and handwashing were the leading risks for global DALYs, but now these have been replaced by dietary risks and high systolic blood pressure. A large group of risk factors recorded declines of more than $10 \%$ in age-standardised PAFs from 1990 to 2013, including unsafe water, sanitation, and handwashing; household air pollution; suboptimal breastfeeding; childhood undernutrition; vitamin A deficiency; secondhand smoke; and diet high in trans fats. By contrast, for several risk factors, age-standardised PAFs are increasing: intimate partner violence, drug use, high BMI, high fasting plasma glucose, low glomerular filtration rate, unsafe sex, and several components of diet (ie, low whole grains, high red meat, and high sugarsweetened beverages). This transition in risks reflects a general shift from environmental risks towards behavioural and metabolic risks. These insights should strengthen our understanding of the epidemiological transition and our capacity to forecast population health.

The risk factors included in this study are those that met our inclusion criteria. After removing the effect of these risks, a substantial fraction of global deaths and DALYs remain. What might account for the unexplained component of death rates and the even greater unexplained component for YLDs? Risk-deleted death rates (not shown in this paper) vary substantially across countries. Other environmental risks, such as soil and water contamination, or behavioural risks, such as lack of sleep, could explain a component of the unexplained variation. $^{53-55}$ Inclusion of new risk factors in future iterations of the GBD might reduce the unattributed fraction. Social, economic, and cultural factors could be an important part of the explanation, but only the components of these risks expressed through differential behaviours or environmental risks have been incorporated in the GBD CRA work so far. Higher 
risk-deleted age-specific death and DALY rates are seen in low-income countries and those countries with lower educational attainment. Parts of both effects would be mediated through access to care and coverage with curative interventions. From a quarter to half of the decline in cardiovascular and circulatory diseases in high-income countries have been attributed to treatments. ${ }^{56-58}$ Another aspect of understanding the unexplained morbidity is that epidemiological studies have studied fewer of, and yielded fewer insights into, the drivers of key contributors to YLDs, such as mental and substance use disorders, musculoskeletal disorders, and neurological disorders. More research on the areas we know less about might redress this imbalance.

The behavioural risk factors included in this study range from explaining fewer than 19\% of DALYs in 2013 in the Maldives to more than 54\% in South Africa. There is substantial scope through changing behaviours to improve individual and population health. Although there is a role for drugs and vaccines to mitigate the harmful effects of some behaviours, interventions to affect and change behaviours must be the primary mechanisms to reduce this burden. In view of their large role, funding for research on interventions to change health behaviours by major research funders has been scarce. Intellectual property rights are harder to establish for behavioural change interventions so there are fewer incentives for the private sector to pursue this type of investigation. One exception to the absence of private sector engagement in this arena is the recent rise of personal health mobile device applications. More behavioural and social science research into solutions for behavioural risks, particularly those that are increasing such as the nexus of diet, physical activity, and BMI, is urgently needed.

Shifting from the behavioural, environmental and occupational, and metabolic risk factors to a more comprehensive view of risks including genes, the microbiome, public health, and medical care interventions, and distal social, economic, and cultural factors, would provide a more coherent account of health and its causes. The GBD has sought to provide a standardised framework, an evidence-based accounting, of the contribution of diseases and injuries and selected risks to deaths, YLLs, YLDs, and DALYs. It is natural to extend this framework progressively to quantify the broader set of risks for health outcomes. The rules of evidence, however, used so far in the CRA studies might need to be modified to allow this expansion. Social, economic, and cultural factors, for example, are mediated through several interactive pathways in the causal web; we would not expect that effect sizes would be consistent across contexts. This expansion will not be a quick undertaking, but the annual revisions of the GBD will provide an opportunity to encompass this broadened vision progressively.

The aggregation of the 14 specific components of diet accounted for nearly one tenth of global DALYs in 2013.
At the global level, the most important contributors to the overall burden of diet are low fruit, high sodium, low whole grains, low vegetables, and low nuts and seeds. But diet patterns vary greatly across countries and as a result the most important diet components vary substantially by country. Our diet estimates do not reflect the total effect of diet on health. Dietary risk factor exposures reflecting the literature on diet epidemiology are standardised to a 2000 calorie diet, resulting in dietary exposures that reflect diet composition rather than direct caloric contribution for each risk factor. This holds true for all dietary risks except for sugar-sweetened beverages, for which the effect of calories is captured through effects on BMI. Other dietary components probably affect overweight and obesity, in both protective and detrimental directions..$^{59,60}$ If one were to quantify the contribution of diet mediated through weight gain and BMI, the overall effect of diet would be much larger than is estimated here. Since GBD 2010, the PREDIMED randomised clinical trial reported an effect of nut consumption that was quite consistent with the estimated effect from cohort studies. ${ }^{61,62}$ Yet criticism of dietary studies and the effects derived from them abounds. ${ }^{63,64} \mathrm{~A}$ considerable challenge in the diet estimation is that component exposures are also likely to be interrelated within individuals. There are correlations across individuals in the intake of different diet components, and there might also be synergistic or antagonistic effects of dietary components that are consumed together. Furthermore, various methods for diet recall all have substantial measurement error and biomarkers to measure recent diet have not been operationalised to date. In view of the importance of diet in this analysis, more attention should be paid to quantifying the correlation structure of diet components and the effects of different diet components on weight gain, including the effect of total caloric intake. Although there are many opportunities to improve the estimation of the burden attributable to diet, the potential magnitude of the benefits of shifting to a more optimum diet justify concerted examination of policy options to shift individual and national diets now.

After diet, high systolic blood pressure is the next most important global risk factor accounting for $9.6 \%$ of all DALYs, up from $5.6 \%$ in 1990, making high systolic blood pressure larger than ischaemic heart disease and three times larger than HIV/AIDS in terms of DALYs. Our estimates for DALYs attributable to high systolic blood pressure in 2010 are 15\% higher than in the GBD 2010 analysis for two primary reasons: new estimates of the mean blood pressure for each country, age, and sex reflecting new data and an improved model; and the shift to use of the lognormal distributional assumption, which more closely follows the available data. Despite its importance, there has been comparatively little global health policy discussion or initiatives focused on blood pressure. The WHO voluntary targets for 
non-communicable diseases have called for a $25 \%$ reduction in the prevalence of high blood pressure by 2025. For World Health Day 2013, WHO issued a global brief calling for salt reduction and integrated primary care management as cost-effective routes to address the burden of high blood pressure. Although these efforts are welcome, high blood pressure needs a stronger and more coherent global response; one that will both monitor the burden of high blood pressure and provide policy guidance for the most effective intervention strategies tailored to different contexts.

One key component of diet related to systolic blood pressure is high sodium intake; we find that $3.0 \%$ of global DALYs can be related to sodium intake (95\% UI $1 \cdot 8-5 \cdot 3)$. The wide UI reflects the uncertainty in the sodium TMREL from $1 \mathrm{~g}$ to $5 \mathrm{~g}$ per day. This widening of the TMREL compared with that in GBD 2010 of $1 \mathrm{~g}$ per day reflected the growing debate on the optimum level of sodium intake. On the one hand, the PURE cohort study found a J-shaped association between sodium, mortality, and major cardiovascular events among 101945 individuals in 17 countries. On the other hand, the J-shaped curve could be due to residual confounding or reverse causation. The findings from PURE have generated much debate on the methods used to measure sodium intake, as well as the potential for low sodium intake to reduce blood pressure but raise mortality through some aspect of the renin-aldosterone system. ${ }^{49,65,66}$ While the debate on optimum sodium intake is likely to continue, even with a much wider TMREL, high sodium intake is a major global risk. If the optimum sodium intake is $5 \mathrm{~g}$, we still estimate that sodium accounts for at least $1.6 \%$ of global DALYs, which is more than the global DALYs caused by tuberculosis. Voluntary and mandatory reductions in sodium content of processed foods have been tried and found to be cost effective in some settings. ${ }^{67,68}$ Salt substitutes such as potassium chloride or blends of sodium and potassium chloride are being tested in randomised trials. ${ }^{69,70}$ Even as the science on how far individuals should reduce their sodium consumption will continue to evolve, the argument for a population-level strategy to reduce sodium intake is compelling.

Maternal and child undernutrition was the leading global risk in this analysis in 1990 and remains the third most important in 2013, causing 6.8\% (95\% UI 6 -2-7·4) of global DALYs. This cluster of risks includes in terms of importance childhood undernutrition, iron deficiency, suboptimal breastfeeding, vitamin A deficiency, and zinc deficiency. Compared with the GBD 2010 analysis, this cluster of risks is estimated to account for more DALYs primarily because for childhood undernutrition we have computed the joint distribution of child stunting, wasting, and underweight. In the GBD 2010, only child underweight was computed. By examining the combined effects of all three anthropometric measures, we have increased the estimated burden by $71 \%$. In sub-Saharan
Africa, childhood undernutrition remains the leading risk factor emphasising the strong link of this risk to socioeconomic development; by contrast, in developing countries outside sub-Saharan Africa, childhood undernutrition has declined profoundly. By estimating the combined effects of stunting, wasting, and underweight, we have documented the enormous burden still caused by these risks in the poorest countries. The joint estimation, however, is based on backcalculating the relative risks for stunting, wasting, and underweight from published risks that are confounded by each other. These estimations will be strengthened by pooled analysis of available cohort data that directly computes the independent relative risks and their joint distribution.

Particulate matter pollution from both ambient sources and from household use of solid fuels is a major risk. Our estimates for DALYs attributable to ambient particulate matter air pollution are slightly lower than those in GBD 2010, but our estimates for household air pollution are lower by $22 \%$ for 2010 . The reduction reflects the much larger number of studies used to map household fuel use to PM2.5 exposure levels in different settings. Regardless of the exact values of these estimates, both ambient particulate matter pollution and household air pollution are estimated to be major risk factors, particularly for non-communicable diseases. These environmental risks are classic examples for which public policy is required to mitigate risk. ${ }^{71}$ Because of the concave relation between PM2.5 concentration and relative risk, the benefits of reducing exposure per unit of exposure to PM2 5 are greater at lower levels of exposure than at higher levels. This benefit puts a premium on reducing exposure down to low levels near the TMREL. Both for ambient and household air pollution, the full implications of the concave nature of the risk curve need to be factored into policy interventions.

Tobacco use remains a major determinant of global health, ranking second in terms of risk in 2013, although the age-standardised DALY rate has fallen by $32 \%$ since 1990. Although the prevalence of smoking seems to be declining or stable in most countries, the burden of tobacco suggests that it ought to remain a key focus of global health policy debates..$^{20}$ Continued vigilance is absolutely required to ensure that women in developing countries, particularly in those with rapidly growing economies, do not begin to smoke in large numbers as women have done in some high-income countries. Equally, the failure of societies to bring down tobacco use among men faster than what has been observed over the past three to four decades, when the magnitude of the hazards had been well established, is of great public health concern. The experience of countries such as Australia, the UK, and USA, where male smoking prevalence has fallen from $70 \%$ post war to $15-20 \%$ today, provides clear evidence that targeted tobacco control strategies can work, but are likely to require a 
combination of strong government commitment, fiscal measures, and an informed and active civil society and non-governmental organisation sector to advocate effectively for comprehensive tobacco control measures. ${ }^{33,72}$ Without all of these ingredients, now facilitated by WHO's stewardship and private philanthropy driving the MPOWER programme, progress will be slow, difficult, and at risk of reversals. ${ }^{73,74}$

Alcohol remains a major risk, ranking sixth among level 3 global risk factors, whereas all illicit drug use combined ranks 22nd. Yet, although drugs are internationally controlled by treaties and a UN agency, there is no international public health treaty on alcohol. The WHO voluntary targets for non-communicable diseases have called for a $10 \%$ reduction in the volume of alcohol consumption by 2025 where this is nationally appropriate, but this is a substantially more modest target than those for other leading NCD risk factors, and policy initiatives for alcohol are recommended only in general terms. ${ }^{75}$ There is a need for a more coherent and effective global response, including detailed policy guidelines based on the substantial evidence available on effective intervention strategies.

Our estimates for the burden attributable to high BMI are substantially higher than those in GBD 2010 for two reasons. First, based on new published pooled cohort or meta-analyses, we added several new outcomes related to high BMI. Second, we have more accurately captured the fraction of the population with high BMI using the beta distribution compared with the assumption of a normal distribution. There remains some debate in the literature on the risks associated with overweight. Flegal and colleagues ${ }^{76}$ reported in a meta-analysis of studies reporting on broad categories of BMI that risk is lowest in the category of overweight. ${ }^{21}$ Pooled cohort analysis with more detailed BMI categories with a much larger number of person-years of exposure found a regular association with rising BMI from 23 onwards. ${ }^{7}$ Part of the discrepancy in the findings is also related to how many years of observation are excluded from the analysis to remove the bias of sick individuals having lowered BMIs. Stokes and colleagues showed that re-analysing NHANES follow-up data by maximum lifetime BMI suggested that people in the overweight category were at substantially elevated risk (relative risk 1.28) compared with normal weight individuals. ${ }^{78-81}$ We believe that the balance of the evidence clearly supports our TMREL of 21-23 and that the pooled cohort studies provide the most robust relative risks available to date for this analysis. Regardless of this debate, however, the burden attributable to high BMI more generally is large and increasing at the global level. Intensified research and policy experimentation into the options to reduce BMI or to slow its increase is needed.

Our estimates of the burden attributable to unsafe water, unsafe sanitation, and no handwashing with soap are substantial: 38 countries have more than $5 \%$ of DALYs attributable to these risks, rising as high as $16 \%$ in Chad.
Redefining the risk to be unsafe water and unsafe sanitation, and adding in the risk from lack of handwashing with soap, increases the burden attributable to the cluster of water, sanitation, and hygiene. It also has important policy implications: in terms of risk reduction, achieving the MDG targets of improved water and sanitation would have little effect on reducing diarrhoea morbidity and mortality. Based on new meta-regressions, much of the potential benefit of water and sanitation is through achieving levels of access that are far higher than those in the MDG category of improved water or sanitation. ${ }^{12}$ These findings are reflected in the much larger attributable fractions for unsafe water and unsafe sanitation as compared with improved water and improved sanitation. We believe that future monitoring efforts related to water, sanitation, and hygiene, such as those that might emerge from the sustainable development goals, should take into account the levels of risk associated with different levels of access. Setting the goal to be minimum risk, the approach taken here, would also mean that many countries, including some middleincome countries, have a great distance to go. The finding that no handwashing with soap is a global risk present in all regions is a reminder that this nexus of risks is relevant to all countries, not just the poorest.

An important aspect of the GBD 2013 has been the attempt to estimate the joint counterfactual for metabolic risks and all risks together, taking into account mediation of some risks through others such as BMI through systolic blood pressure. We assume that the fraction mediated through another risk is the same across countries based on the available literature.52 A more precise approach would be to estimate the correlation of the risks directly in each population and, through pooled studies, analyse the relative risks for the full joint distribution of each combination of risks-eg, BMI and blood pressure. Administrative data such as electronic medical record data might provide a useful database to understand the correlation of risks in different populations. Use of the average level of mediation noted in studies probably means that, at the global level, our results are not biased up or down, but in specific countries our results could be either too high or too low for the joint distribution of risks. We propagated the uncertainty in the fraction mediated into the final results, but this might still underestimate uncertainty because we only incorporated the uncertainty in the mean estimate of mediation. However, because the joint PAF for cardiovascular disease across all risks is so largeranging from $63.5 \%$ in Chad to $94.3 \%$ in Belarus in 2013 - these limitations of the mediation analysis would have only a minimum effect on the cardiovascular disease PAF due to all risk factors. Mediation for other major outcomes plays a much smaller part than it does for cardiovascular diseases.

In GBD 2010, the integrated exposure-response curve for PM2. 5 was introduced to take a more unified view of 
risk exposure across different sources of PM2 $\cdot 5 .^{31,82}$ The crucial assumption is that the PM2. 5 is a robust indicator of the risk associated with a mixture of pollutants from ambient air pollution, tobacco smoking, secondhand smoke exposure, and household air pollution exposure to PM2.5. This simplifying assumption has received substantial attention. ${ }^{83,84}$ In GBD 2013, we have more consistently mapped the outcomes across this set of sources of PM2.5: pneumonia has been added as an outcome of tobacco smoking, which has been supported by tobacco cohort studies..$^{85,86}$ We have expanded PM2 5 to cover child and adult lower respiratory infections. In view of the crucial importance of the integrated exposureresponse curve to the validity of estimates for household air pollution particularly, further research on this is required. For household air pollution, one of the crucial steps in the analysis is to map from the proxy measure of exposure to the level of PM2.5 that is actually experienced, to estimate the relative risk from the integrated exposure-response curve. In GBD 2010, this was mapped using a large study from India and no uncertainty in this mapping was incorporated into the final results. For GBD 2013, we have based this on 67 studies from eight regions and have propagated uncertainty in this mapping into the final results. The net effect of these changes has been to widen uncertainty and capture regional variation in the level of PM2. 5 exposure in households using solid fuels.

A major improvement for CRA implemented in the GBD 2013 has been the use of exposure distributions across individuals that are more consistent with the available survey data. The shift from assuming normal distributions to lognormal distributions has important effects on metabolic risks, as does the use of the beta distribution for BMI. Fasting plasma glucose has an unusual distribution that is not well represented by any of the parametric distributions that we tested. In future research, it will be important to explore the use of alternative methods such as mixture distributions or non-parametric approaches. More attention to the consistency of the distribution of exposure across populations conditional on mean and SD is warranted in future cycles of the GBD.

At the global level, the correlation of the number of DALYs attributable to the same risks for the year 2010 across GBD 2010 and GBD 2013 is 0 . 97. There are several notable changes detailed above for risks such as high BMI, high systolic blood pressure, and unsafe water, sanitation, and handwashing. For other risks there are also changes, but, globally, they are generally smaller than $10 \%$ in the year 2010. At the country level, however, there are more important changes. The correlation coefficient for PAFs at the country level is $\mathbf{0 \cdot 8 4}$. These changes can be traced to changes in exposure where newer data or model revisions have altered the assessments.

The attributable burden of disease formula (equation 1) multiplies PAFs by deaths, YLLs, YLDs, or DALYs. All the limitations of the estimates of deaths, YLLs, YLDs, and DALYs apply to this analysis. ${ }^{18,19}$ There are, however, several important limitations that relate to the components of the PAF analysis. First, for most outcomes, cohort or randomised controlled trial data are available for either mortality or morbidity, but rarely both. Second, we apply relative risks from meta-analyses or meta-regressions for a disease category such as ischaemic heart disease to all the sequelae of that disease, but more detailed studies might reveal different relative risks. Third, the data representativeness index for some risk factors is quite low-eg, handwashing and diet low in polyunsaturated fatty acids. Our modelling strategies attempt to quantify uncertainty as captured in the available data, but it remains possible that new data collected in countries without data might reveal levels of exposure that are outside the uncertainty intervals that we have estimated. Fourth, for unsafe water and unsafe sanitation, we assess the availability of infrastructure not the use of the infrastructure. Our estimates are not biased because the relative risks are derived from similar exposure definitions. Fifth, some risk factors are measured with very coarse proxies for exposure. The most extreme example is zinc deficiency, for which we analysed Food and Agriculture Organization of the United Nations food balance sheets for absorbable zinc and estimated the balance between theoretical intake and physiological requirements. Although the proportion of people with estimated inadequate zinc intake is a proxy of zinc deficiency, it lacks the anchor to individual level measurement of the exposure as a gold standard to estimate the number of people at risk. Other examples of the use of exposure proxy measurements are the proportion of the population in coarse occupational categories as a proxy for exposure to specific carcinogens, and the type of fuel used as a proxy for household air pollution. Capturing geographical variation and uncertainty in the mapping from household solid fuel use to PM2.5 exposure enhances the validity of our findings and uncertainty intervals. Nevertheless, more direct PM2.5 measurement in households to calibrate the more widely available data for fuel use would be strongly preferable. Sixth, robust models to estimate variation in the SD of risk exposure are harder to develop than are estimations of the mean. In many cases, we are only able to capture regional variation in the SD. Measured SDs from studies are an overestimate of the true SDs, because they include the effects of measurement error. We have not in this study corrected SDs for measurement error except for correcting observed systolic blood pressure to usual blood pressure.

Seventh, we have not systematically corrected relative risks for publication bias. In some cases, there are not enough studies to do this. Eighth, relative risks have not been corrected for non-masking in studies. For example, if the meta-regression of handwashing studies is corrected for non-masking, the effect size would be 
non-significant. Many risks, however, cannot be studied in a masked fashion, such as tobacco smoking. Correction of some risks but not others could introduce worse issues of comparability so we have chosen for this study to not correct for non-masking in study design.

Ninth, with few exceptions, we assume that relative risks are universal across countries for a given age-sex group with few exceptions..$^{45,46}$ Some studies have argued that the BMI relative risk curve and TMREL might vary geographically, but there was insufficient evidence to date to identify statistically significant differences in relative risks, except in the case of breast cancer. Generally, as further evidence accumulates, we might find more examples of non-universal relative risks. We have not incorporated into our uncertainty intervals any qualitative assessment of the potential for non-universal risks.

Tenth, some heterogeneity remains around the implementation of the TMREL concept. For example, for exposure to ambient particulate matter pollution, the TMREL has been chosen as between $5.9 \mu \mathrm{g} / \mathrm{m}^{3}$ and $8.7 \mu \mathrm{g} / \mathrm{m}^{3}$, but zero PM2. 5 arguably might be the lowest risk. Cohort data to support the notion that the relative risk continues to decline below $5.8 \mu \mathrm{g} / \mathrm{m}^{3}$, however, are limited. Eleventh, for unsafe sex, HIV risk from injecting drug use, and occupational injuries, we have not used the relative risk and exposure PAF calculation. Attributable fractions of HIV for unsafe sex and injecting drug use have been based on direct evidence of the attributable fraction. These direct or categorical approaches might not yield results that are strictly comparable to the risks estimated with the relative risk and exposure model.

Twelfth, for risk factors for which we do not correct for mediation, we assume their joint effect can be estimated with the multiplicative risk model. This model, while plausible, might not accurately capture how all risks interact. Unfortunately, there are no cohort studies available of sufficient size to study the nature of these interactions in more detail. Thirteenth, the fraction of a risk factor mediated through another risk factor might be underestimated because of measurement error in both risk factors (similar to the case of regression dilution bias due to the exposure measurement error).$^{28}$

Fourteenth, for air pollution, there are few studies that allow estimation of the quantitative contribution of household air pollution to ambient air pollution or vice versa. $^{87}$ As such we might have underestimated the burden of household air pollution as a single risk factor; we might also have overestimated the burden of air pollution combined. Lastly, estimating burden for risks divided into polytomous risks might underestimate their burden compared with estimating burden with a continuous risk variable.

Strategies and policies to improve the health of populations should be guided by the comparative importance of health loss arising from exposure to major risk factors, whatever their position in the causal chain. It is the underlying causes of diseases and injuries that ought to guide prevention efforts, and knowing their comparative magnitude and trends in causing health loss is arguably among the most important information required by countries to prioritise health programmes and policies. The comprehensive assessment of risk factors presented in this study provides a clear indication of where prevention programmes aimed at risk factor modification can have major effects on health. The challenge for governments and the health development community more broadly is to heed this knowledge about the comparative effect of health risks more assiduously, and orient health policies towards their mitigation with much greater conviction than that currently observed. Yet our findings that the list of risk factor-outcome pairs that meet the bar of convincing or probable evidence account for slightly less than $40 \%$ of the entire GBD strongly suggest that massive health gains could be expected from adoption of policies to avoid what is avoidable. Certainly, there are more risk factors yet to be discovered and some well known risks such as poverty and education have not yet been quantified according to this framework. But such unknowns should not impede a much greater response from countries and donors to implement policies that are known to work in controlling diseases and injuries, and which have demonstrably led to much improved health outcomes in countries that have adopted them.

\section{GBD 2013 Risk Factors Collaborators}

Mohammad H Forouzanfar, Lily Alexander, H Ross Anderson, Victoria F Bachman, Stan Biryukov, Michael Brauer, Richard Burnett, Daniel Casey, Matthew M Coates, Aaron Cohen, Kristen Delwiche, Kara Estep, Joseph J Frostad, Astha KC, Hmwe H Kyu, Maziar Moradi-Lakeh, Marie Ng, Erica Leigh Slepak, Bernadette A Thomas, Joseph Wagner, Gunn Marit Aasvang*, Cristiana Abbafati*, Ayse Abbasoglu Ozgoren*, Foad Abd-Allah*, Semaw F Abera*, Victor Aboyans*, Biju Abraham*, Jerry Puthenpurakal Abraham*, Ibrahim Abubakar*, Niveen M E Abu-Rmeileh*, Tania C Aburto*, Tom Achoki* Ademola Adelekan*, Koranteng Adofo*, Arsène K Adou*, José C Adsuar*, Ashkan Afshin*, Emilie E Agardh*,

Mazin J Al Khabouri*, Faris H Al Lami*, Sayed Saidul Alam*, Deena Alasfoor*, Mohammed I Albittar*, Miguel A Alegretti*, Alicia V Aleman*, Zewdie A Alemu*, Rafael Alfonso-Cristancho*, Samia Alhabib*, Raghib Ali*, Mohammed K Ali*, François Alla*, Peter Allebeck*, Peter J Allen*, Ubai Alsharif*, Elena Alvarez*, Nelson Alvis-Guzman*, Adansi A Amankwaa*, Azmeraw T Amare*, Emmanuel A Ameh*, Omid Ameli*, Heresh Amini*, Walid Ammar*, Benjamin O Anderson*, Carl Abelardo T Antonio*, Palwasha Anwari*, Solveig Argeseanu Cunningham*, Johan Arnlöv*, Valentina S Arsic Arsenijevic*, Al Artaman*, Rana J Asghar*, Reza Assadi*, Lydia S Atkins*, Charles Atkinson*, Marco A Avila*, Baffour Awuah*, Alaa Badawi*, Maria C Bahit*, Talal Bakfalouni*, Kalpana Balakrishnan*, Shivanthi Balalla*, Ravi Kumar Balu*, Amitava Banerjee*, Ryan M Barber*, Suzanne L Barker-Collo*, Simon Barquera*, Lars Barregard*, Lope H Barrero*,

Tonatiuh Barrientos-Gutierrez*, Ana C Basto-Abreu*, Arindam Basu*, Sanjay Basu*, Mohammed O Basulaiman*, Carolina Batis Ruvalcaba*, Justin Beardsley*, Neeraj Bedi*, Tolesa Bekele*, Michelle L Bell*, Corina Benjet*, Derrick A Bennett*, Habib Benzian*,

Eduardo Bernabé*, Tariku J Beyene*, Neeraj Bhala*, Ashish Bhalla*, Zulfiqar A Bhutta*, Boris Bikbov*, Aref A Bin Abdulhak*, Jed D Blore*, Fiona M Blyth*, Megan A Bohensky*, Berrak Bora Başara*, Guilherme Borges*, Natan M Bornstein*, Dipan Bose*, Soufiane Boufous*, Rupert R Bourne*, Michael Brainin*, Alexandra Brazinova*, Nicholas J Breitborde*, Hermann Brenner*, 
Adam D M Briggs*, David M Broday*, Peter M Brooks*, Nigel G Bruce*, Traolach S Brugha*, Bert Brunekreef*, Rachelle Buchbinder*, Linh N Bui*, Gene Bukhman*, Andrew G Bulloch*, Michael Burch*, Peter G J Burney*, Ismael R Campos-Nonato*, Julio C Campuzano*, Alejandra J Cantoral*, Jack Caravanos*, Rosario Cárdenas*, Elisabeth Cardis*, David O Carpenter*, Valeria Caso*, Carlos A Castañeda-Orjuela*, Ruben E Castro*, Ferrán Catalá-López*, Fiorella Cavalleri*, Alanur Çavlin*, Vineet K Chadha*, Jung-chen Chang*, Fiona J Charlson*, Honglei Chen*, Wanqing Chen*, Zhengming Chen*, Peggy P Chiang*, Odgerel Chimed-Ochir*, Rajiv Chowdhury*, Costas A Christophi*, Ting-Wu Chuang*, Sumeet S Chugh*, Massimo Cirillo*, Thomas KD Claßen*, Valentina Colistro*, Mercedes Colomar*, Samantha M Colquhoun*, Alejandra G Contreras*, Cyrus Cooper*, Kimberly Cooperrider*, Leslie T Cooper*, Josef Coresh*, Karen J Courville*, Michael H Criqui*, Lucia Cuevas-Nasu*, James Damsere-Derry*, Hadi Danawi*, Lalit Dandona*, Rakhi Dandona*, Paul I Dargan*, Adrian Davis*, Dragos V Davitoiu*, Anand Dayama*, E Filipa de Castro*, Vanessa De la Cruz-Góngora*, Diego De Leo*, Graça de Lima*, Louisa Degenhardt*, Borja del Pozo-Cruz*, Robert P Dellavalle*, Kebede Deribe*, Sarah Derrett*, Don C Des Jarlais*, Muluken Dessalegn*, Gabrielle A deVeber*, Karen M Devries*, Samath D Dharmaratne*, Mukesh K Dherani*, Daniel Dicker*, Eric L Ding*, Klara Dokova*, E Ray Dorsey*, Tim R Driscoll*, Leilei Duan*, Adnan M Durrani*, Beth E Ebel*, Richard G Ellenbogen*, Yousef M Elshrek*, Matthias Endres*, Sergey P Ermakov*, Holly E Erskine*, Babak Eshrati*, Alireza Esteghamati*, Saman Fahimi*, Emerito Jose A Faraon*, Farshad Farzadfar*, Derek F J Fay*, Valery L Feigin*, Andrea B Feigl*, Seyed-Mohammad Fereshtehnejad*, Alize J Ferrari*, Cleusa P Ferri*, Abraham D Flaxman*, Thomas D Fleming*, Nataliya Foigt*, Kyle J Foreman*, Urbano Fra Paleo*, Richard C Franklin*, Belinda Gabbe*, Lynne Gaffikin*, Emmanuela Gakidou*, Amiran Gamkrelidze*, Fortuné G Gankpé*, Ron T Gansevoort*, Francisco A García-Guerra*, Evariste Gasana*, Johanna M Geleijnse*, Bradford D Gessner*, Pete Gething*, Katherine B Gibney*, Richard F Gillum*, Ibrahim A M Ginawi*, Maurice Giroud*, Giorgia Giussani*, Shifalika Goenka*, Ketevan Goginashvili*, Hector Gomez Dantes*, Philimon Gona*, Teresita Gonzalez de Cosio*, Dinorah González-Castell*, Carolyn C Gotay*, Atsushi Goto*, Hebe N Gouda*, Richard L Guerrant*, Harish C Gugnani*, Francis Guillemin*, David Gunnell*, Rahul Gupta*, Rajeev Gupta*, Reyna A Gutiérrez*, Nima Hafezi-Nejad*, Holly Hagan*, Maria Hagstromer*, Yara A Halasa*, Randah R Hamadeh*, Mouhanad Hammami*, Graeme J Hankey*, Yuantao Hao*, Hilda L Harb*, Tilahun Nigatu Haregu*, Josep Maria Haro*, Rasmus Havmoeller*, Simon I Hay*, Mohammad T Hedayati*, Ileana B Heredia-Pi*, Lucia Hernandez*, Kyle R Heuton*, Pouria Heydarpour*, Martha Hijar*, Hans W Hoek*, Howard J Hoffman*, John C Hornberger*, H Dean Hosgood*, Damian G Hoy*, Mohamed Hsairi*, Guoqing $\mathrm{Hu}^{*}$, Howard $\mathrm{Hu}^{*}$, Cheng Huang*, John J Huang*, Bryan J Hubbell*, Laetitia Huiart*, Abdullatif Husseini*, Marissa L Iannarone*, Kim M Iburg*, Bulat T Idrisov*, Nayu Ikeda*, Kaire Innos*, Manami Inoue*, Farhad Islami*, Samaya Ismayilova*, Kathryn H Jacobsen*, Henrica A Jansen*, Deborah L Jarvis*, Simerjot K Jassal*, Alejandra Jauregui*, Sudha Jayaraman*, Panniyammakal Jeemon*, Paul N Jensen*, Vivekanand Jha*, Fan Jiang*, Guohong Jiang*, Ying Jiang*, Jost B Jonas*, Knud Juel*, Haidong Kan*, Sidibe S Kany Roseline*, Nadim E Karam*, André Karch*, Corine K Karema*, Ganesan Karthikeyan*, Anil Kaul*, Norito Kawakami*, Dhruv S Kazi*, Andrew H Kemp*, Andre P Kengne*, Andre Keren*, Yousef S Khader*, Shams Eldin Ali Hassan Khalifa*, Ejaz A Khan*, Young-Ho Khang*, Shahab Khatibzadeh*, Irma Khonelidze*, Christian Kieling*, Daniel Kim*, Sungroul Kim*, Yunjin Kim*, Ruth W Kimokoti*, Yohannes Kinfu*, Jonas M Kinge*, Brett M Kissela*, Miia Kivipelto*, Luke D Knibbs*, Ann Kristin Knudsen*, Yoshihiro Kokubo*, M Rifat Kose*, Soewarta Kosen*, Alexander Kraemer*, Michael Kravchenko*, Sanjay Krishnaswami*, Hans Kromhout*,
Tiffany Ku*, Barthelemy Kuate Defo*, Burcu Kucuk Bicer*,

Ernst J Kuipers*, Chanda Kulkarni*, Veena S Kulkarni*, G Anil Kumar*, Gene F Kwan*, Taavi Lai*, Arjun Lakshmana Balaji*, Ratilal Lalloo*, Tea Lallukka*, Hilton Lam*, Qing Lan*, Van C Lansingh*,

Heidi J Larson*, Anders Larsson*, Dennis O Laryea*, Pablo M Lavados*, Alicia E Lawrynowicz*, Janet L Leasher*, Jong-Tae Lee*, James Leigh*, Ricky Leung*, Miriam Levi*, Yichong Li*, Yongmei Li*, Juan Liang*, Xiaofeng Liang*, Stephen S Lim*, M Patrice Lindsay*,

Steven E Lipshultz*, Shiwei Liu*, Yang Liu*, Belinda K Lloyd*, Giancarlo Logroscino*, Stephanie J London*, Nancy Lopez*, Joannie Lortet-Tieulent*, Paulo A Lotufo*, Rafael Lozano*, Raimundas Lunevicius*, Jixiang Ma*, Stefan Ma*, Vasco M P Machado*, Michael F MacIntyre*, Carlos Magis-Rodriguez*, Abbas A Mahdi*, Marek Majdan*, Reza Malekzadeh*, Srikanth Mangalam*, Christopher C Mapoma*, Marape Marape*, Wagner Marcenes*, David J Margolis*, Christopher Margono*, Guy B Marks*,

Randall V Martin*, Melvin B Marzan*, Mohammad T Mashal*, Felix Masiye*, Amanda J Mason-Jones*, Kunihiro Matsushita*, Richard Matzopoulos*, Bongani M Mayosi*, Tasara T Mazorodze*, Abigail C McKay*, Martin McKee*, Abigail McLain*, Peter A Meaney*, Catalina Medina*, Man Mohan Mehndiratta*, Fabiola Mejia-Rodriguez*, Wubegzier Mekonnen*, Yohannes A Melaku*, Michele Meltzer*, Ziad A Memish*, Walter Mendoza*, George A Mensah*, Atte Meretoja*, Francis Apolinary Mhimbira*, Renata Micha*, Ted R Miller*, Edward J Mills*, Awoke Misganaw*, Santosh Mishra*, Norlinah Mohamed Ibrahim*, Karzan A Mohammad*, Ali H Mokdad*, Glen L Mola*, Lorenzo Monasta*, Julio C Montañez Hernandez*, Marcella Montico*, Ami R Moore*, Lidia Morawska*, Rintaro Mori*, Joanna Moschandreas*, Wilkister N Moturi*, Dariush Mozaffarian*, Ulrich O Mueller*, Mitsuru Mukaigawara*, Erin C Mullany*, Kinnari S Murthy*, Mohsen Naghavi*, Ziad Nahas*, Aliya Naheed*, Kovin S Naidoo*, Luigi Naldi*, Devina Nand*, Vinay Nangia*, KM Venkat Narayan*, Denis Nash*, Bruce Neal*, Chakib Nejjari*, Sudan P Neupane*, Charles R Newton*, Frida N Ngalesoni*, Jean de Dieu Ngirabega*, Grant Nguyen*, Nhung T Nguyen*, Mark J Nieuwenhuijsen*, Muhammad I Nisar*, José R Nogueira*, Joan M Nolla*, Sandra Nolte*, Ole F Norheim*, Rosana E Norman*, Bo Norrving*, Luke Nyakarahuka*, In-Hwan Oh*, Takayoshi Ohkubo*, Bolajoko O Olusanya*, Saad B Omer*, John Nelson Opio*, Ricardo Orozco*, Rodolfo S Pagcatipunan Jr.*, Amanda W Pain*, Jeyaraj D Pandian*, Carlo Irwin A Panelo*, Christina Papachristou*, Eun-Kee Park*, Charles D Parry*, Angel J Paternina Caicedo*, Scott B Patten*, Vinod K Paul*, Boris I Pavlin*, Neil Pearce*, Lilia S Pedraza*, Andrea Pedroza*, Ljiljana Pejin Stokic*, Ayfer Pekericli*, David M Pereira*, Rogelio Perez-Padilla*, Fernando Perez-Ruiz*, Norberto Perico*, Samuel A L Perry*, Aslam Pervaiz*, Konrad Pesudovs*, Carrie B Peterson*, Max Petzold*, Michael R Phillips*, Hwee Pin Phua*, Dietrich Plass*, Dan Poenaru*, Guilherme V Polanczyk*, Suzanne Polinder*, Constance D Pond*, C Arden Pope*, Daniel Pope*, Svetlana Popova*, Farshad Pourmalek*, John Powles*, Dorairaj Prabhakaran*, Noela M Prasad*, Dima M Qato*, Amado D Quezada*, D Alex A Quistberg*, Lionel Racapé*, Anwar Rafay*, Kazem Rahimi*, Vafa Rahimi-Movaghar*, Sajjad Ur Rahman*, Murugesan Raju*, Ivo Rakovac*, Saleem M Rana*, Mayuree Rao*, Homie Razavi*, K Srinath Reddy*, Amany H Refaat*, Jürgen Rehm*, Giuseppe Remuzzi*, Antonio L Ribeiro*, Patricia M Riccio*, Lee Richardson*, Anne Riederer*, Margaret Robinson*, Anna Roca*, Alina Rodriguez*, David Rojas-Rueda*, Isabelle Romieu*, Luca Ronfani*, Robin Room*, Nobhojit Roy*, George M Ruhago*, Lesley Rushton*, Nsanzimana Sabin*, Ralph L Sacco*, Sukanta Saha*, Ramesh Sahathevan*, Mohammad Ali Sahraian*, Joshua A Salomon*, Deborah Salvo*, Uchechukwu K Sampson*, Juan R Sanabria*, Luz Maria Sanchez*, Tania G Sánchez-Pimienta*, Lidia Sanchez-Riera*, Logan Sandar*, Itamar S Santos*, Amir Sapkota*, Maheswar Satpathy*, James E Saunders*, Monika Sawhney*, Mete I Saylan*,

Peter Scarborough*, Jürgen C Schmidt*, Ione J C Schneider*, Ben Schöttker*, David C Schwebel*, James G Scott*, Soraya Seedat*, Sadaf G Sepanlou*, Berrin Serdar*, Edson E Servan-Mori*, Gavin Shaddick*, Saeid Shahraz*, Teresa Shamah Levy*, Siyi Shangguan*, Jun She*, Sara Sheikhbahaei*, Kenji Shibuya*, 
Hwashin H Shin*, Yukito Shinohara*, Rahman Shiri*, Kawkab Shishani*, Ivy Shiue*, Inga D Sigfusdottir*, Donald H Silberberg*, Edgar P Simard*, Shireen Sindi*, Abhishek Singh*, Gitanjali M Singh*, Jasvinder A Singh*, Vegard Skirbekk*, Karen Sliwa*, Michael Soljak*, Samir Soneji*, Kjetil Søreide*, Sergey Soshnikov*, Luciano A Sposato*, Chandrashekhar T Sreeramareddy*, Nicolas J C Stapelberg*, Vasiliki Stathopoulou*, Nadine Steckling*, Dan J Stein*, Murray B Stein*, Natalie Stephens*, Heidi Stöckl*, Kurt Straif*, Konstantinos Stroumpoulis*, Lela Sturua*, Bruno F Sunguya*, Soumya Swaminathan*, Mamta Swaroop*, Bryan L Sykes*, Karen M Tabb*, Ken Takahashi*, Roberto T Talongwa*, Nikhil Tandon*, David Tanne*, Marcel Tanner*, Mohammad Tavakkoli*, Braden J Te Ao*, Carolina M Teixeira*, Martha M Téllez Rojo*, Abdullah S Terkawi*, José Luis Texcalac-Sangrador*, Sarah V Thackway*, Blake Thomson*, Andrew L Thorne-Lyman*, Amanda G Thrift*, George D Thurston*, Taavi Tillmann*, Myriam Tobollik*, Marcello Tonelli*, Fotis Topouzis*, Jeffrey A Towbin*, Hideaki Toyoshima*, Jefferson Traebert*, Bach X Tran*, Leonardo Trasande*, Matias Trillini*, Ulises Trujillo*, Zacharie Tsala Dimbuene*, Miltiadis Tsilimbaris*, Emin Murat Tuzcu*, Uche S Uchendu*, Kingsley N Ukwaja*, Selen B Uzun*, Steven van de Vijver*, Rita Van Dingenen*, Coen H van Gool*, Jim van Os*, Yuri Y Varakin*, Tommi J Vasankari*, Ana Maria N Vasconcelos*, Monica S Vavilala*, Lennert J Veerman*, Gustavo Velasquez-Melendez*, N Venketasubramanian*,

Lakshmi Vijayakumar*, Salvador Villalpando*, Francesco S Violante*, Vasiliy Victorovich Vlassov*, Stein Emil Vollset*, Gregory R Wagner*, Stephen G Waller*, Mitchell T Wallin*, Xia Wan*, Haidong Wang*, JianLi Wang*, Linhong Wang*, Wenzhi Wang*, Yanping Wang*, Tati S Warouw*, Charlotte H Watts*, Scott Weichenthal*,

Elisabete Weiderpass*, Robert G Weintraub*, Andrea Werdecker*, K Ryan Wessells*, Ronny Westerman*, Harvey A Whiteford*, James D Wilkinson*, Hywel C Williams*, Thomas N Williams*, Solomon M Woldeyohannes*, Charles D A Wolfe*, John Q Wong*, Anthony D Woolf*, Jonathan L Wright*, Brittany Wurtz*, Gelin Xu*, Lijing L Yan*, Gonghuan Yang*, Yuichiro Yano*, Pengpeng Ye*, Muluken Yenesew*, Gökalp K Yentür*, Paul Yip*, Naohiro Yonemoto*, Seok-Jun Yoon*, Mustafa Z Younis*, Zourkaleini Younoussi*, Chuanhua Yu*, Maysaa E Zaki*, Yong Zhao*, Yingfeng Zheng*, Maigeng Zhou*, Jun Zhu*, Shankuan Zhu*, Xiaonong Zou*, Joseph R Zunt*, Alan D Lopez†, Theo Vos $\uparrow$, Christopher J Murray $\dagger$. *Authors listed alphabetically. †Joint senior authors. †Corresponding author.

\section{Affiliations}

Institute for Health Metrics and Evaluation (Prof M H Forouzanfar PhD, L Alexander BA, V F Bachman BA, S Biryukov BS, Prof M Brauer PhD, D Casey BA, M M Coates BS, K Delwiche BS, K Estep MPA, J J Frostad MPH, A KC MSc, H H Kyu PhD, M Moradi-Lakeh PhD, M Ng PhD, E Slepak MLIS, B A Thomas MD, J Wagner BS, T Achoki MD, C Atkinson BA, R M Barber BS, K Cooperrider BA, Prof L Dandona PhD, D Dicker BS, A D Flaxman PhD, T D Fleming BS, K J Foreman MPH, Prof E Gakidou PhD, Prof S I Hay DSc, K R Heuton BChe, M L Iannarone MSc, T Ku BS, H J Larson PhD, S S Lim PhD, Prof A D Lopez PhD, R Lozano PhD, M F MacIntyre MEd, C Margono BS, A McLain MA, A H Mokdad PhD, E C Mullany BA, Prof C J L Murray DPhil, Prof M Naghavi PhD, G Nguyen BA, A W Pain MPH, L Richardson BS, M Robinson BA, L Sandar BS, N Stephens MUS, A M Temesgen PhD, B Thomson BA, T Vos PhD, X Wan PhD, H Wang PhD, B Wurtz MPH), Harborview Injury Prevention and Research Center (B E Ebel MD), Harborview/UW Medicine (Prof R G Ellenbogen MD), School of Medicine (J L Wright MD), University of Washington, Seattle, WA, USA (R Alfonso-Cristancho PhD, Prof B O Anderson MD, P N Jensen PhD, D A Quistberg PhD, A Riederer DSc, M S Vavilala MD, J R Zunt MD); St George's, University of London, London, UK (Prof H R Anderson MD); School of Population and Public Health (F Pourmalek PhD), University of British Columbia, Vancouver, BC, Canada (Prof M Brauer PhD, C C Gotay PhD); Health Canada, Ottawa, ON, Canada (R Burnett PhD H H Shin PhD, S Weichenthal PhD); Health Effects Institute, Boston, MA, USA (A Cohen DSc); Department of Community Medicine, Iran
University of Medical Sciences, Tehran, Iran (M Moradi-Lakeh PhD); Department of Health Registries (A Knudsen PhD), Norwegian Institute of Public Health, Oslo, Norway (G Aasvang PhD, J M Kinge PhD, Prof V Skirbekk MD, Prof S Vollset MD); La Sapienza, University of Rome, Rome, Italy (Prof C Abbafati PhD); Institute of Population Studies (A Abbasoglu Ozgoren MSc, A Çavlin PhD), Institute of Public Health, Hacettepe University, Ankara, Turkey (B Kucuk Bicer PhD); Faculty of Medicine, Cairo University, Cairo, Egypt (Prof F Abd-Allah MD); School of Public Health, College of Health Sciences (S F Abera MSc), Mekelle University, Mekelle, Ethiopia (Y A Melaku MPH); Kilte Awlaelo-Health and Demographic Surveillance Site, Mekelle, Ethiopia (S F Abera MSc); Dupuytren University Hospital, Limoges, France (Prof V Aboyans PhD); Government College Munnar, Munnar, India (Prof B Abraham M Phil); Family Medicine Residency Program at California Hospital, University of Southern California, Los Angeles, CA, USA (J Puthenpurakal Abraham MD); Institute for Global Health (J Puthenpurakal Abraham MD), Department of Nutrition (A L Thorne-Lyman ScD), T H Chan School of Public Health (E L Ding ScD, S Fahimi PhD, S Khatibzadeh MD, G R Wagner MD), Harvard Medical School (G Bukhman PhD), Harvard University, Boston, MA, USA (I R Campos-Nonato PhD, A B Feigl MPH, J A Salomon PhD); Department of Epidemiology and Public Health (H Benzian PhD), University College London, London, UK (Prof I Abubakar PhD); Institute of Community and Public Health, Birzeit University, Ramallah, Pakistan (N ME Abu-Rmeileh PhD); National Institute of Public Health, Cuernavaca, Mexico (R Lozano PhD, T C Aburto MSc, M A Avila BS, S Barquera PhD, T Barrientos-Gutierrez PhD, I R Campos-Nonato PhD, J C Campuzano PhD, A J Cantoral ScD, A G Contreras MSc, Prof L Cuevas-Nasu MSc, V De la Cruz-Góngora MSc, Prof F A García-Guerra MSc, H Gomez Dantes MC, T Gonzalez de Cosio PhD, Prof D González-Castell MSc, I B Heredia-Pi PhD, L Hernandez MS, A Jauregui MSc, C Medina MS, F Mejia-Rodriguez MD, Prof J C Montañez Hernandez MSc, L S Pedraza MSc, A Pedroza MS, A D Quezada MS, D Salvo PhD, L M Sanchez PhDc, T G Sánchez-Pimienta MSc, Prof E E Servan-Mori MSc, T Shamah Levy PhD, M M Téllez Rojo PhD, S Villalpando PhD); Public Health Promotion Alliance, Osogbo, Nigeria (A Adelekan MPH); Kwame Nkrumah University of Science and Technology, Kumasi, Ghana (K Adofo MPH); Association Ivoirienne pour le Bien-Être Familial, Abidjan, Côte d'Ivoire (A K Adou MD); University of Extremadura, Cáceres, Spain (Prof J C Adsuar PhD, U Fra Paleo PhD); Friedman School of Nutrition Science and Policy (A Afshin MD, R Micha PhD, D Mozaffarian MD), Tufts Medical Center (Prof S Shahraz PhD, S Shangguan MD), Tufts University, Boston, MA, USA (G M Singh PhD); Institution of Public Health Sciences, Stockholm, Sweden (E E Agardh PhD); Ministry of Health, Muscat, Oman (M J Al Khabouri PhD); Baghdad College of Medicine, Baghdad, Iraq (F H Al Lami PhD); icddr,b, Dhaka, Bangladesh (S Alam MSc, A Naheed PhD); Ministry of Health, Al Khuwair, Oman (D Alasfoor MSc); Independent, Damascus, Syria (M I Albittar BS); Departamento de Medicina Preventiva y Social (M A Alegretti MD), Facultad de Medicina (F Cavalleri BS), Universidad de la República, Montevideo, Uruguay (A V Aleman MD, V Colistro MSc); Debre Markos University, Addis Ababa, Ethiopia (Z A Alemu MPH); King Abdullah Bin Abdulaziz University Hospital, Riyadh, Saudi Arabia (S Alhabib PhD); Clinical Trial Service Unit, Nuffield Department of Population Health (Prof Z Chen DPhil), Department of Zoology (P Gething PhD), University of Oxford, Oxford, UK (R Ali MSc, D A Bennett PhD, A D M Briggs MSc, Prof S I Hay DSc, K Rahimi DM, P Scarborough DPhil); Rollins School of Public Health (E P Simard PhD), Emory University, Atlanta, GA, USA (M K Ali MBChB, S Argeseanu Cunningham PhD, Prof Y Liu PhD, Prof K M V Narayan MD, S B Omer PhD); University of Lorraine, Nancy, France (Prof F Alla PhD, Prof F Guillemin PhD); Department of Public Health Sciences (Prof P Allebeck PhD, N Roy MD), Aging Research Center (Prof M Kivipelto PhD), Department of Medical Epidemiology and Biostatistics (E Weiderpass PhD), Department of Neurobiology, Care Sciences and Society (S Fereshtehnejad MD), Karolinska Institute, Stockholm, Sweden (R Havmoeller PhD, S Sindi PhD); Ministry of Health, Belmopan, Belize (P J Allen DDS); Charité University Medicine, Berlin, Germany (U Alsharif MPH, Prof M Endres MD, S Nolte PhD, 
C Papachristou PhD); Government, Madrid, Spain (E Alvarez PhD); Universidad de Cartagena, Cartagena de Indias, Colombia (Prof N Alvis-Guzman PhD, A J Paternina Caicedo MSc); Albany State University, Albany, GA, USA (Prof A A Amankwaa PhD); Department of Epidemiology (A T Amare MPH), Department of Psychiatry (Prof H W Hoek MD), University Medical Center Groningen, University of Groningen, Groningen, Netherlands (Prof R T Gansevoort PhD); College of Medicine and Health Sciences (A T Amare MPH), Bahir Dar University, Bahir Dar, Ethiopia (M Yenesew MPH); Ahmadu Bello University, Zaria, Nigeria (Prof E A Ameh MBBS); Boston University, Boston, MA, USA (O Ameli MD); Kurdistan Environmental Health Research Center, Kurdistan University of Medical Sciences, Sanandaj, Iran (H Amini MSPH); Department of Epidemiology and Public Health, Swiss Tropical and Public Health Institute, Basel, Switzerland (H Amini MSPH); Swiss Tropical and Public Health Institute (Prof M Tanner PhD), University of Basel, Basel, Switzerland (H Amini MSPH); Ministry of Public Health, Beirut, Lebanon (W Ammar PhD, H L Harb MPH); Department of Health Policy and Administration (C A T Antonio MD), College of Public Health (E A Faraon MD), University of the Philippines Manila, Manila, Philippines (C A Panelo MA); Self employee, Kabul, Afghanistan (P Anwari MS); Department of Medical Sciences (Prof J Arnlöv PhD), Uppsala University, Uppsala, Sweden (Prof A Larsson PhD); Dalarna University, Falun, Sweden (Prof J Arnlöv PhD); School of Medicine, Institute of Microbiology and Immunology, University of Belgrade, Belgrade, Serbia (Prof V S Arsic Arsenijevic PhD); University Children's Hospital, Belgrade, Serbia (Prof V S Arsic Arsenijevic PhD); Consultant, Windsor, ON, Canada (A Artaman PhD), South Asian Public Health Forum, Islamabad, Pakistan (R J Asghar MD); Mashhad University of Medical Sciences, Mashhad, Iran (R Assadi PhD); Wellness, Human Services and Gender Relations, Ministry of Health, Castries, Saint Lucia (L S Atkins MPH); Komfo Anokye Teaching Hospital, Kumasi, Ghana (B Awuah MD, D O Laryea MD); Public Health Agency of Canada, Toronto, ON, Canada (A Badawi PhD); INECO Neurociencias, Rosario, Argentina (M C Bahit MD); Ministry of Health, Damascus, Syria (T Bakfalouni MD); Sri Ramachandra University, Chennai, India (Prof K Balakrishnan PhD); National Institute for Stroke and Applied Neurosciences (S Balalla MPH, Prof V L Feigin PhD), Auckland University of Technology, Auckland, New Zealand (B J Te Ao MPH); Public Health Foundation of India, New Delhi,

India (Prof L Dandona PhD, R Balu MD, Prof R Dandona PhD, S Goenka PhD, G Kumar PhD, K S Murthy MPH, K Reddy DM); University of Birmingham, Birmingham, UK (A Banerjee D Phil); School of Psychology (S L Barker-Collo PhD), University of Auckland, Auckland, New Zealand (Dr B del Pozo-Cruz PhD); Department of Occupational and Environmental Health, University of Gothenburg, Gothernburg, Sweden (Prof L Barregard MD); Department of Industrial Engineering, Pontificia Universidad Javeriana, Bogotá, Colombia (L H Barrero ScD); National Institute of Public Health, Mexico City, Mexico (A C Basto-Abreu, C Batis Ruvalcaba PhD, E F de Castro PhD, N Lopez MSc, J L Texcalac Sangrador, MSc); School of Health Sciences, University of Canterbury, Christchurch, New Zealand (A Basu PhD); School of Medicine (L Gaffikin DrPH), Stanford University, Stanford, CA, USA (Prof S Basu PhD); Ministry of Health, Riyadh, Saudi Arabia (M O Basulaiman PhD, Prof Z A Memish MD); Oxford University, Ho Chi Minh City, Vietnam (J Beardsley MBChB); College of Public Health and Tropical Medicine, Jazan, Saudi Arabia (Prof N Bedi MD); Madawalabu University, Bale Goba, Ethiopia (T Bekele MPH); Yale University, New Haven, CT, USA (Prof M L Bell PhD, J J Huang MD); National Institute of Psychiatry Ramon de la Fuente Muñiz, Mexico City, Mexico (C Benjet PhD, Prof G Borges, R A Gutiérrez PhD,

Prof R Orozco MSc); Department of Epidemiology and Health Promotion, College of Dentistry (H Benzian PhD), School of Medicine (L Trasande MD), New York University, New York, NY, USA (Prof H Hagan PhD); King's College London, London, UK (E Bernabé PhD, Prof C D A Wolfe MD); Addis Ababa University, Debre Zeyit, Ethiopia (T J Beyene DVM); Queen Elizabeth Hospital Birmingham, Birmingham, UK (N Bhala DPhil); Capital and Coast District Health Board (N Bhala DPhil), Department of Preventive and Social Medicine, Dunedin School of Medicine (S Derrett PhD), University of Otago, Wellington, New Zealand; Postgraduate Institute of
Medical Education and Research, Chandigarh, India (A Bhalla MD, Prof V Jha DM); Medical Center (Z A Bhutta PhD), Aga Khan University, Karachi, Pakistan (M I Nisar MSc); A I Evdokimov Moscow State University of Medicine and Dentistry, Moscow, Russia (B Bikbov PhD); Academician V I Shumakov Federal Research Center of Transplantology and Artificial Organs, Moscow, Russia (B Bikbov PhD); University of Iowa Hospitals and Clinics, Iowa City, IA, USA (A A Bin Abdulhak MD); Center for Youth Mental Health (Prof L Vijayakumar PhD), General Practice and Primary Health Care Academic Centre (P P Chiang PhD), University of Melbourne, Melbourne, VIC, Australia (J D Blore PhD, Prof P M Brooks MD, A Lakshmana Balaji MPH, S M Colquhoun PhD, Prof A D Lopez PhD, R G Weintraub MB, BS); University of Sydney, Concord, NSW, Australia (Prof F M Blyth PhD); Departments of Medicine and the Florey (A Meretoja PhD), University of Melbourne, Parkville, VIC, Australia (M A Bohensky PhD); General Directorate of Health Research (B Bora Başara PhD, G K Yentür PhD), Ministry of Health, Ankara, Turkey (M R Kose MD, A Pekericli MD, S B Uzun MD); Tel Aviv Saurasky Medical Center, Tel Aviv, Israel

(Prof N M Bornstein MD); World Bank, Washington, DC, USA (D Bose PhD); Transport and Road Safety Research (S Boufous PhD), University of New South Wales, Sydney, NSW, Australia (Prof L Degenhardt PhD); Anglia Ruskin University, Cambridge, UK (Prof R R Bourne FRCOphth); Danube University Krems, Krems, Austria (Prof M Brainin PhD); Faculty of Health Sciences and Social Work, Trnava University, Trnava, Slovakia (A Brazinova PhD, M Majdan $\mathrm{PhD}$ ); Ohio State University, Columbus, OH, USA (Prof N J Breitborde PhD); University of Arizona, Tucson, AZ, USA (Prof N J Breitborde PhD); Division of Clinical Epidemiology and Aging Research (B Schöttker MPH), German Cancer Research Center, Heidelberg, Germany (Prof H Brenner MD); Technion, Haifa, Israel (Prof D M Broday DSc); School of Medicine (Prof R Lunevicius PhD), University of Liverpool, Liverpool, UK (Prof N G Bruce PhD, M K Dherani PhD, D Pope PhD); University of Leicester, Leicester, UK (Prof T S Brugha MD); Institute for Risk Assessment Sciences, Utrecht University, Utrecht, Netherlands (Prof B Brunekreef PhD, Prof H Kromhout PhD); Monash Department of Clinical Epidemiology, Cabrini Institute, Melbourne, VIC, Australia (Prof R Buchbinder PhD); Department of Epidemiology and Preventive Medicine, School of Public Health and Preventive Medicine (Prof R Buchbinder PhD), Monash University, Melbourne, VIC, Australia (Prof B Gabbe PhD, K B Gibney FRACP, Prof A G Thrift PhD); Hanoi School of Public Health, Hanoi, Vietnam (L N Bui MIPH, N T Nguyen MPH); University of Calgary, Calgary, AB, Canada (A G Bulloch PhD, Prof S B Patten PhD, Prof M Tonelli MD, J Wang PhD); Great Ormond Street Hospital for Children, London, UK (M Burch MD); Imperial College London, London, UK (Prof P G J Burney MD, K J Foreman MPH, Prof D L Jarvis MD, Prof A Rodriguez PhD, L Rushton PhD, M Soljak PhD, Prof T N Williams MD); School of Public Health, City University of New York, New York, NY, USA (Prof J Caravanos DrPH, D Nash PhD); Universidad Autonoma Metropolitana, Mexico City, Mexico (R Cárdenas ScD); Centre for Research in Environmental Epidemiology, Barcelona, Spain (Prof E Cardis PhD, M J Nieuwenhuijsen PhD, D Rojas-Rueda PhD); University at AlbanySUNY, Rensselaer, NY, USA (Prof D O Carpenter MD,

Prof R Leung PhD); Stroke Unit, University of Perugia, Perugia, Italy (V Caso MD); Instituto Nacional de Salud, Colombian National Health Observatory, Bogotá, Colombia (C A Castañeda-Orjuela MS); Epidemiology and Public Health Evaluation Group, Public Health Department, Universidades Nacional de Colombia, Bogotá, Colombia (C A Castañeda-Orjuela MS); Universidad Diego Portales, Santiago, Chile (R E Castro PhD); Division of Pharmacoepidemiology and Pharmacovigilance, Spanish Medicines and Healthcare Products Agency, Ministry of Health, Madrid, Spain (F Catalá-López PhD); Department of Medicine, University of Valencia/CIBERSAM, Valencia, Spain (F Catalá-López PhD); National Tuberculosis Institute, Bengaluru, India (V K Chadha MD); College of Medicine, National Taiwan University, Taipei, Taiwan (Prof J Chang PhD); Centre for Clinical Research (J G Scott PhD), School of Population Health (D G Hoy PhD), School of Public Health (L D Knibbs PhD), University of Queensland, Brisbane, QLD, Australia (F J Charlson MIPH, H E Erskine B PsySc, A J Ferrari B PsySc, H N Gouda PhD, L J Veerman PhD, 
Prof H A Whiteford MD); Cancer Institute (W Chen PhD,

Prof X Zou MD), Institute of Basic Medical Sciences (X Wan PhD), Chinese Academy of Medical Sciences, Beijing, China; Division of Intramural Research, National Institute of Environmental Health Sciences, National Institutes of Health, Research Triangle Park, NC, USA (H Chen PhD, S J London MD); Department of Health Development (Y Jiang PhD), Institute of Industrial Ecological Sciences (Prof K Takahashi MD), Department of Environmental Epidemiology (O Chimed-Ochir MPH), University of Occupational and Environmental Health, Kitakyushu, Japan; University of Cambridge, Cambridge, UK (R Chowdhury PhD, J Powles MA); Cyprus University of Technology, Limassol, Cyprus (C A Christophi PhD); Taipei Medical University, Taipei, Taiwan (Prof T Chuang PhD); Cedars-Sinai Medical Center, Los Angeles, CA, USA (Prof S S Chugh MD); University of Salerno, Baronissi, Italy (Prof M Cirillo MD); Department of Environment and Health (T K D Claßen Dr rer.nat.), School of Public Health, University of Bielefeld, Bielefeld, Germany (Prof A Kraemer PhD, M Tobollik MPH); UNICEM, Montevideo, Uruguay (M Colomar MSc); Murdoch Children's Research Institute, Melbourne, VIC, Australia (S M Colquhoun PhD); MRC Lifecourse Epidemiology Unit, University of Southampton, Southampton, UK (Prof C Cooper FMedSci); Mayo Clinic, Rochester, MN, USA (L T Cooper MD); Bloomberg School of Public Health (J Coresh PhD, K Matsushita PhD), Johns Hopkins University, Baltimore, MD, USA (B X Tran PhD); Hospital Dr Gustavo N Collado, Chitre, Panama (K J Courville MD); University of California, San Diego, La Jolla, CA, USA (M H Criqui MD, M B Stein MD); Building and Road Research Institute, Kumasi, Ghana (J Damsere-Derry MPH); Walden University, Minneapolis, MN, USA (H Danawi PhD, Prof A H Refaat PhD); Guy's and St Thomas' NHS Foundation Trust, London, UK (P I Dargan FRCP); Public Health England, London, UK (A Davis PhD, D F J Fay MSc, J C Schmidt Dott.med.); University of Medicine and Pharmacy Bucharest, Bucharest, Romania (D V Davitoiu PhD); Department of Surgery, Jacobi Medical Center, Atlanta, GA, USA (A Dayama MD); Griffith University, Brisbane, QLD, Australia (Prof D De Leo DSc); Local Health Unit of Matosinhos, Matosinhos, Portugal (G de Lima MS); Public Health Department (G de Lima MS, V M P Machado MSc), Northern Region Health Administration, Porto, Portugal (J R Nogueira MPH, C M Teixeira MD); Eastern Colorado Healthcare System, US Department of Veterans Affairs, Denver, CO, USA (R P Dellavalle MD); Brighton and Sussex Medical School, Brighton, UK (K Deribe MPH); School of Public Health (K Deribe MPH), Addis Ababa University, Addis Ababa, Ethiopia (W Mekonnen PhD); School of Public Health, College of Health, Massey University, Palmerston North, New Zealand (S Derrett PhD); Mount Sinai Beth Israel, New York, NY, USA (Prof D C Des Jarlais PhD); Icahn School of Medicine at Mount Sinai, New York, NY, USA

(Prof D C Des Jarlais PhD); Africa Medical and Research Foundation in Ethiopia, Addis Ababa, Ethiopia (M Dessalegn MPH); Hospital for Sick Children (G A deVeber MD), Institute of Health Policy, Management and Evaluation (M P Lindsay PhD), University of Toronto, Toronto, ON, Canada (Prof H Hu MD); London School of Hygiene and Tropical Medicine, London, UK (K M Devries PhD, H J Larson PhD, Prof M McKee DSc, Prof N Pearce PhD, H Stöckl DPhil, T Tillmann MBChB, Prof C H Watts PhD); University of Peradeniya, Peradeniya, Sri Lanka (S D Dharmaratne MD); Department of Social Medicine, Faculty of Public Health, Medical University-Varna, Varna, Bulgaria (K Dokova PhD); University of Rochester Medical Center, Rochester, NY, USA (E R Dorsey MD); Sydney School of Public Health (Prof T R Driscoll PhD), Woolcock Institute of Medical Research (Prof G B Marks PhD), University of Sydney, Sydney, NSW, Australia (J Leigh PhD); National Center for Chronic and Noncommunicable Disease Control and Prevention (L Duan MD, Y Li MPH, S Liu PhD J Ma PhD, Prof L Wang MD, P Ye MPH, Prof M Zhou PhD), China CDC, Beijing, China (Prof X Liang PhD); National Institutes of Health, Montgomery Village, MD, USA (A M Durrani MD); Food Science Department, Faculty of Agriculture, University of Tripoli, Tripoli, Libya (Prof Y M Elshrek PhD); The Institute of Social and Economic Studies of Population, Russian Academy of Sciences, Moscow, Russia (Prof S P Ermakov DSc); Federal Research Institute for Health Organization and Informatics, Ministry of Health of the Russian Federation, Moscow, Russia (Prof S P Ermakov DSc, S Soshnikov PhD);
Arak University of Medical Sciences and Health Affairs, Arak, Iran (B Eshrati PhD); Non-Communicable Diseases Research Center (F Farzadfar MD), Endocrinology and Metabolism Research Center (Prof A Esteghamati MD, N Hafezi-Nejad MD, S Sheikhbahaei MD), Digestive Diseases Research Institute (S G Sepanlou MD), Multiple Sclerosis Research Center, Neuroscience Institute (P Heydarpour MD, M Sahraian MD), Sina Trauma and Surgery Research Center (Prof V Rahimi-Movaghar MD), Tehran University of Medical Sciences, Tehran, Iran; Federal University of São Paulo, São Paulo, Brazil (C P Ferri PhD); Institute of Gerontology, Academy of Medical Science, Kyiv, Ukraine (N Foigt PhD); James Cook University, Townsville, QLD, Australia (R C Franklin PhD); National Center for Disease Control and Public Health, Tiblisi, Georgia (Prof A Gamkrelidze PhD,

I Khonelidze MPA, L Sturua PhD); Leras Afrique, Cotonou, Benin (F G Gankpé MD); CHU Hassan II, Fez, Morocco (F G Gankpé MD); Tuberculosis and Other Respiratory Diseases Division (E Gasana MPH), Rwanda Biomedical Centre, Kigali, Rwanda (N Sabin MD); Division of Human Nutrition, Wageningen University, Wageningen, Netherlands (J M Geleijnse PhD); Agence de Médecine Préventive, Paris, France (B D Gessner MD); Melbourne Health, Parkville, VIC, Australia (K B Gibney FRACP); Howard University, Washington, DC, USA (R F Gillum MD); College of Medicine, University of Hail, Hail, Saudi Arabia (I A M Ginawi MD); University Hospital of Dijon, Dijon, France (Prof M Giroud MD); IRCCS Mario Negri Institute for Pharmacological Research, Milan, Italy (G Giussani Biol D); Ministry of Labour, Health and Social Affairs, Tblisi, Georgia (K Goginashvili MPH); University of Massachusetts Boston, Boston, MA, USA (Prof P Gona PhD); Department of Public Health, Tokyo Women's Medical University, Tokyo, Japan (A Goto MD); School of Medicine (R L Guerrant MD), Department of Anesthesiology (A S Terkawi MD), University of Virginia, Charlottesville, VA, USA; Saint James School of Medicine, Kralendijk, Netherlands Antilles (Prof H C Gugnani PhD); University of Bristol, Bristol, UK (Prof D Gunnell DSc); West Virginia Bureau for Public Health, Charleston, WV, USA (R Gupta MD); Fortis Escorts Hospital, Jaipur, India (R Gupta PhD); Karolinska Institute, Huddinge, Sweden (M Hagstromer PhD); Brandeis University, Waltham, MA, USA (Y A Halasa MS, B T Idrisov MD); Arabian Gulf University, Manama, Bahrain (Prof R R Hamadeh DPhil); Wayne County Department of Health and Human Services, Detroit, MI, USA (M Hammami MD); The University of Western Australia, Perth, WA, Australia (Prof G J Hankey MD); School of Public Health (Prof Y Hao PhD), Zhongshan Ophthalmic Center (Y Zheng MD), Sun Yat-sen University, Guangzhou, China; African Population and Health Research Center, Nairobi, Kenya (T Haregu PhD, S van de Vijver MD); Parc Sanitari Sant Joan de Déu-CIBERSAM, Sant Boi de Llobregat, Spain (Prof J Haro MD); Universitat de Barcelona, Barcelona, Spain (Prof J Haro MD); Mazandaran University of Medical Sciences, Sari, Iran (Prof M T Hedayati PhD); Fundacion Entornos AC, Cuernavaca, Mexico (Prof M Hijar PhD); Department of Epidemiology, Columbia University, New York, NY (Prof H W Hoek MD); Epidemiology and Statistics Program, National Institute on Deafness and Other Communication Disorders (H J Hoffman MA), Center for Translation Research and Implementation Science (G A Mensah MD), National Heart, Lung, and Blood Institute (U K Sampson MD), National Institutes of Health, Bethesda, MD, USA; Cedar Associates, Menlo Park, CA, USA (J C Hornberger MD); Albert Einstein College of Medicine, Bronx, NY, USA (Prof H Hosgood PhD); National Institute of Public Health, Tunis, Tunisia (Prof M Hsairi MD); Public Health Division, Secretariat of the Pacific Community, Noumea, New Caledonia (D G Hoy PhD); School of Public Health, Central South University, Changsha, China (G Hu PhD); George Washington University, Washington, DC, USA (Prof C Huang PhD); US Environmental Protection Agency, Research Triangle Park, NC, USA (B J Hubbell PhD); CHU La Réunion, SaintDenis, France (L Huiart PhD, L Racapé MD); Qatar University, Doha, Qatar (A Husseini PhD); Aarhus University, Aarhus, Denmark (K M Iburg PhD); National Institute of Health and Nutrition, Shinjuku, Japan (N Ikeda PhD); National Institute for Health Development, Tallinn, Estonia (K Innos PhD); Graduate School of Medicine (M Inoue PhD), School of Public Health (Prof N Kawakami MD), University of Tokyo, Tokyo, Japan (K Shibuya MD); American Cancer Society, New York, NY, USA (F Islami PhD); Self-employed, Sumgayit, 
Azerbaijan (S Ismayilova MPH); George Mason University, Fairfax, VA, USA (Prof K H Jacobsen PhD); UNFPA Asia and the Pacific Regional Office, Bangkok, Thailand (H A Jansen Drs); VA San Diego, University of California, San Diego, San Diego, CA, USA (S K Jassal MD); Virginia Commonwealth University, Richmond, VA, USA (Sudha Jayaraman MD); Centre for Chronic Disease Control, New Delhi, India (P Jeemon PhD, D Prabhakaran DM); Shanghai Children's Medical Center (Prof F Jiang PhD), Tianjin Centers for Disease Control and Prevention, Tianjin, China (Prof G Jiang MD); Shanghai Jiao Tong University School of Medicine, Shanghai, China (Prof M R Phillips MD); Department of Ophthalmology, Medical Faculty Mannheim, RuprechtKarls University Heidelberg, Mannheim, Germany (Prof J B Jonas MD); The National Institute of Public Health, Copenhagen, Denmark (Prof K Juel PhD); Zhongshan Hospital (J She MD), Fudan University, Shanghai, China (Prof H Kan MD); MARIKANI, Bamako, Mali (S S Kany Roseline MD); University of Balamand, Beirut, Lebanon (Prof N E Karam MD); Department of Epidemiology, Helmholtz Centre for Infection Research, Braunschweig, Germany (A Karch MD); Hannover-Braunschweig Site, German Center for Infection Research, Braunschweig, Germany (A Karch MD); Malaria and Other Parasitic Diseases Division, Ministry of Health, Kigali City, Rwanda (C K Karema MSc); All India Institute of Medical Sciences, New Delhi, India (Prof G Karthikeyan DM, Prof V K Paul MD, M Satpathy PhD, Prof N Tandon PhD); Oklahoma State University, Tulsa, OK, USA (A Kaul MD); University of California, San Francisco, San Francisco, CA, USA (D S Kazi MD); University of São Paulo, São Paulo, Brazil (Prof A H Kemp PhD, Prof P A Lotufo DrPH, Prof G V Polanczyk PhD, Prof I S Santos PhD); University of Sydney, Camperdown, NSW, Australia (Prof A H Kemp PhD); South African Medical Research Council, Cape Town, South Africa (A P Kengne PhD, R Matzopoulos PhD, Prof C D Parry PhD); Faculty of Health Sciences, Hatter Institute for Cardiovascular Research in Africa (Prof K Sliwa PhD), School of Public Health and Family Medicine (R Matzopoulos PhD), University of Cape Town, Cape Town, South Africa (A P Kengne PhD, Prof B M Mayosi DPhil, Prof D J Stein MD); Cardiology, Hadassah Ein Kerem University Hospital, Jerusalem, Israel (Prof A Keren MD); Jordan University of Science and Technology, Irbid, Jordan (Prof Y S Khader ScD); Supreme Council of Health, Doha, Qatar (S E Ali Hassan Khalifa MSc); Health Services Academy, Islamabad, Pakistan (E A Khan MD); Expanded Programme on Immunization, Islamabad, Pakistan (E A Khan MD); Seoul National University College of Medicine, Seoul, South Korea (Prof Y Khang MD); Federal University of Rio Grande do Sul, Porto Alegre, Brazil (C Kieling PhD); Northeastern University, Boston, MA, USA (Prof D Kim DrPH); Soonchunhyang University, Seoul, South Korea (Prof S Kim PhD); Southern University College, Johor, Malaysia (Y Kim PhD); Simmons College, Boston, MA, USA (R W Kimokoti MD); University of Canberra, Canberra, ACT, Australia (Y Kinfu PhD); University of Cincinnati, Cincinnati, OH, USA (Prof B M Kissela MD); National Cerebral and Cardiovascular Center, Suita, Japan (Y Kokubo PhD); Center for Community Empowerment, Health Policy and Humanities (S Kosen MD), National Institute of Health Research and Development, Ministry of Health Indonesia, Jakarta, Indonesia (T S Warouw PhD); Research Center of Neurology, Moscow, Russia (M Kravchenko PhD, Prof Y Y Varakin MD); Oregon Health and Science University, Portland, OR, USA (S Krishnaswami MD); University of Montreal, Montreal, QC, Canada (Prof B Kuate Defo PhD); Erasmus MC, University Medical Center Rotterdam, Rotterdam, Netherlands (Prof E J Kuipers PhD,

S Polinder MS); Rajrajeswari Medical College \& Hospital, Bangalore, India (Prof C Kulkarni MD); Arkansas State University, State University, AR, USA (V S Kulkarni PhD); Boston Medical Center, Boston, MA, USA (G F Kwan MD); Fourth View Consulting, Tallinn, Estonia (T Lai PhD); School of Dentistry and Oral Health, Griffith University, Gold Coast, QLD, Australia (Prof R Lalloo PhD); Australian Research Centre for Population Oral Health, School of Dentistry, University of Adelaide, Adelaide, SA, Australia (Prof R Lalloo PhD); Disability Prevention Research Centre (T Lallukka PhD), Finnish Institute of Occupational Health, Helsinki, Finland (R Shiri PhD); Faculty of Medicine, University of Helsinki, Helsinki, Finland (T Lallukka PhD); Institute of Health Policy and Development Studies, National Institutes of Health, Manila, Philippines (Prof H Lam PhD); National Cancer Institute, Rockville,
MD, USA (Q Lan PhD); Help Me See Inc, New York, NY, USA

(V C Lansingh PhD); Instituo Mexicano de Oftalmologia, Queretaro, Mexico (V C Lansingh PhD); Servicio de Neurologia, Clinica Alemana, Universidad del Desarrollo, Santiago, Chile (P M Lavados MD); Instituto Nacional de Epidemiología "Dr Juan H Jara”, Mar del Plata, Argentina (Prof A E Lawrynowicz MPH); Nova Southeastern University College of Optometry, Fort Lauderdale, FL, USA (J L Leasher OD); Korea University, Seoul, South Korea (Prof J Lee PhD, S Yoon PhD); Tuscany Regional Centre for Occupational Injuries and Diseases, Florence, Italy (M Levi MD); Anolinx LLC, Salt Lake City, UT, USA (Y Li PhD); National Office for Maternal and Child Health Surveillance, West China Second University Hospital, Sichuan University, Chengdu, China (Prof J Liang MD, Prof Y Wang BS, Prof J Zhu MD); Heart and Stroke Foundation Canada, Ottawa, ON, Canada (M P Lindsay PhD); Wayne State University, Miami, FL, USA (Prof S E Lipshultz MD); Eastern Health Clinical School, Monash University, Fitzroy, VIC, Australia (B K Lloyd PhD); Turning Point Alcohol and Drug Centre, Eastern Health, Fitzroy, VIC, Australia (B K Lloyd PhD, Prof R Room PhD); University of Bari, Bari, Italy (Prof G Logroscino PhD); American Cancer Society, Atlanta, GA, USA (J Lortet-Tieulent MSc); Aintree University Hospitals NHS Foundation Trust, Liverpool, UK

(Prof R Lunevicius PhD); Ministry of Health Singapore, Singapore (S Ma PhD, H P Phua MSc); Saw Swee Hock School of Public Health, National University of Singapore, Singapore (S Ma PhD); Centro Nacional Para la Prevención y Control del VIH/SIDA, Secretaría de Salud, Mexico City, Mexico (C Magis-Rodriguez PhD); King George's Medical University, Lucknow, India (Prof A A Mahdi PhD); Digestive Disease Research Institute, Shariati Hospital, Tehran, Iran (Prof R Malekzadeh MD); Shiraz University of Medical Sciences, Shiraz, Iran (Prof R Malekzadeh MD); Technical Standards and Safety Authority, Toronto, ON, Canada (S Mangalam MS); University of Zambia, Lusaka, Zambia (C C Mapoma PhD, F Masiye PhD); Botswana-Baylor Children's Clinical Centre of Excellence, Gaborone, Botswana (M Marape PhD); Queen Mary University of London, London, UK (Prof W Marcenes PhD); Pereleman School of Medicine (P A Meaney MD), University of Pennsylvania, Philadelphia, PA, USA (D J Margolis PhD, D H Silberberg MD); Dalhousie University, Halifax, NS, Canada (Prof R V Martin PhD); University of the East Ramon Magsaysay Memorial Medical Center, Quezon City, Philippines (M B Marzan MSc); Ministry of Public Health, Kabul, Afghanistan (M T Mashal PhD); University of York, York, UK (A J Mason-Jones PhD); Automotive Industry Development Centre Eastern Cape, Port Elizabeth, South Africa (T T Mazorodze MA); EmergentCorp, Belize City, Belize (A C McKay PhD); Children's Hospital of Philadelphia, Philadelphia, PA, USA (P A Meaney MD); Janakpuri Superspecialty Hospital, New Delhi, India (Prof M Mehndiratta DM); Thomas Jefferson University, Philadelphia, PA, USA (M Meltzer MD); United Nations Population Fund, Lima, Peru (W Mendoza MD); Department of Neurology, Helsinki University Central Hospital, Helsinki, Finland (A Meretoja PhD); Ifakara Health Institute, Bagamoyo, Tanzania (F Apolinary Mhimbira MS); Pacific Institute for Research \& Evaluation, Calverton, MD, USA (T R Miller PhD); Curtin University Centre for Population Health, Perth, WA, Australia (T R Miller PhD); University of Ottawa, Ottawa, ON, Canada (E J Mills PhD); Population Education Resource Centre, Department of Continuing and Adult Education and Extension Work, SNDT Women's University, Mumbai, India (S Mishra PhD); Department of Medicine, Universiti Kebangsaan Malaysia Medical Centre, Bandar Tun Razak, Malaysia (Prof N Mohamed Ibrahim MRCP); University of Salahaddin, Erbil, Iraq (K A Mohammad PhD); University of Papua New Guinea, Boroko, Papua New Guinea (Prof G L Mola MD); Institute for Maternal and Child Health, IRCCS “Burlo Garofolo", Trieste, Italy (L Monasta DSc, M Montico MSc, L Ronfani PhD); University of North Texas, Denton, TX, USA (Prof A R Moore PhD); International Laboratory for Air Quality and Health (Prof L Morawska PhD), Institute of Health and Biomedical Innovation (R E Norman PhD), Queensland University of Technology, Brisbane, QLD, Australia; National Center for Child Health and Development, Setagaya, Japan (R Mori PhD); Department of Medicine (Prof M Tsilimbaris PhD), University of Crete, Heraklion, Greece (J Moschandreas PhD); Egerton University, Egerton, Kenya (W N Moturi PhD); Competence Center Mortality-Follow-Up of the German National Cohort (A Werdecker Dipl.oec.troph.); Federal 
Institute for Population Research, Wiesbaden, Germany

(Prof U O Mueller PhD, R Westerman PhD); Okinawa Chubu Hospital, Okinawa, Japan (M Mukaigawara MD); American University of Beirut Medical Center, Beirut, Lebanon (Prof Z Nahas MD); University of KwaZulu-Natal, Durban, South Africa (Prof K S Naidoo PhD); Azienda Ospedaliera Papa Giovanni XXIII, Bergamo, Italy (Prof L Naldi MD); Ministry of Health, Suva, Fiji (D Nand MPH); Suraj Eye Institute, Nagpur, India (Prof V Nangia MD); The George Institute for Global Health, Sydney, NSW, Australia (B Neal PhD); Faculty of Medicine, Fez, Morocco (Prof C Nejjari PhD); University of Oslo, Oslo, Norway (S P Neupane PhD); Kilifi, Kenya (Prof C R Newton MD); Ministry of Health and Social Welfare, Dar es Salaam, Tanzania (F N Ngalesoni MSc); East African Community Health Research Commission, Kigali, Rwanda (J D Ngirabega PhD); Hospital Universitari de Bellvitge, L'Hospitalet, Spain (J M Nolla PhD); Deakin University, Melbourne, VIC, Australia (S Nolte PhD); Department of Global Public Health and Primary Care (Prof S E Vollset MD), University of Bergen, Bergen, Norway (Prof O F Norheim PhD); Department of Clinical Sciences, Lund University, Lund, Sweden (Prof B Norrving PhD); Makerere University, Kampala, Uganda (L Nyakarahuka MPH); Kyung Hee University, Seoul, South Korea (Prof I Oh PhD); Teikyo University School of Medicine, Tokyo, Japan (Prof T Ohkubo MD); Center for Healthy Start Initiative, Ikoyi, Nigeria (B O Olusanya PhD); Lira District Local Government, Lira Municipal Council, Uganda (J N Opio MPH); United Laboratories Inc, Mandaluyong City, Philippines (R S Pagcatipunan Jr MD); Christian Medical College Ludhiana, Ludhiana, India (J D Pandian DM); Kosin University College of Medicine, Busan, South Korea (E Park PhD); Unit on Anxiety \& Stress Disorders (Prof D J Stein MD), South African Medical Research Council, Cape Town, South Africa (Prof C D Parry PhD); Stellenbosch University, Cape Town, South Africa (Prof C D Parry PhD, Prof S Seedat PhD); Independent Researcher, Boroko, Papua New Guinea (B I Pavlin MD); Economics Institute, Belgrade, Serbia (L Pejin Stokic MSc); REQUIMTE/LAQV, Laboratório de Farmacognosia, Departamento de Química, Faculdade de Farmácia, Universidade do Porto, Porto, Portugal (Prof D M Pereira PhD); National Institute of Respiratory Diseases, Mexico City, Mexico (Prof R Perez-Padilla MD); Hopsital Universitario Cruces, OSI EE-Cruces, Baracaldo, Spain (F Perez-Ruiz PhD); Biocruces Health Research Institute, Baracaldo, Spain (F Perez-Ruiz PhD); IRCCS Mario Negri Institute for Pharmacological Research, Bergamo, Italy (N Perico MD, Prof G Remuzzi MD, M Trillini MD); Washington State Department of Health, Kent, WA, USA (S A L Perry MSCE); Postgraduate Medical Institute, Lahore, Pakistan (A Pervaiz MHA); Flinders University, Adelaide, SA, Australia (Prof K Pesudovs PhD); Aalborg University, Aalborg Esst, Denmark (C B Peterson PhD); Health Metrics Unit, Gothenburg, Sweden (Prof M Petzold PhD);

The University of the Witwatersrand, Johannesburg, South Africa (Prof M Petzold PhD); Emory University, Atlanta, GA, USA (Prof M R Phillips MD); Section Exposure Assessment and Environmental Health Indicators, Federal Environment Agency, Berlin, Germany (D Plass Dr PH); Montreal Children's Hospital, McGill University, Montreal, QC, Canada (Prof D Poenaru MD); MyungSung Medical College, Addis Ababa, Ethiopia (Prof D Poenaru MD); University of Newcastle, Callaghan, NSW, Australia (Prof C D Pond PhD); Brigham Young University, Provo, UT, USA (Prof C Pope PhD); Centre for Addiction and Mental Health, Toronto, ON, Canada (S Popova PhD, Prof J Rehm PhD); The Fred Hollows Foundation, Sydney, NSW, Australia (N M Prasad DO); College of Pharmacy, University of Illinois, Chicago, IL, USA (D M Qato PhD); Contech International Health Consultants, Lahore, Pakistan (A Rafay MS, Prof S M Rana PhD); Contech School of Public Health, Lahore, Pakistan (A Rafay MS, Prof S M Rana PhD); Hamad Medical Corporation, Doha, Qatar (S Ur Rahman FCPS); University of Missouri, Columbia, MO, USA (M Raju PhD); WHO Regional Office for Europe, Copenhagen, Denmark (I Rakovac PhD); Warren Alpert Medical School, Brown University, Providence, RI, USA (M Rao BA); Center for Disease Analysis, Louisville, CO, USA (H Razavi PHD); Suez Canal University, Ismailia, Egypt (Prof A H Refaat PhD); Hospital das Clinica (Prof A L Ribeiro PhD), Escola de Enfermagem (Prof G Velasquez-Melendez PhD), Universidade Federal de Minas Gerais, Belo Horizonte, Brazil, Department of Clinical Neurological
Sciences, London Health Sciences Centre, University of Western Ontario, London, ON, Canada (P M Riccio MD, L A Sposato MD); George Washington University, Washington, DC, USA (A Riederer DSc); MRC Unit, Fajara, The Gambia (A Roca PhD); Mid Sweden University, Stersund, Sweden (Prof A Rodriguez PhD); International Agency for Research on Cancer, WHO, Lyon, France (I Romieu ScD, K Straif PhD); BARC Hospital, HBNI University, Mumbai, India (N Roy MD); Muhimbili University of Health and Allied Sciences, Dar es Salaam, Tanzania (G M Ruhago MA, B F Sunguya MSc); Miller School of Medicine, University of Miami, Miami, FL, USA (R L Sacco MD); Queensland Centre for Mental Health Research, The Park Centre for Mental Health, Brisbane, QLD, Australia (S Saha PhD); Universiti Kebangsaan Malaysia Medical Centre, Kuala Lumpur, Malaysia (R Sahathevan PhD); Calvary Healthcare Bruce, Canberra, ACT, Australia (R Sahathevan PhD); Case Western Reserve University, Cleveland, OH, USA (J R Sanabria MD); Cancer Treatment Centers of America-RFU Chicago Medical School, North Chicago, IL, USA (J R Sanabria MD); Centre on Ageing and Mobility, University of Zurich and City Hospital Waid, Zurich, Switzerland (L Sanchez-Riera PhD); School of Public Health, University of Maryland, College Park, MD, USA (A Sapkota PhD); Dartmouth Hitchcock Medical Center (J E Saunders MD), Dartmouth College, Lebanon, NH, USA (S Soneji PhD); Marshall University, Huntington, WV, USA (M Sawhney PhD); Novartis Turkey, Istanbul, Turkey (M I Saylan PhD); Federal University of Santa Catarina, Florianópolis, Brazil (I J C Schneider PhD); University of Alabama at Birmingham, Birmingham, AL, USA (D C Schwebel PhD, J A Singh MD); University of Colorado, Aurora, CO, USA (B Serdar PhD); University of Bath, Bath, UK (G Shaddick PhD); University of Pittsburgh Medical Center, Pittsburgh, PA, USA (S Shangguan MD); Tachikawa Hospital, Tokyo, Japan (Y Shinohara PhD); School of Health Sciences, University of Tampere, Tampere, Finland (R Shiri PhD); Washington State University, Spokane, WA, USA (K Shishani PhD); Health and Life Sciences, Northumbria University, Newcastle upon Tyne, UK (I Shiue PhD); Alzheimer's Scotland Dementia Research Centre, University of Edinburgh, Edinburgh, Scotland, UK (I Shiue PhD); Reykjavik University, Reykjavik, Iceland (I D Sigfusdottir PhD); International Institute for Population Sciences, Mumbai, India (A Singh PhD); Stavanger University Hospital, Stavanger, Norway (K Søreide PhD); Faculty of Medicine and Health Sciences, Universiti Tunku Abdul Rahman, Kajang, Cheras, Malaysia (C T Sreeramareddy MPH); Griffith University, Southport, QLD, Australia (N J C Stapelberg FRANZCP); Attikon University Hospital, Athens, Greece (V Stathopoulou PhD); University Hospital Munich, Institute and Outpatient Clinic for Occupational, Social and Environmental Medicine, Munich, Germany (N Steckling MSc); Alexandra General Hospital of Athens, Athens, Greece (K Stroumpoulis PhD); Centre Hospitalier Public du Cotentin, Cherbourg, France (K Stroumpoulis PhD); National Institute for Research in Tuberculosis, Chennai, India (S Swaminathan MD); Northwestern University, Chicago, IL, USA (M Swaroop MD, Dr Y Yano MD); University of California, Irvine, CA, USA (Prof B L Sykes PhD); University of Illinois at Urbana-Champaign, Champaign, IL, USA (K M Tabb PhD); Ministry of Health, MINSANTE, Yaounde, Cameroon (R T Talongwa); Chaim Sheba Medical Center, Tel Hashomer, Israel (Prof D Tanne MD); Tel Aviv University, Tel Aviv, Israel (Prof D Tanne MD); Westchester Medical Center, Valhalla, NY, USA (M Tavakkoli MD); Outcomes Research Consortium, Cleveland, $\mathrm{OH}$ USA (A S Terkawi MD); Department of Anesthesiology, King Fahad Medical City, Riyadh, Saudi Arabia (A S Terkawi MD); New South Wales Health, North Sydney, NSW, Australia (S V Thackway MPH); Nelson Institute of Environmental Medicine, School of Medicine, New York University, Tuxedo, NY, USA (Prof G D Thurston ScD); Aristotle University of Thessaloniki, Thessaloniki, Greece (Prof F Topouzis PhD); Le Bonheur Children's Hospital, Memphis, TN, USA

(Prof J A Towbin MD); University of Tennessee Health Science Center, Memphis, TN, USA (Prof J A Towbin MD); Health Care Center of Anjo Kosei Hospital, Anjo City, Japan (H Toyoshima MD); University of Southern Santa Catarina, Palhoça, Brazil (Prof J Traebert PhD); Hanoi Medical University, Hanoi, Vietnam (B X Tran PhD); Servicio Canario de Salud, Santa Cruz de Tenerife, Spain (U Trujillo MD); Department of Population Sciences and Development, Faculty of Economics and 
Management, University of Kinshasa, Kinshasa, DR Congo (Z Tsala Dimbuene PhD); Cleveland Clinic, Cleveland, OH, USA (Prof E Tuzcu MD); Department of Veterans Affairs, Washington, DC, USA (U S Uchendu MD); Department of Internal Medicine, Federal Teaching Hospital, Abakaliki, Nigeria (K N Ukwaja MD); European Commission, Joint Research Centre, Ispra, Italy (R Van Dingenen $\mathrm{PhD}$ ); National Institute for Public Health and the Environment, Bilthoven, Netherlands (C H van Gool PhD); Maastricht University Medical Centre, Maastricht, Netherlands (Prof J van Os PhD); UKK Institute for Health Promotion Research, Tampere, Finland (Prof T J Vasankari PhD); Universidade de Brasilia, Brasilia, Brazil (Prof A N Vasconcelos PhD); VHS SNEHA, Chennai, India (Prof L Vijayakumar PhD); University of Bologna, Bologna, Italy (Prof F S Violante MD); Higher School of Economics, Moscow, Russia (Prof V Victorovich Vlassov MD); Nationa Institute for Occupational Safety and Health, Washington, DC, USA (G R Wagner MD); Uniformed Services University of Health Sciences, Bethesda, MD, USA (Prof S G Waller MD); Neurology Department, Georgetown University, Arlington, VA, USA (M T Wallin MD); VA Medical Center, Washington, DC, USA (M T Wallin MD); Beijing Neurosurgical Institute, Beijing, China (Prof W Wang MD); Murdoch Children's Research Institute, Royal Children's Hospital, Melbourne, VIC, Australia (R G Weintraub MB, BS); University of California, Davis, CA, USA (K Wessells PhD); German National Cohort Consortium, Heidelberg, Germany (R Westerman PhD); Wayne State University, Detroit, MI, USA (Prof J D Wilkinson MD); University of Nottingham, Nottingham, UK (Prof H C Williams PhD); Institute of Public Health, University of Gondar, Gondar, Ethiopia (S M Woldeyohannes MPH); Ateneo School of Medicine and Public Health, Manila University, Pasig City, Philippines (J Q Wong MD); Royal Cornwall Hospital, Truro, Cornwall, UK (Prof A D Woolf FRCP); Jinling Hospital, Nanjing University School of Medicine, Nanjing, China (Prof G Xu PhD); Duke Kunshan University, Kunshan, China (Prof L L Yan PhD); Peking Union Medical College, Beijing, China (Prof G Yang MD); Jichi Medical School, Tochigi, Japan (Y Yano MD); The University of Hong Kong, Hong Kong, China (Prof P Yip PhD); National Center of Neurology and Psychiatry, Kodaira, Japan (N Yonemoto MPH), Jackson State University, Jackson, MS (Prof M Z Younis PhD); Université de Niamey, Niamey, Niger (Z Younoussi PhD); Department of Epidemiology and Biostatistics, School of Public Health, Wuhan, China (Prof C Yu PhD); Global Health Institute, Wuhan University, Wuhan, China (Prof C Yu PhD); Mansoura Faculty of Medicine, Mansoura, Egypt (Prof M E Zaki MD); Chongqing Medical University, Chongqing, China (Prof Y Zhao MSc); and Zhejiang University School of Public Health, Hangzhou, China (Prof S Zhu PhD).

\section{Contributors}

MHF, CJLM, TV, and ADL prepared the first draft. MHF and CJLM finalised the draft based on comments from other authors and reviewer feedback. All other authors provided data, developed models, analysed data, reviewed results, provided guidance on methodology, and/or reviewed the manuscript.

\section{Declarations of interest}

RA-C has been employed by GSK, activities not related to this manuscript. JP is supported by a career development fellowship from the Wellcome Trust, Public Health Foundation of India, and a consortium of UK Universities. CK receives research grants from Brazilian public funding agencies Conselho Nacional de Desenvolvimento Científico e Tecnológico (CNPq), Coordenação de Aperfeiçoamento de Pessoal de Nível Superior (CAPES), and Fundação de Amparo à Pesquisa do Estado do Rio Grande do Sul (FAPERGS). He has also received authorship royalties from publishers Artmed and Manole. RSP Jr has been medical director for United Laboratories Consumer Health Division-United Laboratories Inc. GVP is employed by University of Sao Paulo and receives research support from the National Council for Scientific and Technological Development (CNPq), the São Paulo Research Foundation (FAPESP), Grand Challenges Canada, Fundacao Maria Cecilia Souto Vidigal, and the University of Sao Paulo. He has served as a consultant and speaker to Shire and has received royalties from Manole Editors. HJL, in addition to grant funding from the Bill \& Melinda Gates Foundation, EU, WHO and Novartis, has done some consulting for GSK and on the Merck Vaccines Global Strategic Advisory Boardm outside of this report. All other authors declare no competing interests.

\section{Acknowledgments}

We thank the countless individuals who have contributed to the Global Burden of Disease Study 2013 in various capacities. We acknowledge the extensive support from all staff members at the Institute for Health Metrics and Evaluation and specifically thank James Bullard, Serkan Yalcin, Evan Laurie, Andrew Ernst, Elizabeth Roberts, and Peter Speyer for their tireless support of the computational infrastructure required to produce the results and production of visualisations to review the results; Abigail McLain for her guidance on organising data; Caitlyn Steiner for her management of the GBD estimation; Adrienne Chew for her editorial assistance; Kelsey Pierce for her valuable guidance; and Linda A Ettinger for her expert executive support. We would also like to thank Ivan Ivanov for his contributions. The following individuals acknowledge various forms of institutional support: HC is supported by the Intramural Program of the NIH, the National Institute of Environmental Health Science; KD is supported by a Wellcome Trust Research Training Fellowship (grant number 099876)]; KBG received the NHMRC-Gustav Nossal scholarship sponsored by CSL 2015 (his award is peer-reviewed through the standard NHMRC peerreview process; CSL played no part in selection of the awardee); HH's contribution of this effort was partially supported by NIH ROI ES021446; NK received funding from the Japan Society for the Promotion of Science (JSPS) KAKENHI (grant number 25253045); YK would like to thank the National Heart Foundation of Australia for its financial support for work on modelling cardiovascular disease and risk factors at the University of Canberra; SJL is supported in part by the Intramural Research Program of the NIH, National Institute of Environmental Health Sciences; KM reports personal fees from Mitsubishi Tanabe Pharma, Kyowa Hakko Kirin, and MSD outside the submitted work; WM is program analyst at the UNFPA country office in Peru, which does not necessarily endorse the study; FC-L is partially supported by the PROMETEOII 2015 program/Conselleria d'Educació, Investigació, Cultura i Esport, Generalitat Valenciana and the CIBERSAM/Institute of Health Carlos III, Spanish Ministry of Science and Innovation; DM reports ad-hoc honoraria or consulting from Bunge, Haas Avocado Board, Nutrition Impact, Amarin, Astra Zeneca, Boston Heart Diagnostics, and Life Sciences Research Organization; and is on the scientific advisory board for Unilever North America; UM gratefully acknowledges funding from the German National Cohort Consortium; $\mathrm{CDP}$, in the past 3 years has received consultancy payments from Pfizer and from Nutricia; DAQ was supported by The Eunice Kennedy Shriver National Institute of Child Health and Human Development of the National Institutes of Health under award number 5T32HD057822; KR was funded by the UK NIHR Oxford BRC and NIHR CDF; IR is required to include the following statement: The authors alone are responsible for the views expressed in this Article and they do not necessarily represent the views, decisions or policies of the institutions with which they are affiliated; JR received additional funding from the WHO for the work on alcohol as a risk factor; SS received a research support grant from NIH and the National Research Foundation and has received pharmaceutical sponsorship from Pfizer, AstraZeneca, Servier, and Dr Reddy's, speakers honoraria from Pfizer and Lundbeck, and honoraria from the Discovery Foundation and Cambridge University Press; DJS, in the past 3 years, has received research grants and/or consultancy honoraria from AMBRF, Biocodex, Cipla, Lundbeck, National Responsible Gambling Foundation, Novartis, Servier, and Sun; AGT acknowledges a senior research fellowship from the National Health \& Medical Research Council (Australia; 1042600); and GDT was supported by a Center Grant from the National Institutes of Environmental Health Sciences (ES00260).

\section{References}

1 Lim SS, Vos T, Flaxman AD, et al. A comparative risk assessment of burden of disease and injury attributable to 67 risk factors and risk factor clusters in 21 regions, 1990-2010: a systematic analysis for the Global Burden of Disease Study 2010. Lancet 2012; 380: 2224-60.

2 Watts C, Cairncross S. Should the GBD risk factor rankings be used to guide policy? Lancet 2012; 380: 2060-61.

3 Kim JY. Data for better health—and to help end poverty. Lancet 2012; 380: 2055.

4 Chan M. From new estimates to better data. Lancet 2012; 380: 2054. 
5 Rehm J, Borges G, Gmel G, et al. The comparative risk assessment for alcohol as part of the Global Burden of Disease 2010 Study: what changed from the last study? Int J Alcohol Drug Res 2013; 2: 1-5.

6 Hawkes S, Buse K. Gender and global health: evidence, policy, and inconvenient truths. Lancet 2013; 381: 1783-87.

7 Clasen T, Pruss-Ustun A, Mathers CD, Cumming O, Cairncross S, Colford JM Jr. Estimating the impact of unsafe water, sanitation and hygiene on the global burden of disease: evolving and alternative methods. Trop Med Int Health 2014; 19: 884-93.

8 Dye C, Raviglione M. Perspective: weigh all TB risks. Nature 2013; 502: S13.

9 Bonjour S, Adair-Rohani H, Wolf J, et al. Solid fuel use for household cooking: country and regional estimates for 1980-2010. Environ Health Perspect 2013; 121: 784-90.

10 Abrams DI. Milking the evidence: diet does matter. J Clin Oncol 2014; 32: 2290-92.

11 Freeman MC, Stocks ME, Cumming O, et al. Hygiene and health systematic review of handwashing practices worldwide and update of health effects. Trop Med Int Health 2014; 19: 906-16.

12 Wolf J, Prüss-Ustün A, Cumming $\mathrm{O}$, et al. Assessing the impact of drinking water and sanitation on diarrhoeal disease in low- and middle-income settings: systematic review and meta-regression. Trop Med Int Health 2014; 19: 928-42.

13 Aune D, Norat T, Romundstad P, Vatten LJ. Whole grain and refined grain consumption and the risk of type 2 diabetes: a systematic review and dose-response meta-analysis of cohort studies. Eur J Epidemiol 2013; 28: 845-58.

14 Afshin A, Micha R, Khatibzadeh S, Mozaffarian D. Consumption of nuts and legumes and risk of incident ischemic heart disease, stroke, and diabetes: a systematic review and meta-analysis. Am J Clin Nutr 2014; 100: 278-88.

15 Farvid MS, Ding M, Pan A, et al. Dietary linoleic acid and risk of coronary heart disease: a systematic review and meta-analysis of prospective cohort studies. Circulation 2014; 130: 1568-78.

16 Vander Hoorn S, Ezzati M, Rodger A, Lopez A, Murray CJ. Estimating attributable burden of disease from exposure an hazard data. In: Comparative quantification of health risks: global and regional burden of disease attributable to selected major risk factors. Geneva: World Health Organization, 2004

17 Murray CJ, Lopez AD. On the comparable quantification of health risks: lessons from the Global Burden of Disease Study. Epidemiology 1999; 10: 594-605.

18 GBD 2013 Mortality and Causes of Death Collaborators. Global, regional, and national age-sex specific all-cause and cause-specific mortality for 240 causes of death, 1990-2013: a systematic analysis for the Global Burden of Disease Study 2013. Lancet 2015; 385: 117-71.

19 Global Burden of Disease Study 2013 Collaborators. Global, regional, and national incidence, prevalence, and years lived with disability for 301 acute and chronic diseases and injuries in 188 countries, 1990-2013: a systematic analysis for the Global Burden of Disease Study 2013. Lancet 2015; published online June 7. DOI:10.1016/S0140-6736(15)60692-4.

$20 \mathrm{Ng}$ M, Freeman MK, Fleming TD, et al. Smoking prevalence and cigarette consumption in 187 countries, 1980-2012. JAMA 2014; 311: 183-92.

21 Ng M, Fleming T, Robinson M, et al. Global, regional, and national prevalence of overweight and obesity in children and adults during 1980-2013: a systematic analysis for the Global Burden of Disease Study 2013. Lancet 2014; 384: 766-81.

22 Brauer M, Amann M, Burnett RT, et al. Exposure assessment for estimation of the global burden of disease attributable to outdoor air pollution. Environ Sci Technol 2012; 46: 652-60.

23 Peto R, Lopez AD, Boreham J, Thun M, Heath C Jr. Mortality from tobacco in developed countries: indirect estimation from national vital statistics. Lancet 1992; 339: 1268-78.

24 Rehm J, Kehoe T, Gmel G, Stinson F, Grant B, Gmel G. Statistical modeling of volume of alcohol exposure for epidemiological studies of population health: the US example. Popul Health Metr 2010; 8: 3.

25 Cook RJ, Brumback BB, Wigg MB, Ryan LM. Synthesis of evidence from epidemiological studies with interval-censored exposure due to grouping. Biometrics 2001; 57: 671-80.

26 Brumback BA, Cook RJ, Ryan LM. A meta-analysis of case-control and cohort studies with interval-censored exposure data: application to chorionic villus sampling. Biostatistics 2000; 1: 203-17.
27 Hartemink N, Boshuizen HC, Nagelkerke NJD, Jacobs MAM, van Houwelingen HC. Combining risk estimates from observational studies with different exposure cutpoints: a meta-analysis on body mass index and diabetes type 2. Am J Epidemiol 2006; 163: 1042-52.

28 Lewington S, Clarke R, Qizilbash N, Peto R, Collins R, and the Prospective Studies Collaboration. Age-specific relevance of usua blood pressure to vascular mortality: a meta-analysis of individua data for one million adults in 61 prospective studies. Lancet 2002; 360: 1903-13.

29 Olofin I, McDonald CM, Ezzati M, et al, and the Nutrition Impact Model Study. (anthropometry cohort pooling). Associations of suboptimal growth with all-cause and cause-specific mortality in children under five years: a pooled analysis of ten prospective studies. PLoS One 2013; 8: e64636.

30 Olofin I, McDonald CM, Ezzati M, et al. Associations of suboptima growth with all-cause and cause-specific mortality in children unde five years: a pooled analysis of ten prospective studies. PLoS One 2013; 8: e64636.

31 Burnett RT, Pope CA 3rd, Ezzati M, et al. An integrated risk function for estimating the Global Burden of Disease attributable to ambient fine particulate matter exposure. Environ Health Perspect 2014; 122: 397-403.

32 Doll R, Peto R, Wheatley K, Gray R, Sutherland I. Mortality in relation to smoking: 40 years' observations on male British doctors. BMJ 1994; 309: 901-11.

33 Doll R, Peto R, Boreham J, Sutherland I. Mortality in relation to smoking: 50 years' observations on male British doctors. BMJ 2004 328: 1519.

34 Villeneuve PJ, Johnson KC, Kreiger N, Mao Y, and the Canadian Cancer Registries Epidemiology Research Group. Risk factors for prostate cancer: results from the Canadian National Enhanced Cancer Surveillance System. Cancer Causes Control 1999; 10: 355-67.

35 Crouse DL, Peters PA, van Donkelaar A, et al. Risk of nonaccidental and cardiovascular mortality in relation to long-term exposure to low concentrations of fine particulate matter: a Canadian national-level cohort study. Environ Health Perspect 2012; 120: 708-14.

36 Alavanja MC, Sandler DP, McMaster SB, et al. The Agricultura Health Study. Environ Health Perspect 1996; 104: 362-69.

37 Carey IM, Atkinson RW, Kent AJ, van Staa T, Cook DG Anderson HR. Mortality associations with long-term exposure to outdoor air pollution in a national English cohort. Am J Respir Crit Care Med 2013; 187: 1226-33.

38 Katanoda K, Sobue T, Satoh H, et al. An association between long-term exposure to ambient air pollution and mortality from lung cancer and respiratory diseases in Japan. J Epidemiol 2011; 21: 132-43.

39 Hystad P, Demers PA, Johnson KC, Carpiano RM, Brauer M. Long-term residential exposure to air pollution and lung cancer risk. Epidemiology 2013; 24: 762-72.

40 Navas-Acien A, Schwartz BS, Rothenberg SJ, Hu H, Silbergeld EK, Guallar E. Bone lead levels and blood pressure endpoints: a metaanalysis. Epidemiology 2008; 19: 496-504.

41 Mozaffarian D, Hao T, Rimm EB, Willett WC, Hu FB. Changes in diet and lifestyle and long-term weight gain in women and men. N Engl J Med 2011; 364: 2392-404.

42 Mozaffarian D, Fahimi S, Singh GM, et al, and the Global Burden of Diseases Nutrition and Chronic Diseases Expert Group. Global sodium consumption and death from cardiovascular causes. N Engl J Med 2014; 371: 624-34.

43 Bagnardi V, Zatonski W, Scotti L, La Vecchia C, Corrao G. Does drinking pattern modify the effect of alcohol on the risk of coronary heart disease? Evidence from a meta-analysis. J Epidemiol Community Health 2008; 62: 615-19.

44 Ronksley PE, Brien SE, Turner BJ, Mukamal KJ, Ghali WA Association of alcohol consumption with selected cardiovascular disease outcomes: a systematic review and meta-analysis. BMJ 2011 342: d671.

45 Bhaskaran K, Douglas I, Forbes H, dos-Santos-Silva I, Leon DA, Smeeth L. Body-mass index and risk of 22 specific cancers: a population-based cohort study of $5 \cdot 24$ million UK adults. Lancet 2014; 384: 755-65.

46 Renehan AG, Tyson M, Egger M, Heller RF, Zwahlen M. Body-mass index and incidence of cancer: a systematic review and meta-analysis of prospective observational studies. Lancet 2008; 371: 569-78. 
47 He FJ, Li J, Macgregor GA. Effect of longer term modest salt reduction on blood pressure: Cochrane systematic review and meta-analysis of randomised trials. BMJ 2013; 346: f1325

48 Institute of Medicine of the National Academies. Sodium intake in populations: assessment of evidence. May 14, 2013. http://www.iom. edu/Reports/2013/Sodium-Intake-in-Populations-Assessment-ofEvidence.aspx (accessed Jan 26, 2015).

49 O'Donnell M, Mente A, Rangarajan S, et al, and the PURE Investigators. Urinary sodium and potassium excretion, mortality, and cardiovascular events. N Engl J Med 2014; 371: 612-23.

50 Preston $\mathrm{SH}$. Causes and consequences of mortality declines in less developed countries during the Twentieth Century. In: Population and economic change in developing countries. Chicago: University of Chicago Press, 1980: 289-360.

51 Rhodes HG. Measuring the risks and causes of premature death: summary of a workshop. http://www.nap.edu/catalog/21656/ measuring-the-risks-and-causes-of-premature-death-summary-of (accessed Jan 28, 2015).

52 Lu Y, Hajifathalian K, Ezzati M, Woodward M, Rimm EB, Danaei G, and the Global Burden of Metabolic Risk Factors for Chronic Diseases Collaboration. (BMI Mediated Effects). Metabolic mediators of the effects of body-mass index, overweight, and obesity on coronary heart disease and stroke: a pooled analysis of 97 prospective cohorts with 1.8 million participants. Lancet 2014; 383: 970-83.

53 Patel SR, Malhotra A, Gao X, Hu FB, Neuman MI, Fawzi W/W. A prospective study of sleep duration and pneumonia risk in women. Sleep 2012; 35: 97-101.

54 Saint-Jacques N, Parker L, Brown P, Dummer TJ. Arsenic in drinking water and urinary tract cancers: a systematic review of 30 years of epidemiological evidence. Environ Health 2014; 13: 44.

55 Naveedullah, Hashmi MZ, Yu C, et al. Risk assessment of heavy metals pollution in agricultural soils of siling reservoir watershed in Zhejiang province, China. Biomed Res Int 2013; 2013: 590306.

56 Laatikainen T, Critchley J, Vartiainen E, Salomaa V, Ketonen M, Capewell S. Explaining the decline in coronary heart disease mortality in Finland between 1982 and 1997. Am J Epidemiol 2005; 162: 764-73.

57 Ford ES, Ajani UA, Croft JB, et al. Explaining the decrease in US deaths from coronary disease, 1980-2000. N Engl J Med 2007; 356: 2388-98.

58 Unal B, Critchley JA, Capewell S. Explaining the decline in coronary heart disease mortality in England and Wales between 1981 and 2000. Circulation 2004; 109: 1101-07.

59 Jackson CL, Hu FB. Long-term associations of nut consumption with body weight and obesity. Am J Clin Nutr 2014; 100: 408-11S.

60 Rouhani MH, Salehi-Abargouei A, Surkan PJ, Azadbakht L. Is there a relationship between red or processed meat intake and obesity? A systematic review and meta-analysis of observational studies. Obes Rev 2014; 15: 740-48.

61 Guasch-Ferré M, Bulló M, Martínez-González MÁ, et al, and the PREDIMED study group. Frequency of nut consumption and mortality risk in the PREDIMED nutrition intervention trial. BMC Med 2013; 11: 164

62 Estruch R, Ros E, Salas-Salvadó J, et al, and the PREDIMED Study Investigators. Primary prevention of cardiovascular disease with a Mediterranean diet. N Engl J Med 2013; 368: 1279-90.

63 Hébert JR, Hurley TG, Steck SE, et al. Considering the value of dietary assessment data in informing nutrition-related health policy. Adv Nutr 2014; 5: 447-55.

64 Ioannidis JPA. Implausible results in human nutrition research. BMJ 2013; 347: f6698.

65 Mente A, O'Donnell MJ, Yusuf S. The population risks of dietary salt excess are exaggerated. Can J Cardiol 2014; 30: 507-12.

66 Batuman V. Sodium and Cardiovascular Disease. N Engl J Med 2014; 371: 2134-39.

67 He FJ, MacGregor GA. A comprehensive review on salt and health and current experience of worldwide salt reduction programmes. J Hum Hypertens 2009; 23: 363-84.

68 Cobiac LJ, Vos T, Veerman JL. Cost-effectiveness of interventions to reduce dietary salt intake. Heart 2010; 96: 1920-25.
69 Zhao X, Yin X, Li X, et al. Using a low-sodium, high-potassium salt substitute to reduce blood pressure among Tibetans with high blood pressure: a patient-blinded randomized controlled trial. PLoS One 2014; 9: e110131.

70 China Salt Substitute Study Collaborative Group. Salt substitution: a low-cost strategy for blood pressure control among rural Chinese. A randomized, controlled trial. J Hypertens 2007; 25: 2011-18.

71 Pope CA 3rd, Cropper M, Coggins J, Cohen A. Health benefits of air pollution abatement policy: role of the shape of the concentration-response function. J Air Waste Manag Assoc 2015; 65: 516-22.

72 Banks E, Joshy G, Weber MF, et al. Tobacco smoking and all-cause mortality in a large Australian cohort study: findings from a mature epidemic with current low smoking prevalence. BMC Med 2015 13: 38 .

73 Bloomberg Philanthropies. Accelerating the worldwide movement to reduce tobacco use, 2011. http://www.bloomberg.org/content/ uploads/sites/2/2014/04/BloombergPhilanthropies2011TobaccoReport. pdf (accessed April 10, 2014).

74 WHO. MPOWER: A policy package to reverse the tobacco epidemic Geneva: World Health Organization, 2008. http://www.who.int/ tobacco/mpower/mpower_english.pdf (accessed April 10, 2014).

75 WHO. Global status report on alcohol and health 2014. Geneva: World Health Organization, 2014.

76 Flegal KM, Kit BK, Orpana H, Graubard BI. Association of all-cause mortality with overweight and obesity using standard body mass index categories: a systematic review and meta-analysis. JAMA 2013; 309: 71-82.

77 Whitlock G, Lewington S, Sherliker P, et al, and the Prospective Studies Collaboration. Body-mass index and cause-specific mortality in 900000 adults: collaborative analyses of 57 prospective studies. Lancet 2009; 373: 1083-96.

78 Masters RK, Powers DA, Link BG. Obesity and US mortality risk over the adult life course. Am J Epidemiol 2013; 177: 431-42.

79 Masters RK, Reither EN, Powers DA, Yang YC, Burger AE, Link BG. The impact of obesity on US mortality levels: the importance of age and cohort factors in population estimates. Am J Public Health 2013; 103: $1895-901$

80 Stokes A. Using maximum weight to redefine body mass index categories in studies of the mortality risks of obesity. Popul Health Metr 2014; 12: 6.

81 Preston SH, Mehta NK, Stokes A. Modeling obesity histories in cohort analyses of health and mortality. Epidemiology 2013; 24: $158-66$.

82 Smith KR, Bruce N, Balakrishnan K, et al, and the HAP CRA Risk Expert Group. millions dead: how do we know and what does it mean? Methods used in the comparative risk assessment of household air pollution. Annu Rev Public Health 2014; 35: 185-206.

83 Arnold C. Disease burdens associated with PM2.5 exposure: how a new model provided global estimates. Environ Health Perspect 2014; 122: A111.

84 Pope CA 3rd, Burnett RT, Turner MC, et al. Lung cancer and cardiovascular disease mortality associated with ambient air pollution and cigarette smoke: shape of the exposure-response relationships. Environ Health Perspect 2011; 119: 1616-21.

85 Lin H-H, Ezzati M, Chang H-Y, Murray M. Association between tobacco smoking and active tuberculosis in Taiwan: prospective cohort study. Am J Respir Crit Care Med 2009; 180: 475-80.

86 Katanoda K, Marugame T, Saika K, et al. Population attributable fraction of mortality associated with tobacco smoking in Japan: a pooled analysis of three large-scale cohort studies. J Epidemiol 2008; 18: 251-64.

87 Chafe ZA, Brauer M, Klimont Z, et al. Household cooking with solid fuels contributes to ambient PM2.5 air pollution and the burden of disease. Environ Health Perspect 2014; 122: 1314-20. 